1978

\title{
The Mariposa Site: A Late Prehistoric Site on the Rio Grande Plain of Texas
}

John L. Montgomery

Center for Archaeological Research

Follow this and additional works at: https://scholarworks.sfasu.edu/ita

Part of the American Material Culture Commons, Archaeological Anthropology Commons, Environmental Studies Commons, Other American Studies Commons, Other Arts and Humanities Commons, Other History of Art, Architecture, and Archaeology Commons, and the United States History Commons

Tell us how this article helped you.

This Article is brought to you for free and open access by the Center for Regional Heritage Research at SFA ScholarWorks. It has been accepted for inclusion in Index of Texas Archaeology: Open Access Gray Literature from the Lone Star State by an authorized editor of SFA ScholarWorks. For more information, please contact cdsscholarworks@sfasu.edu. 


\section{The Mariposa Site: A Late Prehistoric Site on the Rio Grande Plain of Texas \\ Creative Commons License \\ (c) (1) \& 8}

This work is licensed under a Creative Commons Attribution-NonCommercial 4.0 International License 
THE MARIPOSA SITE: A LATE PREHISTORIC SITE

ON THE RIO GRANDE PLAIN OF TEXAS

John L. Montgomery

Center for Archaeological Research The University of Texas at San Antonio Special Report, No. 6

1978

Volume 2. Studies in the Archaeology of Chaparrosa Ranch

Thomas R. Hester, Series Editor 


\section{TABLE OF CONTENTS}

Page

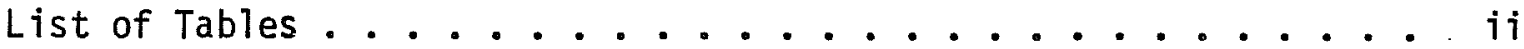

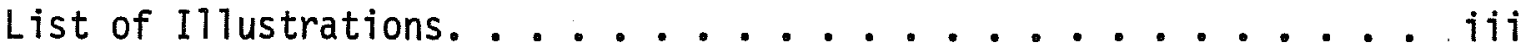

Preface.................... v

Foreword ................... vi

Acknowledgments.............................. vii

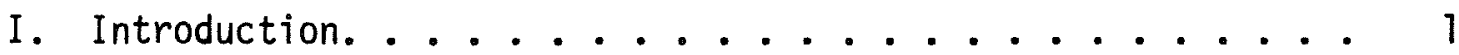

II. The Environmental Setting ............. 3

III. The Archaeological Background . . . . . . . . 15

IV. The Mariposa Site ............. 25

V. The Classification Scheme ............ 33

VI. The Evidence.................. 39

VII. Intrasite Patterns. . . . . . . . . . . 111

VIII. Lithic Technology .............. 129

IX. Intersite Comparisons ............. 137

X. Summary and Conclusions ................ 141

References Cited ................ 143 


\section{LIST OF TABLES}

Table

Page

1. Radiocarbon Dates from 41 ZV 83 (Mariposa Site). . . . . . 32

2. Flake Provenience and Count: Excavated Units (1974)

Mariposa Site.................. 88

3. Flake Provenience and Count: Test Pits

Mariposa Site................... . 91

4. Flake Type Relative Percentage by Excavation Level

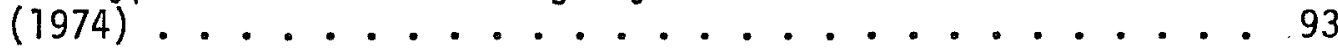

5. Flake Striking Platform Type Relative Percentage by Leve1.................... . . 94

6. Number Recovered and Relative Percentage of Flake Striking Platforms from the Mariposa Site. . . . . . . . 95

7. Number of Burned Rocks Recovered . . . . . . . . . . 99

8. Grams of Burned Rock Recovered . . . . . . . . . . 100

9. Grams per Burned Rock Recovered.............. . 101

10. Rabdotus sp. Specimens Recovered by Unit Level . . . . . . 104

11. Land Gastropods Recovered by Unit Level. . . . . . . . . 105

12. Polygyra sp. Specimens Recovered by Unit Level . . . . . . 106

13. HeZisoma sp. Specimens Recovered by Unit Level . . . . . . 107

14. Unio sp. Fragments Recovered by Unit Level . . . . . . . 108

15. Flake Types Recovered from Mariposa: Number and Relative

Percentage ...................... 131

16. Flake Type Frequency (Percentage) Recorded From Four Rio Grande Plain (South Texas) Sites .......... 132

17. Core Frequency, Other Tool Frequency, and Ratio of Tools/ Cores Frequency at Four Rio Grande Plain Sites . . . . . 134 


\section{LIST OF ILLUSTRATIONS}

Map

Page

1. Map of the Rio Grande Plain of Texas . . . . . . . 4

2. Location of the Mariposa Site, $41 \mathrm{ZV} \mathrm{83,} \mathrm{on} \mathrm{the}$ Chaparrosa Ranch in Zavala County, Texas . . . . . 6

3. Map of the Biotic Provinces of Texas (from Blair

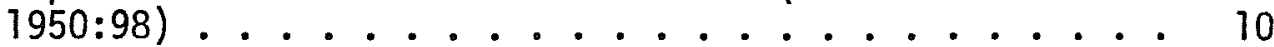

4. Topographic Map of the Mariposa Site, 41 ZV 83 . . . 26

5. Distribution Map of Artifacts, Level One . . . . . 112

6. Distribution Map of Flakes, Level One. . . . . . . 114

7. Distribution Map of Burned Rock, Level One . . . . . 115

8. Distribution Map of Faunal Remains, Level One. . . . 116

9. Distribution Map of Artifacts, Level Two . . . . . 118

10. Distribution Map of Flakes, Level Two. . . . . . . 119

11. Distribution Map of Burned Rock, Level Two . . . . . 120

12. Distribution Map of Faunal Remains, Level Two. . . . . 121

13. Distribution Map of Artifacts, Level Three . . . . . 123

14. Distribution Map of Flakes, Level Three. . . . . . . 124

15. Distribution Map of Burned Rock, Level Three . . . . 125

16. Distribution Map of Faunal Remains, Level Three. . . . 127

Figure

1. North Wall Profile, Unit N38/W2, 41 ZV 83. ..... 30

2. Chipped Stone Classification Scheme from the Mariposa Site, 41 ZV 83.............. 34

3. Ground, Battered, and Polished Stone Classification Scheme from the Mariposa Site, 41 ZV 83. . . . . . . 37 
Page

4. Burinated Biface, A-109 ............ 62

5. Core Reduction Sequence at the Mariposa Site, 41 ZV $83 \ldots . . . . . . . . . . . .64$

Plate

1. Utilized Flakes, Trimmed Flakes and Scrapers. . . . . 44

2. Unifaces and Cores ............. 54

3. Cores and Projectile Points .......... 66

4. Projectile Points, Battered Stone and Ground Stone. . 73

5. Ground Stone ............... . 82 
In Volume I of the Chaparrosa Ranch Series, a series of brief papers outlined the nature and scope of archaeological research conducted at the ranch since 1970. It was noted that in 1974, extensive excavations were conducted at site $41 \mathrm{ZV} 83$ (Chaparrosa 28). The field work was done, under my direction, by the students of the first archaeological field school to be offered by the Division of Social Sciences, The University of Texas at San Antonio (UTSA).

In 1975, John Montgomery, then a graduate student at Texas Tech University, was one of the participants in the 1975 UTSA Field Course in Archaeology, also carried out at the ranch. Montgomery became interested in the past year's work at $41 \mathrm{ZV} \mathrm{83,} \mathrm{and} \mathrm{in} \mathrm{his} \mathrm{spare} \mathrm{time} \mathrm{(i.e.,} \mathrm{in} \mathrm{the} \mathrm{hottest} \mathrm{part} \mathrm{of} \mathrm{the} \mathrm{day} \mathrm{when}$ the rest of us had repaired to the shade of the field camp), he and two other students dug a test unit in a part of the site that had been previously unexcavated. Their discoveries further increased Montgomery's interest in the site.

After the conclusion of the field school, Montgomery and I discussed the possibility of using the 41 ZV 83 materials in the preparation of his Master's Thesis. This was agreed upon by other members of his thesis committee.

Thus, in this second volume in the Chaparrosa Ranch series, the results of Montgomery's extensive analysis are presented. Some minor revisions have been made, and I am grateful to Elizabeth Branch for her careful editing of the draft manuscript. I am particularly proud of John Montgomery's continued efforts and careful research in producing this piece of work. It is the first fully-detailed report of a major archaeological excavation in southern Texas. It is valuable in that regard, and will serve as a basic reference for south Texas archaeologists for many years. In addition, it is an excellent summary of Late Prehistoric cultural remains in southern Texas. The Late Prehistoric, we are now learning, was a time of substantial--and very intriguing--cultural change in southern Texas. Montgomery's data, and those obtained in other parts of south Texas since he completed his research, present a multitude of problems to be resolved and challenges to be faced by archaeologists working in this region.

Thomas R. Hester

Director, Center for Archaeological Research

June 1978 


\section{FOREWORD}

This study of the results of archaeological survey and excavation at the Mariposa site is a contribution to three levels of the discipline. As a pioneering report of detailed excavation data from south Texas, it is a contribution by way of a substantial start on filling in a "gap" which has existed in regional cultural history. While this is an elementary contribution, it is just the sort of fundamental effort which we are discovering must yet be done in many geographic areas of the United States. The fundamental, detailed examination of the archaeological record in North America is far from complete. Happily, with public support, via legislation, the threatened segments of the archaeological record are now receiving much more serious and systematic attention than ever before. We can confidently look forward to a period of massive recovery and interpretation of large segments of the unexplored record of the past.

The second contribution of this study is in the form of a sophisticated attempt to further our understanding or interpretation of evidence from the prehistoric past. The definition, comparison and testing of a lithic technology model (or theory) has moved our understanding of this general aspect of prehistoric people forward, perceptibly.

Thirdly, by using the concepts of "objective" and "operation" explicitly as means of organizing the writing of this study, Montgomery has taken a significant step into the future of explicitly "operational" archaeology. Although of limited application here, these concepts have had in important guiding function in his report preparation and the all-important final step of the research process--communication.

I am pleased to note, finally, that this field and laboratory-library project was from start to finish a joint effort, linking individuals at both Texas Tech University and The University of Texas at San Antonio in the common effort to explore and learn about Texas prehistory. 


\section{ACKNOWLEDGMENTS}

I am greatly indebted to my committee members, Dr. William J. Mayer-0akes, thesis chairman, Dr. P. Hickerson, and Dr. Thomas R. Hester, for their continued suggestions, criticisms and support during the preparation of this thesis. Philip Bandy assisted with many of the technical aspects of this thesis and Richard Alvey prepared several artifact drawings. Many faculty members and graduate students of the Department of Anthropology, Texas Tech University, must be thanked for their useful ideas and comments. The support of the Department of Anthropology, Texas Tech University, and the Center for Archaeological Research, The University of Texas at San Antonio, with facilities and supplies is appreciated. Mr. B. K. Johnson of the Chaparrosa Ranch allowed this research to occur on his ranch and permitted the author to move the artifacts to Lubbock for analysis. Jeannette Shaver typed the initial and final drafts of this thesis, and Sharon Crawford printed the plates. The support and encouragement of my parents made this thesis possible. Words cannot express the thanks due to Cori Montgomery. My wife washed, labeled, and cataloged artifacts, typed and edited many portions of the thesis and contributed needed encouragement during this project. Any errors or omissions are the author's responsibility. 


\section{INTRODUCTION}

It has frequently been asserted that there is a dearth of information concerning the culture history and the lithic and ceramic technologies of south Texas (cf. Hester and Hill 1975b). This study presents archaeological data from the excavation of a Late Prehistoric occupational locality, the Mariposa Site (41 ZV 83), on the Rio Grande Plain of Texas. It is hoped that this report will contribute to the understanding of Late Prehistoric lifeways and material culture, and will constitute a step toward bridging gaps which presently exist in the archaeological record.

Analysis of the materials excavated at Mariposa utilizes three general operations to achieve three corresponding, yet interrelated, archaeological objectives. The first objective to be considered here is description and compilation of the recovered archaeological data. To insure that future archaeological research can proceed from data recovery (in its most general sense) into reaims of processual questions (e.g., settlement patterns, ecological adaptation, etc.), a solid information base as well as initial interpretations must exist. Since this objective has been only partially fulfilled for most areas in the Rio Grande Plain, it was considered to be an important objective to achieve in this thesis. To generate such data, a general site report format was chosen to act as an "outline" within which the operation of material description and analysis would be applied. A brief section on the environmental characteristics of the Mariposa site, along with a summary of the associated archaeological research previously reported, forms a background for the description of the excavated materials. An effort is made to elaborate on the significance of the horizontal and vertical distribution of artifacts and other cultural material (burned rock, snail and mussel shells, bone fragments). This aspect of the thesis results in statements concerning intrasite patterning and the possible location of functionally specific activity areas within the site. All of this information will be derived from the surface collections, test pits and excavation units executed at the Mariposa site.

Interpretation of the lithic technology utilized by the Late Prehistoric inhabitants of Mariposa, the second thesis objective, will be much more limited in scope than the previous objective. Here, the operations to be considered rest upon a test of a generalized lithic technology model previously presented by Hester (1975b). A basically technological artifact description combined with a flake attribute analys is forms the bulk of the operations to be initiated. Tabulation of specific artifactual items mentioned by the model (cf. Hester 1975b) should, when combined with the other two operations mentioned above, spell out the overall validity of the lithic technology model.

Finally, results from the first two objectives form the basis of the third objective: a brief integration of the archaeological evidence excavated from Mariposa into the context of the regional archaeology. Operations necessary to resolve this final objective consist primarily of extracting the pertinent literature for comparison with the archaeological information excavated from Mariposa. Types of data considered most important include the results of the flake analysis, faunal analysis, feature descriptions, intra- and intersite 
patterning of artifacts and/or features, and descriptions of basic lithic assemblage. Data prepared for this report will be compared and contrasted with related materials from other published Late Prehistoric sites within the Rio Grande Plain. 


\section{THE ENVIRONMENTAL SETTING}

For an adequate understanding of the prehistory of any area, a description of the natural resources and the physical setting is necessary. The Rio Grande Plain of southern Texas has many characteristics which directly relate to its utilization by humans in the past and present. The following section presents a physiographic definition of the Rio Grande Plain region, its boundaries, geology, topography and natural features, climate, soils, and biota.

\section{Definition of the Rio Grande Plain}

The Rio Grande Plain is that area of southern Texas whose western boundary is the Rio Grande, whose eastern and southern boundary is the Gulf of Mexico, and whose northern boundary lies just below the Balcones Escarpment of the Edwards Plateau. Thus, the Rio Grande Plain encompasses most of the region of southern Texas between San Antonio and Brownsville (see map 1). Counties within this area are Maverick, Zavala, Dimmit, Frio, LaSalle, Atascosa, McMullen, Live Oak, Jim Wells, Duval, Jim Hogg, Starr, Brooks, Hidalgo, Zapata and Webb. The region covers approximately 26,350 square miles (Chambers 1946:111). Field research for this thes is was centered within the Chaparrosa Ranch, located in northwestern Zavala County.

As a physiographic unit, the Rio Grande Plain lies within the West Coastal Plain of Fenneman (1938) and Thornbury (1965). It is also considered part of the Coastal Plain by Hunt (1972). Johnson (1931) treats the region as a unique one, which he terms the South Texas Plains. To retain terminological consistency established by Inglis (1964) and Hester (1971), this thesis uses the regional term Rio Grande Plain to describe the area in question. Elevation of the plain varies from 1,000 feet in the interior of the region to sea level in the coastal zone. In general, the region is a semi-arid lowland characterized by a mild $\mathrm{climate}$ and a long growing season of approximately 260 days (Johnson 1931:133).

\section{Phys iography and Topography}

The Rio Grande Plain exhibits a varied topography. Overall it is a lowland which reaches a maximum elevation of 1,000 feet to 1,100 feet at the base of the Edwards Plateau (Chambers 1946:112). Sub-areas within the Rio Grande Plain, though, reveal different types of topography. The central and most of the northern areas are rolling plains while the southeastern area is a level section which parallels the Gulf coastline. A more rugged topography is seen in the western and southwestern areas where the land slopes down toward the Rio Grande. This rugged (or dissected) topography is due to the action of short, rapid streams flowing into the Rio Grande (Chambers 1946:112). 


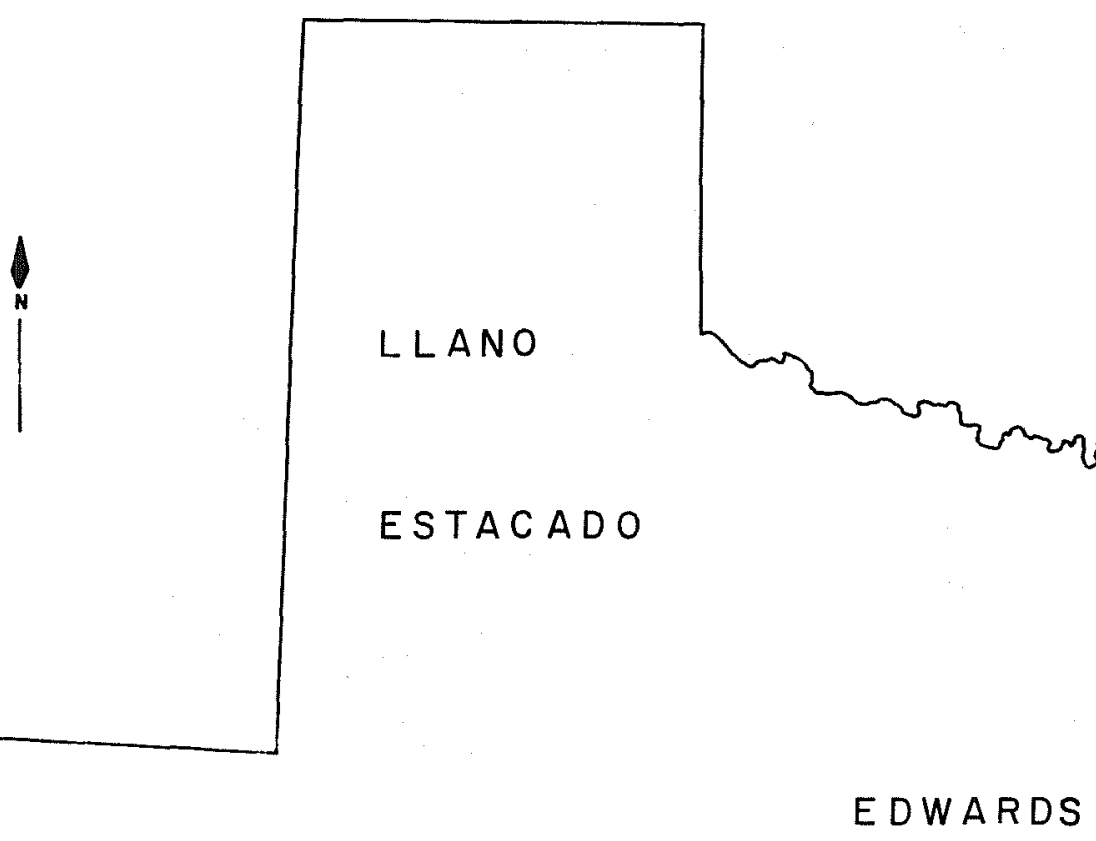

TRANS

PECOS

PLATEAU

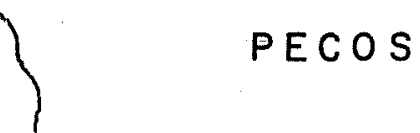

ל

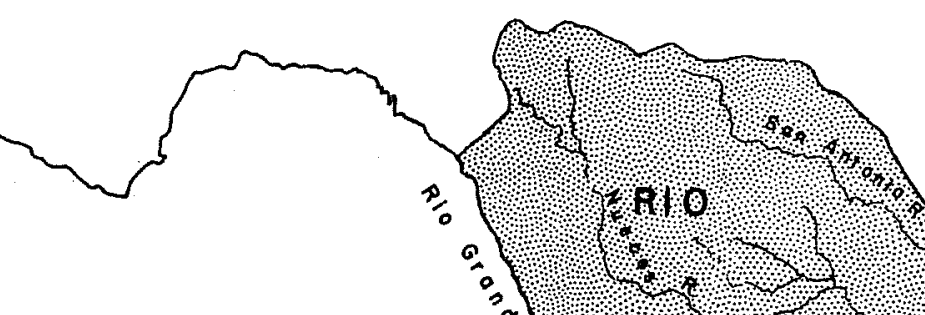

$\circ$

\% 1

OAA 10 
Geologic and Physiographic History

Taken as a whole, the Rio Grande Plain is underlain by poorly consolidated sediments which date from the Cretaceous to the Recent Period (Shimer 1972:7). Resistant layers of these sediments are seen as erosional remnants which have formed low, elongated, asymmetric ridges or cuestas. These ridges are generally oriented parallel to the coastline. Shimer (1972:8) notes that the "steeper slopes of these features face inland." Towards the interior, erosional forces on the underlying Cretaceous and Tertiary sediments have formed a series of lowlands on the weaker rocks and west-facing scarps on stronger rocks (Thornbury 1965:64).

Climate

The fundamental climatic feature of the Rio Grande Plain is its general mildness, which is determined primarily by its areal proximity to the Gulf of Mexico. Seasonal stability of the water temperature in the Gulf of Mexico provides both a stable and a moderate (in terms of temperature) source of air flow over the Rio Grande Plain. In addition, the Rio Grande Plain is geographically the most southward region of Texas, a location favoring (in my opinion) overal1 seasonal climatic stability. The northern boundary of the region, the Edwards Plateau, also forms a "barrier" to severe influences of northern weather (Chambers 1946:112).

In comparison to other regions within the state of Texas, winters are milder and growing seasons are longer in the south Texas area. When colder conditions do occur they are relatively short-lived, and the temperature rarely drops more than a few degrees below freezing.

Records indicate that at La Pryor (in Zavala County, see map 2) the average date of the latest killing frost is March 1 while the average date of the first killing frost is November 28 . This results in an average frost-free season of 272 days (Smith et az. 1940). Monthly, seasonal, and annual temperature and precipitation data reported for La Pryor present quantitative information useful for summarizing Zavala County's climatological picture (cf. Smith et al. 1940:6, Table 1).

Mildness is also a characteristic of the summer season as sea breezes alleviate heat (Chambers 1946:173). While temperatures are generally stable throughout the Rio Grande Plain, other aspects pertaining to the climate of the area, notably rainfall, show some variation.

\section{Hydrology}

Within the south Texas area precipitation is greatest along the eastern border, where the average annual rainfall ranges from 26 to 28 inches. Annual rainfal1 decreases from east to west to around 20 inches at Laredo and increases northward to about 25.5 inches at Uvalde (Chambers 1946:113). The most important amounts of rainfall usually coincide with the early growing months of April, May and June: September and October are also periods of significant precipitation. 


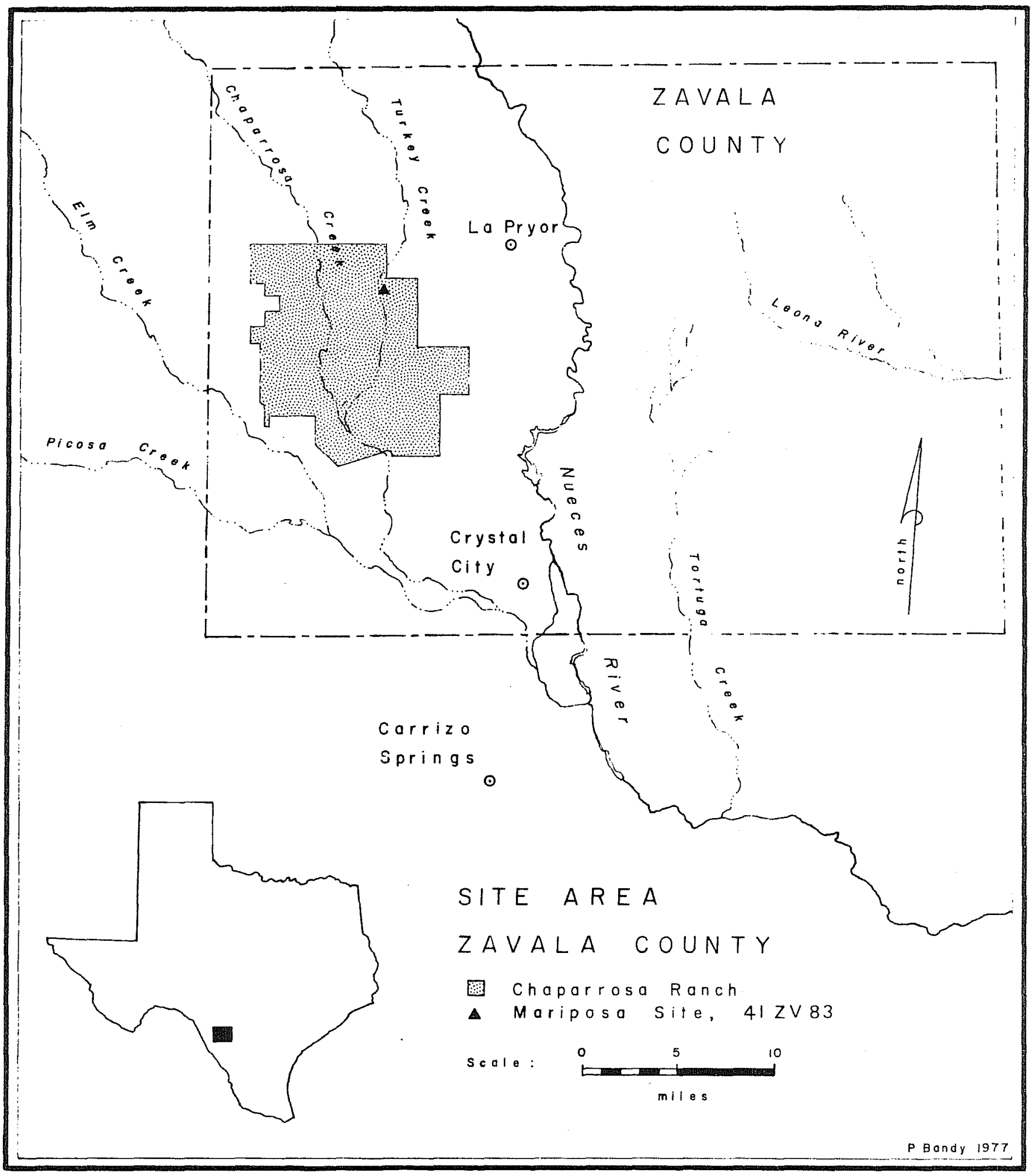

Map 2. Location of the Mariposa Site, 41 ZV 83, on the Chaparrosa Ranch in Zavala County, Texas. 
Chambers (1946:113) has noted that the Rio Grande Plain is regarded as a subhumid region. Despite this classification, irregular rainfall also characterizes the general climatic pattern, causing frequent droughts. This fact makes irrigation an important necessity for the present agricultural economy of the area.

Considerations concerning the rainfall patterns of an area do not, of course, describe the whole hydrological picture. In addition to rainfall pools and runoff, there are two main water sources in the Rio Grande Plain: year-round rivers and streams.

Permanent flowing rivers are fairly numerous in the region. Major river systems (and their tributaries) are the Nueces, the Western Nueces, Frio, Sabinal, and Medina (the last four are not illustrated). These are the "principal springfed streams" within the area (Chambers 1946:115). The largest river in the area, the Rio Grande, also forms the western boundary of the region. These river systems cut across the belted geological strata (described above) and form broad, shallow valleys filled with alluvial deposits (Johnson 1931:134).

When considering only Zavala County, the principal streams are the Nueces and Leona Rivers and Turkey and Chacon Creeks (Chacon not illustrated). These streams "occupy broad shallow valleys, and most of the upland slopes rise smoothly and gently away from the floodplains," due to the original geology and topography of the area (Smith et al. 1940:2).

\section{Soils}

The diverse topography present within the Rio Grande Plain gives rise, in part, to a corresponding variation in soil types in the area. Soil types characteristic of the region range from red and reddish-brown loam to light, sandy soil. The sandy soil actualiy forms dunes when proper wind conditions are present (Chambers 1946:112). Alluvial soils near streams are very fertile and are cultivated today.

Surface deposits and soils within the region consist mainly of marly deposits along the coast and sandy, silty clay deposits associated with the poorly consolidated formations of the Rio Grande Plain interior (Hunt 1972:87). Another large group of soils, the Zonal and Intrazonal soils, are found in most other areas where the underlying bedrock formations are more consolidated. In warm, semi-arid regions, dominated by a mixed shrub and grass vegetation (1ike that of the Rio Grande Plain), both reddish-brown and reddish-chestnut zonals are frequently present, along with the darker Rendzina soils of the Intrazonal group. Local climatic conditions and vegetation patterns can be correlated for the most part to the type of soil group likely to be present (Hunt 1972:87).

"Since soil characteristics and their area distribution may be regarded as a summation of natural forces and conditions" (Johnson 1931:66), it would be advantageous to describe the basic soil characteristics of the Rio Grande Plain region. Soils within the region are very similar to other areas of Texas, especially those of East Texas. But, while the soils commonly found in East 
Texas are leached of their minerals and nutrients, those found on the Rio Grande Plain are not leached to a significant degree, This lack of leaching is principally due to relatively lesser amounts of annual rainfall (about 20 inches). Thus the soils of the region exhibit a continual accumulation of mineral nutrients, most notably calcium carbonate.

Accounts concerning the various soils which have developed in the Rio Grande Plain are available. One source describes 23 soils grouped under six divisions, based on distinctive soil features, topography and vegetation (Carter 1931:91-94). Since these divisions are used to characterize soits found in the $22,000,000$ acres making up the Rio Grande Plain, it is reasonable to scale down the scope of inquiry for detailed soil descriptions.

Light-brown soils are predominant in the northwestern portion of the Rio Grande Plain (Carter 1931:101). Further, this portion of the Rio Grande Plain encompasses the area of immediate concern. Briefly stated, the soil characteristics of this area are: (1) development from calcareous parent-materials, mainiy 7 imestone, marl, or alluvial deposits of calcareous soil materials; (2) lack of heavy grass coverage; and (3) subsurface build-up of calcium carbonate layers. Native vegetation associated with the 1ight-brown soils are "short grasses and scattered shrubs" (Carter 1931:101). Carter (1931:101) divides the 1ight-brown soils into the following series: Maverick, Zapata, Ector and Uvalde.

Within the Chaparrosa Ranch in Zavala County (map 2), the soil complex can be more completely defined. Inspection of the soil survey report dealing with Zavala County reveals considerable soil type variation. For Zavala County alone, 32 soils have been described; these are also considerd representative of the northwestern part of the Rio Grande Plain (Smith et al. 1940:13). Descriptions of all these and the remaining 27 soil groups are available in detail which cannot be approached here. One should consult Smith et al. (1940) for further detailed information.

The Chaparrosa area has been described as a gently sloping upland with some areas being nearly level (Arriaga 1974). The dominant soil type, Uvalde silty clay loam, is considered a member of the finely-silted, mixed, hyperthermic family of Aridic Calciustolls (Arriaga 1974). When profiled, this soil type is generally dark greyish brown, calcareous, silty clay loam from 10 to 20 inches in depth (the Al horizon). The next horizon (B2), from 20 to 42 inches, is characterized by silty clay loam of a greyish brown to brown color. This horizon has a higher $\mathrm{CaCO}_{3}$ content and is also considered more "clayey" (Arriaga 1974). From 42 to 64 inches, the soil color becomes a paler brown. Associated with this horizon, the $\mathrm{Cl}$, is a general increase in alkaline conditions and clayish soil. Highest $\mathrm{CaCO}_{3}$ content (alkalinity) and clayish conditions are found in the last soil divisional profile, the $C 2$. The Cca horizon extends from 64 to 80 inches in depth. Beds of limestone and chert gravel underlie the soil horizons just described. 
The Uvalde soil series described above found on the Chaparrosa Ranch extend from the alluvial fans which flank the Edwards Plateau. They are found on the terraces of streams which drain the Edwards Plateau within Texas. Associated slope gradients are usually less than 1 percent but can range up to 3 percent (Arriaga 1974). Since the soil is formed in alluvium from limestone, there is an associated high percentage of alkalinity within the soil, usually in the form of calcium carbonate $\left(\mathrm{CaCO}_{3}\right)$. Ranges in alkalinity vary from "5 to 25 percent in the A horizon up to 40 to 75 in the C horizon" (Arriaga 1974). There is usually a rise in calcium carbonate content with increasing soil depth.

Johnson $(1931: 66)$ has noted the soils, topography and climate are interrelated features within the total environment of any area. Each one determines (to some degree) the characteristics of the other features, and together they form the environmental setting. However, biota must be included as another aspect of the environment which exerts infiuence upon and which is influenced by the other three environmental factors.

\section{Biota}

Blair's (1950:102-105) Tamaulipan biotic province encompasses most of the Rio Grande Plain area, and his data can be drawn on for a description of the flora and fauna characteristic of the region (see map 3). The dominant vegetation of the Tamaulipan province of Texas is thorny brush. Blair (1950:103) notes that this vegetation pattern begins just below the Balcones fault line and continues to the south across the Rio Grande into Mexico. When viewed from east to west, the brushland tends to thin out as available moisture declines. Plant species presently found in the Tamaulipan province include mesquite (Prosopis juliflora), certain species of Acacia and Mimosa, granjeno (Celtis palizda), Iignum vitae (Porliera augustifolia), cenizo (Leucophyllum texanum), white brush (AZoysia texana), prickiy pear (Opuntia Zindheimemi), tasajillo (Opuntia leptoaviis), Condalia and Castela (Blair 1950:103).

Describing floral components associated with the Uvalde silty clay loam soil series, Smith et al. (1940:14) indicate that the soil supports a

- grassland, on which a more or less thick growth of small trees and shrubs characteristic of a semiarid climate, has encroached. The grass cover is fairly thick in places and consists of curly mesquite, buffalo grass, certain species of grama, and some tobresa grass. There is a growth of scattered mesquite trees and of such shrubs as guajillo, soapbrush, false-mesquite, persimmon, lotebush and others.

Large trees such as live oak, pecan, elm, cottonwood and cypress presently populate river floodplains" and stream courses. Many of the smaller stream valleys are characterized by stands of mesquite trees. Grama, buffalo grass, mesquite grasses--to name only a few--are found in the upland areas among the 


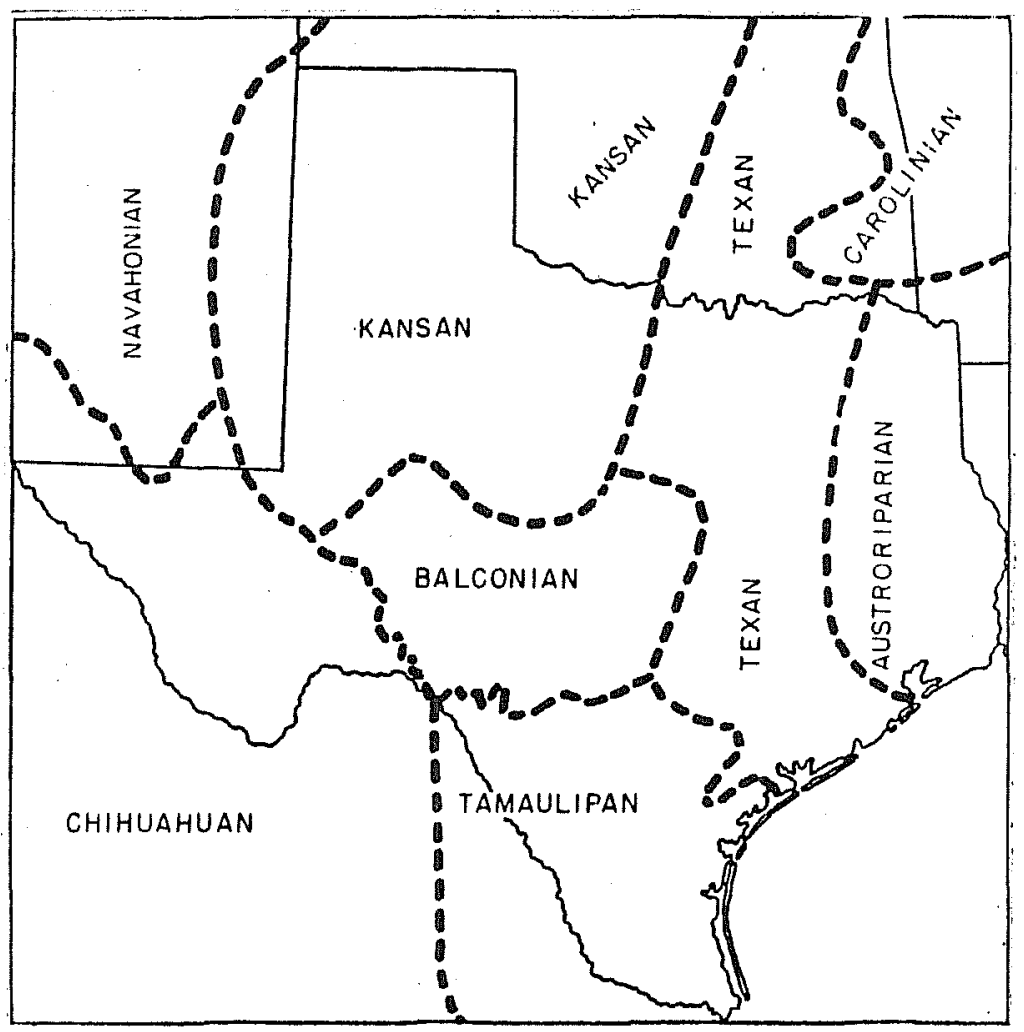

Map 3. Map of the Biotic Provinces of Texas (from Blair 1950:98). 
scattered growth of small trees and shrubs. Mesquite is the most widespread small tree here. Shrubs characteristically found in the upland areas include blackbrush, huisache, guajillo, black persimmon, false-mesquite (lambrush), catclaw, soapbrush or guayacan, lotebush, whitebrush, yucca, sangre de drago, prickly pear and other catci, and jointfir. This brush assemblage is commoniy termed chaparral (Smith et al. 1940). Cenizo, creosotebush, saladillo, and alkali weed are present where local conditions are suitable.

Tamaulipan biota are well adapted to the semiarid and megathermal climate of the area (Thornwaite 1948). In quantitative terms, a moisture deficiency index ranging from -20 to -40 percent is regarded as characteristic of a semiarid and megathermal climate. Climatically, the south Texas plain is unique, as it is the only megathermal climate area in Texas and one of three located in the United States.*

According to Blair (1950:103-104), the vertebrate fauna within the Tamaulipan biotic province are characterized by a large number of "Neotropical" species and a group of grassland species which range to the neighboring Texan and Kansan provinces (see map 3). A few species from the Austroriparian province are also present. A total of 61 mammal species have been recorded in the Tamaulipan biotic province. In addition to the mammals, 36 species of snakes, 19 species of lizards, 9 of anurans, 3 of urodeles, and 2 species of land tortoises have been reported.

Blair (1950:T04) describes in detail the distribution of Neotropical mammal species and other fauna within the Tamaulipan province (see also Blair 1952). Previous statements concerning regional flora and fauna are extended further by Holdsworth (1972). In "A Study of Modern Flora and Fauna in the Vicinity of the Holdsworth Site (41 ZV 14)," Holdsworth (1972) presents a summary of plant and animal species now living within the local site area. This indepth view provides the best approximation of the ecological situation faced by the inhabitants of this site, and the possible ramifications of this study should be explored.

The vegetation patterns presently observed on the south Texas plain have not, however, been constant since the first human occupation of the area (Inglis 1964; Hester 1971). Prior vegetational shifts will be included as part of the paleo-environmental presentation.

*Southern Florida and the arid portions of southern California and southwestern Arizona are the other megathermal areas of the United States. 


\section{Paleo-Environment}

Introduction

There is evidence of human occupation of the Rio Grande and the surrounding area for approximately the last 11,000 years (Hester 1975a, 1976a). Over this period of time, man has lived in environments quite unlike that of the present. It is therefore important to examine the available evidence for previous environments of the Rio Grande Plain. This review provides the background of climatic and concomitant biotic changes to which man has adapted.

\section{Climate Change}

Significant climate shifts have occurred in the general southwestern United States region since the end of the Pleistocene, considered to have occurred at about 10,000 B.P. (Butzer 1971:41). Ecological conditions present today have developed since the end of the Pleistocene. Climate, a significant part of the ecology, has fluctuated through time, probably in response to small changes of other variables (Bryson 1974). While intensive investigations concerning the paleo-environment of the Rio Grande Plain have not been conducted, neighboring areas, most notably the Trans-Pecos region of Texas, have produced useful environmental data directly pertaining to previous climates.

Based on the palynological data, Bryant and Larson (1968) have constructed a paleo-climatic model of the post-Pleistocene environment for the Trans-Pecos region of Texas. A more recent investigation in this area by Alexander (1970: 7) provides the following interpretation:

In brief, pollen data collected from a number of localities in southwest Texas, but principally from three canyon and floodplain sites indicate a gradually increasing aridity from post glacial times (ca. 10,000 B.P.) to present. A pinyon-juniper (and perhaps oak?) parkland-savanna dominates the uplands until about 4000 B.P. When more xeric vegetation dominates the pollen spectra. A brief return to mesic conditions is seen at 2500 B.P., but dramatic shifts in climate are not in evidence.

It is most probable that this general climatic pattern occurred in the Rio Grande Plain as well. To the north, in central Texas, Bryant (in Valastro, Davis and Rightmire 1970:625) has outlined a climatic picture generally equivalent to Alexander's. Mammalian cave populations in Kinney County, Texas (south-central Texas), reinforce this pattern of general aridity being interrupted "at least once by a period of increased moisture" (Semken 1967:10). Studies of Late Pleistocene and Holocene faunal assemblages in central Texas also point to climate conditions of increasing aridity in the last 10,000 years (Lundelius 1967). As can be expected, climate shifts will necessarily cause some corresponding changes in the biotic community of the area. 


\section{Biotic Change}

The biotic structure of the Rio Grande Plain has also changed within the last 11,000 years. However, a quantification of this change would be highly tenuous, given the present evidence. The major change within this time period has been the introduction and subsequent domination (by the 19th century) of thorny brush in most areas. The most notable protagonist of this "invasion," as it has been termed, is mesquite. This type of thorny brush is a relatively recent phenomenon, first present perhaps no more than 300 or 400 years ago (Bogusch 1952; Johnston 1963; Harris 1966). Considerable research for the origin and cause of this abrupt takeover has as yet revealed no clear details (Inglis 1964). The change was probably induced, or at least aided, by human activity. Field clearing, fencing, grass fire suppression, and short term climate fluctuations are now recognized as important factors leading to the mesquite invasion of the area (Harris 1966; Wells 1970). This recent change in the flora obscures the Late and post-Pleistocene environments which once existed on the Rio Grande Plain.

Bryant (1970), working in central Texas, has reported the environment of that area was a "parkland" in the Late Pleistocene period. In addition, mastodon and mammoth remains in southern Texas point to the presence of both grassland and forest areas during the Pleistocene (Hester 1971:2). The previously noted climatic shift toward aridity affected both flora and fauna of the Pleistocene to the extent that grasslands increased at the expense of the forests, thus forming a savanna environment in the post-Pleistocene (Hester 1971:2). The floral environment encountered by early peoples was most probably divided into the two ecological zones which can sti17 be distinguished today. One of these can be termed the upland zone. This zone is "rather open" and has a "plant community dominated by mesquite and other thorn brush, grasses and prickly pear" (Hester 1971:1). The other zone, the floodplain, is associated with rivers and their tributaries. Hester (1971:2) notes that the floodplains "are often infested with mesquite, but have forested areas of oak, ash, elm, hackberry and pecan in riparian zones along the stream courses."

Obviously much more research is needed to further define the ecological picture of the Pleistocene and post-Pleistocene periods. It is still necessary to rely upon data drawn from neighboring areas to construct a complete environmental model for the Rio Grande Plain. Given the data at hand, the general picture of the paleo-environment reveals an area dominated by both savanna and forested zones of vegetation. The forested zone is centered primarily along the stream and river channels while the savanna covers the areas away from the watercourses (Hester 1971:2). Temperatures during this period were probably not significantly different from those presently reported for the area. Hester (1971:3) succinctly outlines the faunal component of the paleo-environment as follows:

The fauna were similar to those of today though habitats have no doubt been altered by historic farming and ranching practices. Notably absent from contemporary fauna, but present in the early post contact and prehistoric periods are bison, antelope and bear. Bison may have been restricted to the northern fringes of the region (Inglis 1964) and are excellent indicators of the former savanna conditions. 
Analyses of faunal remains recovered from excavated and tested Late Prehistoric sites in Zavala County have contributed information regarding both the possible aboriginal subsistence regime and the possible change in savanna conditions. The emerging picture indicates that a large variety of animals were utilized as food. One site contained 26 different faunal species (Hester and Hi11 1975b). Preferred large game were antelope and deer; smaller game, such as rabbits and a variety of rodents, were also taken. Riverine fauna were not neglected, since remains of turtles, frogs and fish have been recovered (Hester and Hill 1975b). This variety of faunal utilization indicates that the aboriginal inhabitants frequented a corresponding variety of "microenvironments" (upland, floodplain, riparian, aquatic) al1 relatively close to "their streamside camps" (Hester and Hi11 1975b:17).

The reported occurrence of certain mammal remains in many sites has been shown to be correlated to vegetation shifts (Hester and Hill 1975b; Hester 1971, 1975c). Noteworthy in this respect are bison and antelope, both of which are no longer present in the area. Both mammals are usually found in short grass biotic communities (Gilbert 1973:60). Their existence in prehistoric contexts indicates that the present "mesquite brushland environment" of this part of the Rio Grande Plain was more savanna-like during prehistoric times (Hester and Hill 1975b:17). This position has also been taken by range and wildlife ecologists (Price and Gunter 1943; Inglis 1964).

Along with the overall indication of a prior savanna environment, there are early Spanish and Anglo accounts (Hester 1971:3) which point to the fact that surface water was more plentiful in prehistoric times. Numerous perennial streams and springs mentioned in these sources had failed by the middle of the 20 th century, due to lowered water tables "resulting from watershed destruction and deep wel1 irrigation" (Hester 1971:3).

A clear sequence detailing the floral and faunal changes during the last 10,000 years is still unavailable. Contrasting terminology and research results have led to a general conflict concerning the reasons and facts concerning biotic changes on the Rio Grande Plain. No attempt can be made (in this thesis) to weigh the many sides of the issue and arrive at a satisfactory synthesis. 


\title{
III. THE ARCHAEOLOGICAL BACKGROUND
}

\author{
Introduction
}

It is best to consider the known archaeological sequence for the Rio Grande Plain in light of the overall outline as put forth by Suhm, Kreiger and Jelks (1954). According to this framework, four cultural periods are represented within Texas: the Paleo-Indian, Archaic, Late Prehistoric and Historic. The temporal parameters given for each period within the Rio Grande Plain have been adapted from Hester (1974d). Problems which arise when one considers the prehistory of the Rio Grande Plain stem from one fundamental source: paucity of long-term prehistoric research in most areas for almost all the periods considered. It is beyond the scope of this study to synthesize all the known archaeological sites and the associated material found within southern Texas. Such syntheses already exist (Sayles 1935; Suhm, Kreiger and Jelks 1954; Kelley 1959; Campbel1 1960; and Hester 1975a) and can be referred to for a more complete picture of the regional prehistory. Such "pictures" should, however, be examined in light of an observation by Hester (1971:1):

Archaeological work has been sporadic in the region, with most activity occurring within the past 10 years. Some smal1 areas are now known in some detail, but vast portions remain to be studied.

The archaeological record has recently been supplemented by contract-related work within the region. Though hindered by the lack of a firm chronological sequence, these reports nonetheless contribute much needed descriptions of the variety of cultural resources in the region and generate new ideas for further archaeological exploration and testing. Such work includes Nunley and Hester (1975), Wakefield (1968), Hester and Bass (1974), Shafer and Baxter (1975), Hester et a.. (1977) and Mallouf, Fox and Briggs (1973). Hester (1974b) has described the problem-orientation of his recent work in Zavala County. Though smaller in scope, many non-contract related reports have concentrated on describing archaeological resources through surface reconnaissance and/or limited test excavations (cf. Hester, White and White 1969; Nunley and Hester 1966; Prewitt 1974; Varner 1968; and Weir 1956).

Paleo-Indian Period (9200-6000 B.C.)

Scattered surface remains of distinctive projectile points (many of them fluted) associated temporally with this period occur within the Rio Grande Plain and adjoining areas (Arguedas and Aveleyra 1953; Enlow and Campbe11 1955; Hester 1966, 1967, 1968a, 1968c, 1971, 1974a, 1975a; Hester and Hi11 1971b; House 1974; Mitche11 1974b; Mitche11 and Winsch 1973; Orchard and Campbe11 1954; Weir 1956). An excellent synthesis of the evidence concerning the Paleo-Indian occupation in Texas may be found in Hester (1976a).

For the initial portion of this period, evidence consists primarily of Clovis and Folsom projectile points. While no distinctive distributional patterns can be constructed for the Tithic material associated with the Paleo-Indian period, Hester (1971:3) has noted some general geographical patterns for projectile points: 
The greatest concentration of Clovis points are found in the northern part of the Rio Grande Plain. Folsom specimens . . . are present in the south.

Since sea levels were lower in the Late Pleistocene period, Hester (1971:3) bel ieves that much of the evidence for early human occupations may now actually lie below water on the continental shelf. However, there is some additional evidence (beyond scattered projectile point finds) which can be assigned to this period.

For example, near the Texas coast on the Berclair terrace, Sellards' (1940) excavations revealed early point styles in apparent association with a variety of extinct fauna. In addition, evidence of association between mammoth remains and human artifacts has been reported for the Falcon Reservoir located on the lower portion of the Rio Grande (Hester 1971:3). Hester (1971:3) reports a site near Corpus Christi, on 0so Creek, in which a large mineralized bone point (suggestive of those characteristic of the Llano Complex ki1l-sites) was loosely associated with extinct elephant remains (cf. Haynes 1966).

Until very recently, no Paleo-Indian occupation sites had been reported within south Texas. However, excavations conducted at the St. Mary's Hall site (41 BX 229) have exposed occupational material assigned to the Paleo-Indian period (Hester 1975a, 1978). Underlying a compressed Archaic deposit, Folsom and Plainview artifacts have been excavated in association with "bone tools, faunal remains (mainly deer-sized mammals), lithic debris, and fragmentary preforms" (Hester 1975a:3). Percussion flakes, pressure flakes, and bifacial thinning flakes have been recorded from the same geological stratum as the Paleo-Indian artifacts (an alluvial deposit of small gravels in a reddish brown clay matrix labeled as Stratum III; Hester 1975a).

Clovis points, associated in certain sites with manmoth remains, have been assigned a temporal position between 9500 and 9000 B.C. Other fossil faunal species from this time span (and also now extinct) include the camel, horse, and bison (Haynes 1966:107). With the subsequent disappearance of species of mammoth, camel and horse, a now extinct species of bison became the focus of human hunting activities. From a general time period between 8500 and 7000 B.C., Folsom points dominate the tool kit used to kill bison. After this period new varieties of projectile points came into use. Lanceolate points and stemmed dart points such as Plainview, Plainview golondrina, Angostura, Meserve, Milnesand, Lerma and Scottsbluff are common varieties which have been reported from the Rio Grande Plain (Hester 1971). Recovery of such projectile points indicates more extensive aboriginal occupation in the area during the latter part of the Paleo-Indian period. As Hester (1971) points out, the lack of clearly stratified Paleo-Indian sites in the Texas Rio Grande Plain necessarily dictates comparison with points forms and associated tools excavated under tighter chronological control from neighboring areas of Texas and Mexico. For Texas, both Alexander (1963) and Sorrow, Shafer and Ross (1967) provide comparative evidence from central Texas. MacNeish's (1958) investigation in the Sierra de Tamaulipas furnishes dated Paleo-Indian materials from northeastern Mexico for comparison and chronological correlation. Additional comparative information concerning the Paleo-Indian period from other regions of Texas close to the Rio Grande Plain includes Bonfire shelter, a kill-site in Val Verde County (Dibble and 
Lorra in 1968), Montell Rockshelter in Uvalde County (Sellards 1952; Suhm, Kreiger and Jelks 1954). Kincald Rockshelter in Uvalde County (Sellards 1952; Suhm, Kreiger and Jeiks 1954). Baker Cave in Val Verde County (Word and Douglas 1970, Hester 1978)., the Johnston-Heller site in Victoria County (Birmingham and Hester 1976), and Devil's Mouth in Val Verde County (Johnson 1964; Sorrow 1968).

Other areas within Mexico have also generated valuable data in this context. Epstein's (1969, 1972)' work in Neuvo Leon has brought to light Paleo-Indian materials which have crystallized some reinterpretation of Paleo-Indian subsistence and technology (cf. Hester 1976a).

After describing the distribution of Paleo-Indian artifacts within the Rio Grande Plain, little can be conclusively said, due to the lack of clear evidence concerning the hunting of Pleistocene megafauna. According to Hester (1971) and Newton (1968), sma 17, nomadic groups of non-specialized hunters and gatherers constituted the human population in the Paleo-Indian period on the Rio Grande Plain.

The question of whether or not this general type of subsistence regime lasted throughout the 3000wyear period designated as Paleo-Indian cannot currently be answered. Broad theoretical pictures concerning the technology and subsistence pattern have been formulated for other areas during the later stages of this period (Late Paleo-Indian) (Mason 1962; Sollberger and Hester 1972). Citing the archaeological evidence for the Eastern United States, Mason (1962: 246) constructs an image of "involution" during the Late Paleo-Indian period. This involution is characterized by a "regionalization" of the Paleo-Indian artifact types which is probably due to a greater dependence and subsequent "adaptation to local food resources."

In an area closer to southern Texas, a somewhat similar statement has been forwarded by Sollberger and Hester (1972). With the loss of the megafaunal component in the environment, dependence shifted to vegetable materials to supplant small game kills. This adaptation can be seen in the archaeological record, especially at the Strohacker site of central Texas. Careful surface collection of this site adds to a growing body of data which demonstrates the presence of corner-notched and stemmed dart points in "both Paleo-Indian and pre-Archaic contexts in Texas" (Sollberger and Hester 1972:335). The evidence reviewed for Texas has now tentatively defined a pre-Archaic transitional phase (Sollberger and Hester 1972:335-337). Over a period of approximately 2500 years, between 6000 and 3500 B.C. new projectile points appear along with Late Paleo-Indian styles. There are three types: (1) corner-notched, expanding stem dart points, similar to the Martindale type; (2) stemmed dart points with concave bases (Gower type); and (3) corner-notched dart points similar to the Uvalde typer. This sequence, as defined by Sollberger and Hester. still lacks specification in terms of associated lithic material. Clear evidence for the corresponding transition into the Archaic period in southern Texas has yet to appear. 


\section{Archaic Period (6000 B, C, - A.D, 1200)}

As a distinct period, the Archaic has only been nebulously defined for the Rio Grande P. Pain. This situation arises from the lack of stratified sites associated with this period in time. In general, the Archaic is characterized by the appearance of dart points, which are believed to be technologically and morphologically separate from the preceding points associated with the PaleoIndian period. Point types commonly recovered from this period are Tortugas, Abasolo, Refugio, Langtry, Shumla and Almagre, with Tortugas being the type most frequently encountered. Projectile point types usually associated with the Paleo-Indian period are also known to be present in eroded Archaic sites (Plainview, Angostura and Scottsbluff) but most investigators believe these to be either mixed via erosion or picked up by later aboriginals (Suhm, Kreiger and Jelks 1954:139; Hester 1968c:159). Other chipped stone artifacts known to occur in Archaic contexts are triangular and leaf-shaped knives, and side, oval and end scrapers. Ground stone tools such as manos and metates are recognized as part of the Archaic technology. As Suhm, Kreiger and Jelks (1954:140-141) note, based on tool types, the Archaic period of the Rio Grande Plain exhibits ties with almost all the neighboring areas of Texas and Mexico within the same time period. Descriptions of this period have, until recently, consisted of two foci, the Falcon and Mier. Neither of these complexes was ever clearly isolated and defined and Hester (1971) recommends dropping these terms, since they seem to only confuse what little is known archaeologically about the Archaic period in this area.

Evidence for the occupation of the Rio Grande Plain during the Archaic period is scattered and in many cases, incomplete. Up until the late 1960s, few field studies had been initiated dealing specifically with the Archaic. Within the last decade, however, attention has been drawn to the need for clearer archaeological definition of the Archaic period. At Falcon Reservoir, a living floor dated to this period was described by Hartle and Stephenson (1951). This floor revealed triangular and subtriangular dart points with various unifacial and bifacial tools, including Clear Fork gouges (Hester 1971). A radiocarbon analysis from organic material recovered on the floor indicated a date of 2700 B.C. (Krieger 1954:565). In Mexico, MacNeish (1958) has outlined the Archaic sequence for the northern Tamaulipas area. The archaeological data from his survey and excavation research resemble much of the scattered evidence recorded on the Rio Grande Plain and his divisions of the Archaic period can only be broadly applied to southern Texas. These divisions, the Nogales, Repelo, Abasolo and Catan Complexes, however, do little to describe human adaptations thoughout the Archaic. Instead, the picture of an overall continuum of similar artifacts which are not significantly changed permeates the period (Hester 1971). As an example, Hester (1971) refers to a unique artifact tool type, the Clear Fork gouge, which is actualiy present in contexts associated from the PaleoIndian period up to the Late Prehistoric period, a length of time which roughly approximates 10,400 years (from 9200 B.C. to A.D. 1200).

Integration of data from surrounding areas has changed the picture of Archaic subsistence and technology on the Rio Grande Plain (Hester 1976b). Throughout the period, dart points such as Tortugas, Langtry, Shumla, Abasolo, Refugio 
and AZmagre, show relationships to the Pecos River focus to the west, while the presence of Almagre points indicates cantact to the south in Tamaulipas (Suhm, Kretger and Jelks 1954), According to Suhm, Kreiger and Jelks (1954). the above mentioned dart points are associated with the faicon focus, which they place chronologically between 5000 B,C. to A,D, 500 or 100,0. The introduction of smaller yet morphologically similar points such as Matamoros and Catan and the much smaller arrow points of the Enesno and Perdiz variety marks the beginning of the next focus, Mier. The similarity of artifact types in these two foci makes them hard to distinguish, Suhm, Krieger and Jelks (1954: 142) regard the Mier Pocus as being "transitional between Falcon Focus and the historic horizon. It might also be regarded as a late phase of Falcon Focus."

Investigators in the area, most notably Hester, have produced evidence for a clearer definition of the Archaic period. Again using projectile points as time-space markers, triangular and stemless Tortugas points are taken to indicate "Middle Archaic" occupations, followed temporally by the appearance of "smaller, notched forms" (Ensor, Frio) in the "late Archaic" (Hester 1974a:8). Associated radiocarbon dates for Late Archaic forms from the Zavala County area appear to cluster around A.D. 580 (Hester 1975a:8). A smaller, dart-1ike point with side notching, typed as zavala, is also interpreted as indicating Late Archaic occupation. Unfortunately, artifactual evidence for other tools associated with Middle and Late Archaic point types has not yet been specified.

Although the nature of the Archaic occupations on the Rio Grande Plain is obscured by the lack of stratified contents and absolute dates, investigations are now underway to improve matters. A summary of the Archaic period in southern Texas (including the Rio Grande Plain) is now available (Hester 1976a). Studies concerning the aboriginal settlement patterning during this period have appeared for various areas and/or river drainages (Hester 1974b, 1975a, 1976b; Nunley and Hester 1966, 1975; Shafer and Baxter 1975; Shiner 1969). Archaic subsistence strategies (Hester 1975b; Hester and Hill 1971a, 1976b) and technological strategies (Hester 1975b; Hester and Hill 1971a; Nunley and Hester 1975; Hester, Gilbow and Albee 1973; Shafer and Hester 1971; Shiner 1969) are also being reconstructed. Additional information concerning some or al1 of the abovementioned aspects of the Archaic lifeway is being contained in site reports (Hester and Hi11 1972; Hi11 and Hester 1971; Mitche11 1974c; Schuetz 1966) and survey reports (Newton 1968; Nunley and Hester 1966; 1975; Weir 1956).

\section{Late Prehistoric Period (A.D. 1200-A.D. 1528)}

By contrast to the confusion associated with the Archaic period, evidence for the Late Prehistoric period occupations on the Rio Grande Plain is readily available. Suhm, Kreiger and Jelks (1954) indicated an apparent absence of a Late Prehistoric occupation in the area. However, since 1954 a significant number of single and multi-component sites for this period have been tested and/or excavated and subsequently reported. Zavala County stands out as a center of research dealing with Late Prehistoric subsistence settlement pattern 
and technology. Hester and Hill (1975b) have compiled an important synthesis of the Late Prehistoric data in this area.

For Texas, the beginning of the Late Prehistoric is marked by the occurrence of new items in the cultural inventory. These new traits include arrow points, ceramics, and agriculture (Hester and Hill 1975b). Lack of research in the area of south Texas led to the erroneous conclusion that the Late Prehistoric period, as defined above, did not exist in the area (Suhm, Kreiger and Jelks 1954). This earlier view held

- . that the peoples of this area, ancestors of historic Coahuiltecan groups, survived in an Archaic-style, hunting and gathering 1 ifeway until historic contact. There was some indication from surface sites (in the form of arrow points of the Perdiz, Scazzom and Fresno types) that the bow and arrow had been used in the area. However, there was no substantial evidence for the presence of ceramics, alterations in settlement patterns, different subsistence activities, or other Archaic patterns (Hester and Hil1 197.5b:1).

With the description of a bone-tempered plainware ceramic tradition in a Late Prehistoric time span, related to the already known Leon Plain ware of central Texas, initial archaeological definitions for the south Texas area during the Late Prehistoric have been attempted (Hester 1975c; Hester and Hill 1971a, 1975b). Intensive excavations and survey work in Zavala and Dimmit Counties form the interpretative basis for this new definition (Hester 1970a, 1974c; Hester and Hill 1972; Hill and Hester 1973).

The archaeological evidence for Late Prehistoric sites from areas geographically proximal to the Rio Grande Plain remains fragmentary, especially when compared to the known information available for the lower Rio Grande (Hester 1975c:109125). Data from one nearby region, termed the Chihauhuan desert area, has been summarized elsewhere (Hester 1975c:109-111), and there are

- . similarities between the late prehistoric remains from the lower Pecos and the southeastern Trans-Pecos and the materials in southern Texas. Unfortunately, so little is known about the late prehistoric that we cannot go much beyond this generalization (Hester 1975c:121).

No cultural "complex" presently exists for the Rio Grande Plain, except near the coast. Two complexes which represent Late Prehistoric occupations have been defined for this coastal area. The Brownsville Complex, described by MacNeish (1947, 1958), is represented by a shell industry, triangular arrow points and possible ceramic artifacts and is generaliy in the Rio Grande delta (Hester 1971). On the central Texas coast, the Rockport Complex (Campbe11 1960), with its various types of arrow points and an asphalt painted, sandy paste pottery, existed during the same time (Hester 1971:4). Corbin (1974) has recent7y summarized evidence for the Rockport Complex, noting that some re-evaluation in interpretation is necessary. 
No similar Late Prehistoric complex has been defined for the south Texas interior (Hester 1971:4). Artifacts assumed to date from this period include a variety of arrow points, with Perdiz, Scazlorn and Fresno the most frequently occurring types. Zavala points, which appear to be morphologically and technologically intermediate between arrow points and dart points, are often recovered in association with Late Prehistoric artifacts. It is believed that the Zavala type (which is very similar to Johnson's Figueroa of Trans-Pecos and Trinity of East Texas) functioned as arrow points (Hill and Hester 1971).

The Late Prehistoric lithic inventory also contains blades exhibiting lateral retouch, end scrapers (made from flakes), and perforators (Hester 1971), in addition to an occasional occurrence of plain bone-tempered ceramics (Hester 1968b; Hester and Hi11 1971a). Hester and Hill (1975b) and Hester (1975c) describe items of 1ithic, ceramic and bone which are commonly found in the Late Prehistoric context. Most radiocarbon dates from these sites indicate a span of only 250 years (A.D. 1400 to A.D. 1650) (Hester 1975a; Hester and Hi11 1975b). Tortuga Flat and 41 ZV 155 appear to have been inhabited into early historic times or about A.D. 1760 (Hester and Hil1 1975b; Hill and Hester 1973). Despite the fact that this date seems to place Tortuga Flat outside Late Prehistoric temporal parameters, there is no evidence of historic contact (Hill and Hester 1973; Hester 1975c).

Because recent investigations have dealt with more (numerically) Late Prehistoric sites as compared with earlier sites, the information concerning settlement patterns, general subsistence, and technology is more readily available and more detailed (cf. Hester 1975c; Hester and Hill 1975b). This archaeological evidence indicates that environmental zones which closely flank stream channels were considered prime occupation areas by the aboriginal inhabitants. Large sites (approximately 3600 meters) with rich middens have been located and excavated in such areas. Midden material generally consists of large quantities of lithic tools, animal bone, land snail shells, charcoal, hearths and burned (fire-cracked) rock (Hester 1975a, 1975c).

Terraces located some distance from the streams supported two activities: workshop and occupation. Since these terraces frequently contain outcrops of chert and other knappable material, it is only natural that chipping stations and workshops should be located there. Most of the workshop sites were utilized for brief periods of time and were abandoned when the desired lithic materials had been obtained. Such sites contain "large amounts of flake refuse, partially worked cores, and broken preforms" (Hester 1971:66). Sporadically occupied, short-term campsites also are found in the terrace areas. These sites may represent overnight "stations" for extended hunting and/or gathering activities originating from the floodplain sites (Hester 1971:6). Occupation sites are also encountered in upland areas, above the terraces, and at considerable distances from water sources. Again, temporary or short-term habitation is indicated for these sites.

There are detailed statements concerning settlements and subsistence of the northwestern part of Zavala County (Hester 1975c; Hester and Hi11 1975b). Most Late Prehistoric occupation sites occur on the floodplains of the Nueces River 
and its tributaries. At least 12 major single and multi-component sites, including Mariposa, have been described and mapped for this area (Hester 1975a; Hester and Hill 1975b). Holdsworth (Hester and Hil1 1972) and Tortuga Flat (Hill and Hester 1973) stand out as important published Late Prehistoric sites located in close proximity to Mariposa. Away from the Nueces River drainage, yet still within the Rio Grande Plain area, Oulline (41 LS 3) (Hester, White and White 1969), 41 ZV 153 (Hester et al. 1975), Stewart (Hester and Hill 1972) and Berclair (Hester and Parker 1970) sites also have provided published material concerning Late Prehistoric occupation of southern Texas.

Subsistence strategies have also been a focus of attention in the Zavala County area. Large land snails (Rabdotus sp.) and river mussels (Unio sp.) are found in great numbers and frequently clustered. Such patterning may indicate that snails were collected and extracted, perhaps by boiling (Hester and Hil1 1975a, 1975b).

Along with invertebrate remains, vertebrate remains are also present at many Late Prehistoric sites. Diversity of species seems to be typical, for as many as "twenty-two different species of mammals and reptiles" were recovered from a "bone pile" at 41 ZV 155 (Hester and Hill 1975b; Hester et aZ. 1975). The Holdsworth site, in one locality, contained 21 species.

While the archaeological record indicates that many types of animals were being utilized, it is also evident that patterns of "preferred" food sources had been established. Among the larger mammals, deer and antelope were sought instead of bison (Hester and Hill 1975b:17), although bison was utilized. Rabbits and rodents constitute the major components in the sma11 mammal category (Hester et $a$. 1975). Turtle, snake and frog were favorite reptilian species obtained by the aboriginal population, with the box turtle (Terrepene ornata) the most commonly occurring species (Hester and Hill 1975b).

The natural deterioration of evidence through time inhibits statements concerning the gathering activities of the Late Prehistoric populations. Two sites have produced data which can shed some light on the matter. It appears that acorns and spiny hackberry (granjeno) seeds were obtained by the inhabitants of Holdsworth and $41 \mathrm{ZV} \mathrm{10,} \mathrm{respectively.} \mathrm{Both} \mathrm{samples} \mathrm{have} \mathrm{been} \mathrm{burned}$ (Hester and Hill 1975b).

Riverine areas close to the occupation sites probab7y provided the majority of animal food resources (Hester and Hill 1975b). Upland areas were utilized when larger mammals (deer, bison, antelope) were being sought.

\section{Historic Period (After A.D. 1528)}

Cabeze de Vaca's journey across Texas marks the beginning of the Historic period. His entrance is generally thought to have occurred around A.D. 1528. Spanish influence in southern Texas gradually culminated in the local Indians being either killed, missionized, or assimilated into Spanish-Mexican groups. Not to be overlooked, though, is the large number of ethnohistorical accounts which also resulted from the Spanish and Anglo occupation. 
Only a few archaeological sites exist which can be attributed to the Historic period, aside from Indian occupatians at the several Spanish Colonial missions in southern Texas. (Hester 1975a). Historical material remains from those sites external to the missions are scattered and "include glass trade beads and metal projectile points." (Hester 1975a:11; see also Hester 1970b and Mitche11 1974a), The cultural assemblage associated with the mission Indians has been described by Schuetz (1969).

The aboriginal populations Tiving away from the Spanish missions have been described primarily from ethnohistorical accounts rather than from archaeological excavations. Whether or not such information is adequate for cultural descriptions of the native peoples is a question which cannot be satisfactorily resolved at present. Disease and expansionist pressures from the south doubtlessly altered the structure, technology, and subsistence patterns of these populations prior to actual Spanish settlement of south Texas (Campbe11 1975).

Newcomb (1961:29) has included the Rio Grande Plain of southern Texas within the Western Gulf culture area. Semi-nomadic hunting and gathering groups, labeled as "Coahuiltecan," occupied the interior region of southern and southwestern Texas. Coahuiltecan, a loosely applied linguistic term which encompasses many smaller distinct groups of both southern Texas and northeastern Mexico, was first used by J. W. Powe11 in the 1800s (Troike 1962:57).

Until recently, the description of Coahuiltecan culture has generally included all the various subgroups in one larger category. Such a classification obscures specialized adaptation to limited microenvironments. Studies concentrating on the smaller, local groups are now appearing (cf. Campbel1 1975).

Briefly, the small bands of Coahuiltecan speakers were semi-nomadic, probably moving with the changing seasons. Large and smal1 mammals, fish, reptiles, and plant materials (especially mesquite and cacti) were obtained when and where available. Other important cultural aspects have been published elsewhere (Newcomb 1956, 1958, 1961; Ruecking 1953, 1954, 1955a, 1955b; Skeels 1972; Troike 1962); these sources should be consulted for more detailed descriptions of these groups. To complicate matters, Nunley (1971) feels that current interpretations of the historic Coahuiltecans are over-generalized, causing erroneous conclusions. Attempts have also been made to reconstruct prehistoric subsistence patterns from contemporary situations (Hi11, Holdsworth and Hester 1972). 
IV. THE MARIPOSA SITE

Physical Dimensions and Definitions

The Mariposa site (41 ZV 83) parallels the east bank of Turkey Creek on the Chaparrosa Ranch in northwestern Zavala County, Texas (maps 2 and 4). Turkey Creek is a tributary of the Nueces River, one of the major streams draining the Rio Grande Plain. Since Mariposa is located adjacent to a stream channel, it is termed a floodplain site (Hester 1971). In contrast, terrace sites within the same region are situated some distance away from a stream channel and are usually located at a somewhat higher elevation.

Horizontally, Mariposa encompasses over 200 meters which parallel Turkey Creek in a general north/south line. The site extends eastward away from the creek bank about 30 meters. Overall the horizontal area of Mariposa contains approximately 6,000 square meters.

Taken as a whole, the site is almost level except near the present creek bank along the western edge of the site. Mariposa is located on a long knoll and has two clear areas where sheet erosion and gullying (in the southern part of the site) have exposed cultural debris and artifacts. There is a thick brush area along Turkey Creek and to the east of the site on the floodplain. Vegetation present on the site includes guayacan, granjeno, white brush, allthorns, catclaws, Texas persimmon and guajuillo. Woody vegetation, mostly oak and white ash, is prominent on the creek bank. The creek area supports the densest vegetation near Mariposa (Hester n.d.).

\section{Outline of Previous Investigations}

Three separate investigations of Mariposa have been made in the span of five years. In 1970, preliminary site testing directed by Hester was achieved by excavating two test pits. Test Pit 1 measured $1 \times 1$ meter and Test Pit 2 measured $1 \times 2$ meters--both were located in the west central portion of the site (map 4). Each test pit was shovel excavated by $20 \mathrm{~cm}$ levels and all material was screened by passing dirt through 1/4-inch hardware screen. A11 lithic material (flakes and artifacts), most of the complete snail shell specimens, all mussel shell, all retrievable charcoal, and some burned rock samples were collected and bagged for each unit level. Profiles, along with soil and pollen samples, were obtained from the north wall of Test 2 . The 1970 investigations determined that Mariposa contained substantial archaeological debris (burned rock, land snail shells, chert flakes) buried in alluvium to a depth of one meter. Only faint traces of definable stratigraphy were noted. Attempts to analyze the collected pollen samples were not successful, but three radiocarbon dates were secured.

The second investigation at Mariposa (a University of Texas archaeological field course directed by Hester) occurred during the summer of 1974, and initial results of this excavation have been published (Hester 1974c). Nine two-meter squares were opened near the center of the site and carefully excavated in fivecentimeter levels. One major objective was to achieve a view of the horizontal 


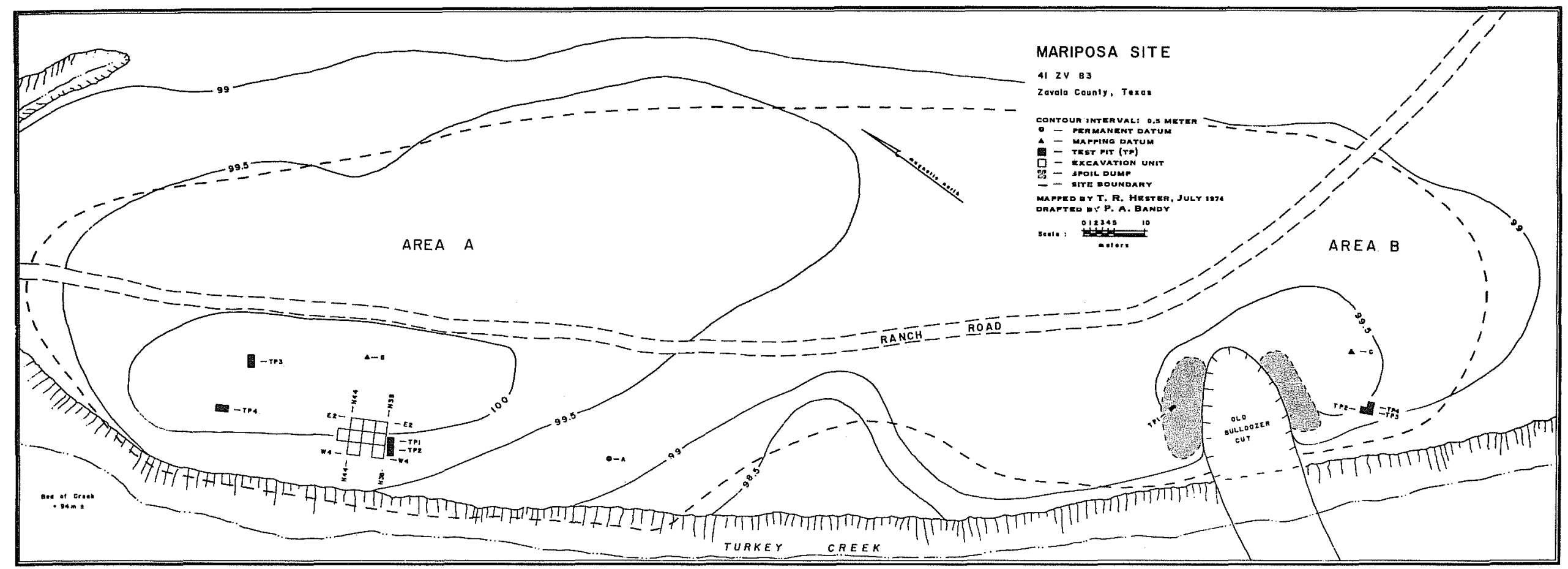

Map 4. Topographic Map of the Mariposa Site, 41 ZV 83. 
distribution of cultural remains within the site (adjacent to the earlier Tests 1 and 2). With this in mind, excavation proceeded for the most part with trowel and brush, with all artifacts being mapped prior to removal and bagging. The recorded materials obtained from this investigation form the bulk of the analyzed data of this thesis. One test pit in Area A (TP3) and four test pits in Area B (TP7-TP4) were also completed along with the excavation.

The third and final investigation at Mariposa occurred in July of 1975. The writer, assisted by Charles Moffat and Irma Richie, returned to test another area of the site, TP4. A $1 \times 2$ meter test pit in Area 4 was excavated to a depth of $60 \mathrm{~cm}$, in $15-\mathrm{cm}$ levels. While there was only sparse evidence of lithic materials, a substantial hearth was revealed at the deepest level of the test ( $60 \mathrm{~cm}$ below the surface). Preliminary analyses of this test pit excavation have been prepared (Montgomery, Moffat and Richie 1975).

\section{Excavation Methodology}

Hester (1974c) has presented a statement concerning the excavation methodologies utilized at the Mariposa site. Initial testing in 1970 provided only a brief indication of the archaeological materials present, along with an estimate of the age and cultural affiliation of the site. The 1974 excavations were initiated with two objectives in mind. One objective was the recording and subsequent definition of intrasite artifact patterning. Variability in the archaeological record of spatial patterning could only be recorded by a horizontal excavation orientation. To this end, nine two-meter squares were excavated, each by five centimeter leve1s. Such a technique would "obtain a view of the horizontal distribution of cultural remains in one portion of the site" (Hester 1974c:19). Each excavation unit retained ten centimeter balks and the southeast corner stake (relative to grid north) was considered the datum for the associated unit. As each five centimeter level was excavated, all materials were left in situ and mapped. Small objects (such as small chert chips, fragmentary snail shells, etc.) were bagged and labeled from the appropriate unit level quadrant. This excavation and recording process resulted in a series of "distribution maps" (Hester 1974c) which reflect the spatial relationship among artifacts. Further discussion of these relationships will be presented in "Intrasite Patterns."

A metal pipe (Datum A) was established as a permanent datum point in the middle of the site on the first field day of the 1974 excavations. Datum B, in Area A (see map 4), served as the reference point in constructing a site grid for accurate provenience control. Subsequent to the Datum A placement, the site was cleared of vegetation and a contour map was prepared using a telescopic alidade and plane table.

Vertical provenience was recorded in relation to a datum plane with an assumed elevation of 100 feet. This datum was established at Datum B. Accurate vertical provenience facilitated completion of the excavation's second major objective: projectile point sequence. Hester (1974c) has documented the general results of Mariposa's projectile point sequence. 
After field work was completed, the bagged artifacts and materials were stored in San Antonio. This material was then turned over to the author, who cleaned, labeled and cataloged that portion of the site's material which had not been processed. Cataloging and labeling the excavated material followed these procedures:

1. Each quadrant within a level of every separate excavation unit was assigned a unique lot number.

2. All similar materials within one lot (burned rock, gastropod shells, flakes) were grouped together and bagged.

3. Materials within a lot "bag" were labeled with the site number (41 ZV 83), lot number, provenience information, excavation date and material description.

4. All worked artifacts were individually labeled with permanent ink in the following manner:

$$
\frac{41 \mathrm{ZV} 83}{\operatorname{Lot} \# A \#}
$$

A separate artifact sheet was maintained for these items, listing al1 metric attributes, qualitative description, and provenience information. Projectile points were similarly labeled, with a $P$ number instead of an A number. A projectile point sheet was also maintained which recorded pertinent quantitative and qualitative data.

These procedures produced catalog sheets describing all materials recorded for each lot provenience and associated data on all artifacts prior to analysis.

\section{Site Morphology}

Two profiles are available from Mariposa for use in this study. In Test 2 (dug in 1970), a profile of the northern wall was prepared. Examination of this profile indicates that four strata can be distinguished. The first $45 \mathrm{~cm}$ below the surface, designated Stratum 1, is composed of fine (alluvial) grey-brown, clay-loam soil. Scattered burned rock, flint flakes, mussel shell fragments, gastropod shells, and scattered charcoal occur in this level. Cultural material is densest in the first $20 \mathrm{~cm}$, with two projectile points (Scalzorn and Frio) and one projectile point fragment being recorded (Hester n.d.). From $45 \mathrm{~cm}$ to $80 \mathrm{~cm}$ below the surface, an increasingly granular and browner clay-loam soil constitutes stratum 2. Cultural debris such as burned rock and flake fragments increases in comparison to the lower portion of 1. A large charcoal concentration was encountered and a projectile point basal fragment (Kinney) was recovered. Indicators of occupation are strongest in the upper part of this stratum. The division between Strata 2 and 3 is ill-defined, with 3 lying generally 80 
centimeters to 100 centimeters deep, Lower portions of Stratum 3 exhibit increasing clay content. The depth of Stratum 3 s.lopes for $90 \mathrm{~cm}$ at the western extreme of the profile to $110 \mathrm{~cm}$ at the eastern edge. Burned rock, charcoal and scattered flakes occur in this brown granular clay-loam soil stratum.

Stratum 4 underl jes Stratum 3 and has been recorded to a depth of $140 \mathrm{~cm}$ in the eastern half of Test 2. Composed of compact and hard tan clay, this stratum contains a few burned rocks and is considered to be culturally sterile.

Excavations in 1974 produced the other profile from Mariposa, Using the north wal1 of N38/W2, a slightly different profile picture was obtained (see Fig.1). Here the initial five centimeters were termed Stratum I. This layer of reworked colluvium was laminated at the stratum bottom, with blocky to wind-blown dust occurring above the laminated bottom up to the present surface. Color is light brown to tan when wet and brown-grey when dry. Lying beneath Stratum I to a depth of $50 \mathrm{~cm}$ is Stratum II. Stratum II is a layer of silty clay-loam filled with alluvial deposits and organic material. The greatest amount of cultural material in the excavation occurs in this stratum. Stratum II is characteristically grey to grey-brown in color. From $50 \mathrm{~cm}$ to $135 \mathrm{~cm}$ below the surface, a yellow to tan clay layer is observed. This layer, termed Stratum III, is marked by an increasing ciay content with increasing depth and a corresponding decrease in cultural materials. The Stratum II-III boundary is very ill-defined.

The two profiles from Mariposa depict somewhat different conditions concerning the depth of cultural deposits. Test 2 (1970) produced more material at a greater depth than the 1974 profile, as well as more varied stratigraphic relationships (four instead of three strata). However, considering the somewhat obscure boundary between Strata 2 and 3 in the 1970 profile, there is probably no great difference between the profiles.

Diagnostic materials encountered in both profiles indicate both Archaic and Late Prehistoric occupations for Mariposa. The first $30 \mathrm{~cm}$ below the surface in the 1974 excavations revealed Perdiz, Scalzom and Zavala points. Both Archaic (Frio point) and Late Prehistoric (Scalzom point) materials occur in the initial $20 \mathrm{~cm}$ of deposit in the Test Pit 2 profile and a possible Kinney point fragment (Archaic) was recovered 40 to $60 \mathrm{~cm}$ below the surface. Indicators of Archaic occupation at Mariposa are especially strong in Area B, where several Archaic projectile points were recovered from eroded contexts.

As will be stated in the following section, projectile points in south Texas are not concrete time markers. Such being the case, more work at Mariposa wi11 necessarily have to be done before statements can be generated concerning possible Archaic occupation(s) at Mariposa. However, within Stratum 1 of the 1970 profile and Strata I and II of the 1974 profile, a definite Late Prehistoric occupation, concentrated in the upper $30 \mathrm{~cm}$ of the deposit, has been demonstrated (Hester 1974c). 


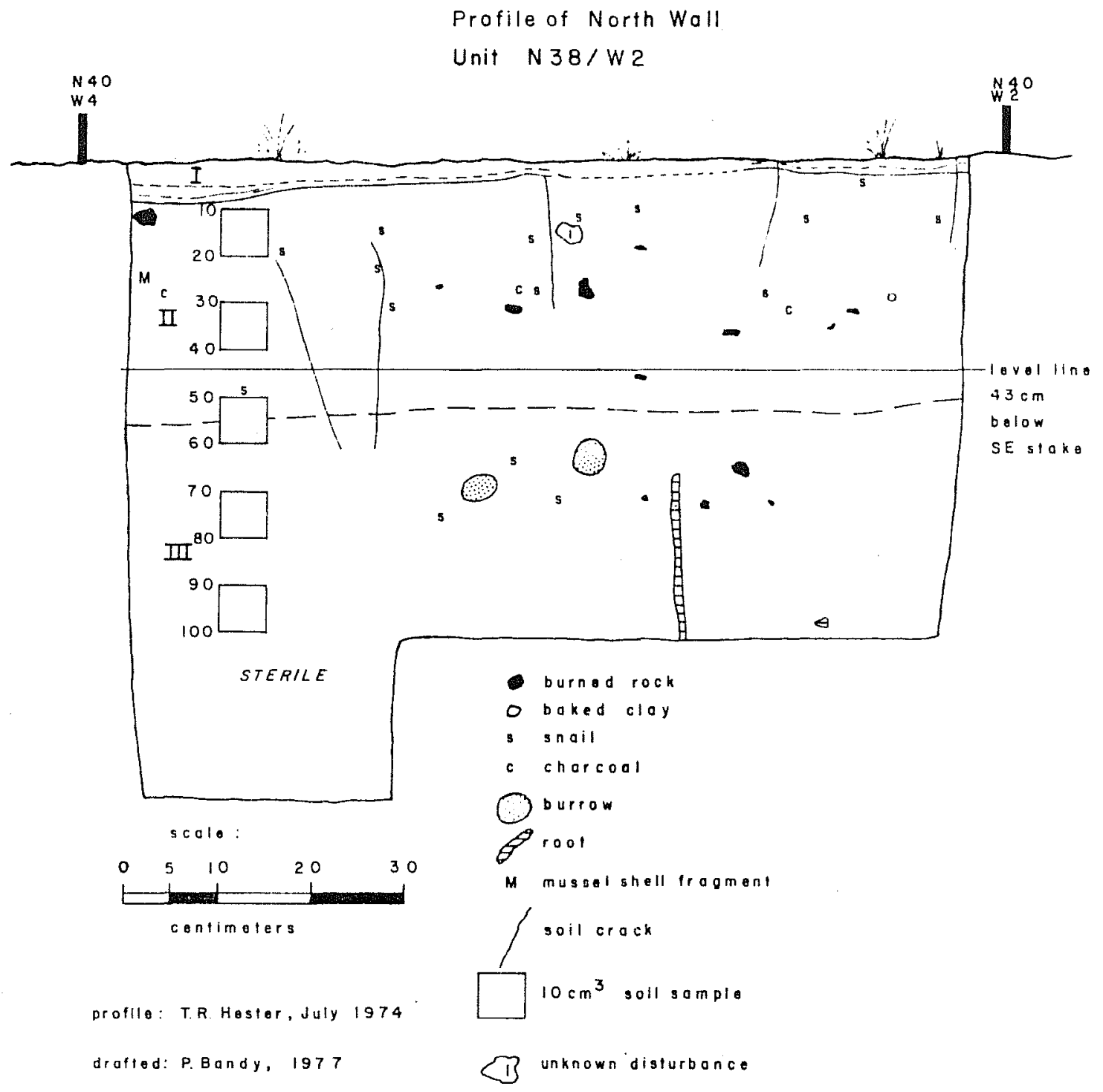

Figure 1. North Wall Profile, Unit N38/W2, 41 ZV 83. 
Radiocarbon Analysis

Typological (relative) and chronometric (absolute) dating are the techniques most commonly used for dating sites in south Texas. In the majority of cases, typological comparisons rested upon already established projectile point sequences in central Texas (Hester and Hill 1975b:18). However, recent excavations in southern Texas have cast doubt on cross-dating south Texas projectile points (see Hester and Hill 1975b:18) with similar central Texas projectile points, making necessary the use of other dating methods for more accurate results.

Fortunately, radiocarbon dates are becoming available at many sites in southern Texas. This allows definition of the temporal parameters of many sites, including Mariposa. Hester and Hill (1975b:19) have previously reported the results of radiocarbon dating at Mariposa ( 41 ZV 83). Level 3 of the site has been dated at A.D. 1430 (sample Tx-1526) and a hearth at the same level was dated to ca. A.D. 1650 (sample UCLA 1821D). Still deeper, at level 4, a date of A.D. 620 (UCLA-1821E) was obtained. These three radiocarbon determinations form the known time 1 imits of the Mariposa occupation(s).

It must be pointed out that the levels used for the radiocarbon dates are not the same levels used in the 1974 excavations. Each level of Test Pit 2 (1970) was $20 \mathrm{~cm}$, while the 1974 excavations proceeded by $5 \mathrm{~cm}$. Implications for this will be explored further in this section.

The earliest occupation of the site can be documented at around A.D. 620 and the latest occupation took place sometime near A.D. 1650 or later. Radiocarbon dates and sample descriptions from the Mariposa site are presented in Table 1.

Recognizing that Mariposa was possibly occupied for approximately 1,000 years (A.D. 620-A.D. 1650) poses some immediate problems. First, the earliest possible occupation of Mariposa falls in the Archaic Period (6000 B.C.-A.D. 1200). Second, the Late Prehistoric dates recovered from Mariposa are stratigraphicaliy deep (40-60 cm below the present surface) and the 1974 excavations did not extensively sample to this depth. The majority of the 1974 excavation units penetrated only $25 \mathrm{~cm}$ below the surface. While no estimate of elapsed time has been prepared for the soil deposition between the dated soil level and the excavated, it is possible that the documented occupation of Mariposa may be quite close to historic times. Evidence for European contact, however, was not produced from site excavations.

Data necessary for solving the first problem are not yet available and will not be until excavations penetrate deeper into the site. This necessarily depends on whether or not future excavations are initiated at Mariposa. Resolution of the second problem also cannot be achieved without absolute dates associated with the upper $30 \mathrm{~cm}$ in Stratum I and II (1974). Thus, the excavated material from the Mariposa site must be considered to date past A.D. 1430 at this stage of the investigation. 
TABLE 1

RADIOCARBON DATES FROM 41 ZV 83 (MARIPOSA SITE)

Years B.P.

$430 \pm 60$

"not older than 300 years"

UCLA-1821E

TX-1526

UCLA-1821D

$1400 \pm 100$
A.D.

1520

1650

550
Corrected*

1430

$1650(?)$

620

*Corrections added according to Hester and Hill (1975b). 


\section{THE CLASSIFICATION SCHEME}

Before turning to the material excavated from Mariposa, a brief review of the classification scheme will be presented. Al1 1 ithic and metal materials (except burned rock) which had been altered by human activity (artifacts) were divided into three classes, based on the technological processes which produced them. Artifacts produced by the chipping (flaking) of siliceous materials are classed under chipped stone. This flaking or chipping is a process which results by removing material from the "objective piece by pressure, percussion, indirect percussion or the combination of pressure and percussion" (Crabtree 1972:65).

The second class of materials is also lithic, but these artifacts have been modified by processes of grinding, battering or polishing. Battering is produced by a specific use of the percussion technique, where "overlapping superimposed cones" are sought to shape the material (Crabtree 1972:80). Rubbing an object with abrasive material will, over time, produce either a smoothed or polished surface. If a glossy surface results, the process may be termed polishing. This occurs on only one artifact from Mariposa. Ground stone artifacts are also produced by abrasive action, but the smoothed surfaces of these artifacts do not exhibit gloss or sheen.

The third major class of materials was produced by a metal technology and therefore is probably not aboriginal. Only one such artifact was recovered from Mariposa.

Two of the three material classes of artifacts from Mariposa are divided into artifact groups which fall in each class, Only brief descriptions and reasons for division will be presented here. A more detailed examination of the artifacts is contained in the following chapter. All illustrated artifacts are drawn and photographed on a 1:1 scale. Artifacts were smoked with ammonium chloride before being photographed.

\section{Chipped Stone}

A morpho-technological division of these materials is presented graphically in Fig. 2. The first division is technological, separating chipped stone products from chipped stone by-products and from cores.

\section{By-Products}

Chipped stone by-products result from the reduction of 1 ithic material to finished tools. The smaller (usually) debris caused by the chipping reduction is called by-products, or flakes and flake fragments. By-products may be altered or unaltered, another technological distinction. Unaltered by-products are composed of identifiable flake forms and flake fragments. Flakes which exhibited typical characteristics (bulb of force, compression rings, etc.) are further classified and subjected to analysis later in this chapter and thesis. Flake fragments were only counted, since they held no identifiable flake characteristics. 


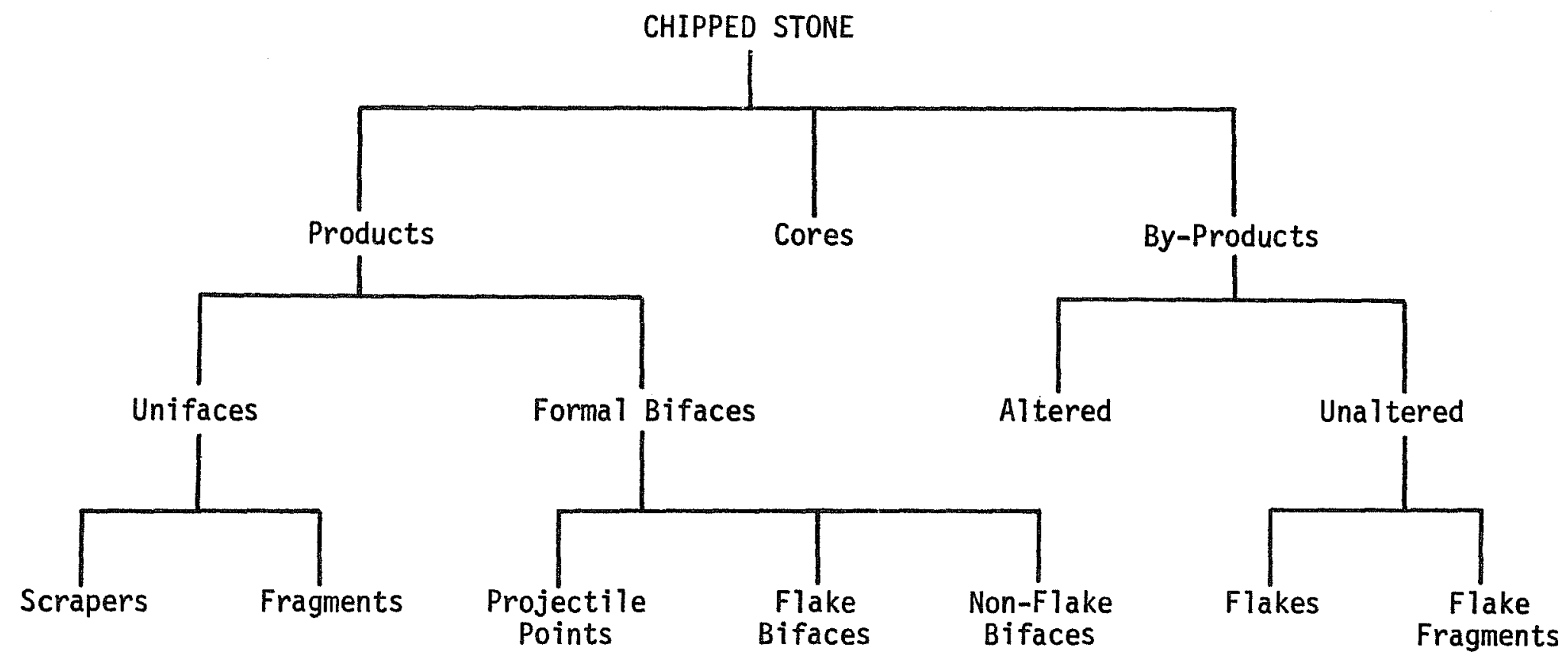

Figure 2. Chipped Stone Classification Scheme from the Mariposa Site, 41 ZV 83. 
Two forms of alteration may be applied to by-products: utilization and trimming. Each of these technological processes was exhibited on secondary cortex flakes. Descriptions of these lithic processes are given in the following chapter; they do form a definite technological division for altered by-products.

\section{Products}

Products are the desired end-result, or artifacts, manufactured by a systematic reduction process. Products may be divided into two large groups: unifaces and formal bifaces. Unifaces are flaked on one face only while formal bifaces are flaked on two faces.

Unifaces may be complete or fragmentary. Fragmentary unifaces were further classified by the amount of cortex remaining on the tool fragment (division not shown in Fig. 2). Complete unifacial products al1 retained steep edge angles and were Tabeled scrapers for convenience (not by assumed function). There are four classes of scrapers (not shown in Fig. 2), depending on the location of the artifact's worked edges.

Formal bifaces were first classified by the presence or absence of hafting modification. Those artifacts which did retain some form of hafting modification were termed projectile points. Types of projectile points were assigned following the morphological and technological guidelines set forth in Suhm and Jelks (1962) and Hill and Hester (1971). Metric distinctions such as projectile point neck width, weight, maximum width and thickness (cf. Corliss 1972; Fenenga 1953; Jelinek 1967) between dart points and arrow points were informally recognized but not rigorously utilized. Projectile point fragments were classified as distal, medial or basal depending on whether the fragment was the point tip, the middle section or the portion closest to the haft (respectively).

The remainder of the bifaces were classified as flake bifaces or non-flake bifaces. Flake bifaces retained some evidence of being manufactured from a flake. Distal and proximal fragments (not shown in Fig. 2), as well as complete specimens, were recognized.

Non-flake bifaces retain no evidence of being manufactured from a flake. These artifacts were subdivided according to their existing condition (complete or fragmentary). Complete non-flake bifaces were also divided into five morphological and technological categories (not shown in Fig. 2). Fragmentary nonflake bifaces were subdivided into two categories, proximal and distal. Distal fragments were worked to a point or tip. Proximal fragments lacked this feature.

\section{Cores}

Cores result from the reduction of parent material by a flaking process. In this study, cores are classed as a separate category from products and byproducts, since cores are not prepared to be shaped implements. Cores reta in the numerous flake scars caused from by-product removal. No macroscopic edge 
wear is present on cores. The direction of flake (by-product) removal and the number and nature of flake platforms were among the attributes used to classify seven groups of cores (not illustrated in Fig. 2). A special core specimen, a core overshot flake, was recognized (see the following section).

\section{Ground, Battered or Polished Stone}

Ground stone was divided into morphological and technological classes, as well as artifact material. Both hematite and sandstone were ground. The abrasive grinding action took the form of localized scratching and grooving. General grinding of sandstone slabs produced smoothed sandstone slabs and smoothed hematite. Limestone was shaped into manos by general grinding action. Mano fragments were also recognized. Polishing was present on only one quartzite pebble. Hammerstones retained evidence of battering at one or more areas along their surfaces. The division of ground, battered or polished stone is presented in Fig. 3. 


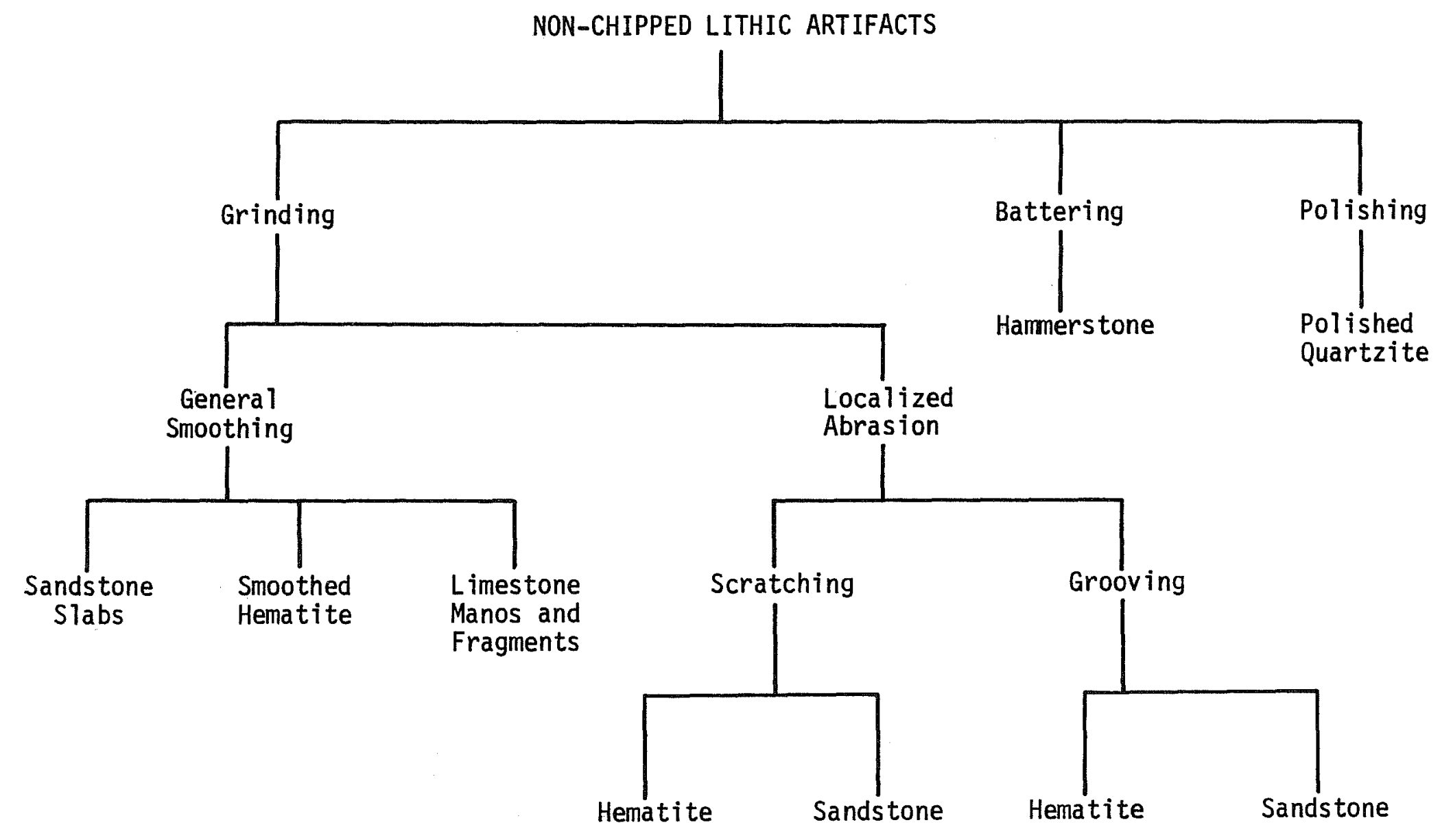

Figure 3. Ground, Battered and Polished Stone Classification Scheme from the Mariposa Site, $41 \mathrm{ZV} 83$. 


\section{THE EVIDENCE}

\section{Lithic Material}

The basis for describing the chipped and ground stone recovered from archaeological contexts at Mariposa has been drawn from many sources. Hester (1975b), Crabtree (1972), Shafer (1969) and Hester and Hill (1972) were considered important publications explaining terminology. Terms needing definition for greater understanding of the lithic descriptions follow:

Beveled Edge: "An edge which has been manufactured to produce the desired edge angle or exposure for the removal of a desired flake or flake series" (Crabtree 1972:38).

Biface: "Artifact bearing flake scars on both faces" (Crabtree 1972:38).

Bulb of Force: "The bulbar part on the ventral side at the proximal end of a flake. The remnant of a cone part, the result of the application of either pressure or percussion force" (Crabtree 1972:48).

Compression Rings: "Ripple rings radiating from the point of force. Can be both positive and negative--positive on the flake and blade; and negative on the core . . . compression rings are generally more prominent with percussion than with pressure" (Crabtree 1972:52).

Denticulation: "Prominence resembling teeth similar to those on a saw. ToothTike serrating on margins of artifacts" (Crabtree 1972:58).

Dorsa 1: "Outer surface. Keeled part of blade or flake. For instance, the dorsal side of a blade is the face of the core prior to detachment" (Crabtree 1972:59).

End View: "Perpendicular view of either proximal or distal end" (Crabtree 1972:60).

Exhausted: "Used up. Consumed, either from function wear or by the flint knapper. Adjective applied most often to cores. Exhaustion may occur for the following reasons: steps and hinges, reduction of platform size or angle, lack of material, too smal1" (Crabtree 1972:62).

Face: "The dorsal or ventral surface of the artifact" (Crabtree 1972:62).

Flake: "Any piece of stone removed from a larger mass by application of force. . A portion of isotropic material having a platform and bulb of force at the proximal end" (Crabtree 1972:64).

Hinge Fractures: "A fracture at the distal end of a flake or blade which prevents detachment of the flake at its proposed terminal point. A hinge fracture terminates the flake at right angles to the longitudinal axis and the break is usually rounded or blunt" (Crabtree 1972:68).

Lateral Margins: "Margins of flakes, blades and other stone tools on either or both sides of the longitudinal axis" (Crabtree 1972:72). 
Lip: "(1) Projection found on core or artifact which results from the bulbar scar. A concavity causing an overhang usually found on the leading edge. (2) Projection found on the proximal ventral surface of some flakes, believed to be associated with soft hammer percussion or pressure" (Crabtree 1972:74).

Longitudinal Lateral Section: "The area of the artifact bounded by the proximal and distal ends and both lateral margins" (Crabtree 1972:74).

Longitudinal Transverse Section: "The thickness of the artifact between the dorsal and ventral side and bounded by the proximal and distal ends" (Crabtree 1972:74).

Percussion Flaking: "A method of striking with a percussor to detach flakes or blades from a core or mass" (Crabtree 1972:80).

Plano-Convex: "Flat on ventral side--curved on dorsal surface. Common to unifaciat artifacts" (Crabtree 1972:82).

Platform: "The table or surface area receiving the force necessary to detach a flake or blade. Can be either natural or prepared" (Crabtree 1972:84).

Pot Lid: "A plano-convex flake leaving a concave scar. Pot lids are the result of differential expansion and contraction of isotropic material but are minus the compression rings of force lines usually associated with these conditions. Generally they are a natural occurrence rather than intentional results of man-made flakes" (Crabtree 1972:84-85).

Pressure Flaking: "Process of forming and sharpening stone by removing surplus materiat--in the form of flakes--from the artifact by a pressing force rather than by percussion" (Crabtree 1972:85).

Primary Retouch: "Removal of irregularities on the artifact by the pressure technique to make the piece ready for the second retouch" (Crabtree 1972:85).

Retouching: "A technique used to thin, straighten, sharpen, smooth and make the artifact more regular in form. Generally involves the use of pressure in one or more stages. Retouching usually follows percussion preforming. Before precision pressure work may be accomplished, one must first remove all irregularities on the objective piece by a primary retouch and then do a secondary retouch" (Crabtree 1972:89).

Serrating: "Indenting the edges by alternating the removal of flakes" (Crabtree 1972:90).

Side View: "The lateral edge or margin of the artifact when it is held horizontal to the viewer" (Crabtree 1972:90).

Sinuous: "Snake-1ike; alternating or wavy. Margins of artifacts are made sinuous by removing flakes alternately from the lateral edge" (Crabtree 1972:92). 
Step Fracture: "A flake or flake scar that terminates abruptly in a right angle break at the point of truncation. Caused by a dissipation of force or the collapse of the flake" (Crabtree 1972:93).

Thermal Treatment: "Method of altering siliceous materials by exposure to controlled heat. This treatment makes the stone more vitreous" (Crabtree 1972:94).

Thinning Flakes: "Flakes removed from a preform either by pressure or percussion to thin the piece for artifact manufacture. Thinning flakes are also removed to thin a biface or uniface. Usually shows special platform preparation" (Crabtree 1972:94).

Transverse: "Crosswise" (Crabtree 1972:95).

Transverse Section: "The area bounded by and between the lateral margins" (Crabtree 1972:95).

Uniface: "Artifact flaked on one surface only" (Crabtree 1972:97).

Ventral: "Plano side or inner surface of flake or blade. The under surface" (Crabtree 1972:97).

Vitreous: "Having the near luster and texture of glass" (Crabtree 1972:98).

Core: "A nodule from which flakes have been removed" (Shafer 1969:3).

Flake: "A chip or spal1 removed from a nodule (the parent stone) by force" (Shafer 1969:4).

Heavy Percussion Flakes: "Flakes with a rather prominent bulb of (force). They are relatively thick at the bulbar end, and frequently possess cortex somewhere on the dorsal surface or on the striking platform. The dorsal surface may or may not be faceted" (Shafer 1969:4).

Cortex Striking Platform: "The cortex (patinated) surface of a core used without modification as the striking platform" (Shafer 1969:4).

Single Faceted Striking Platform: "The striking platform prepared by a single facet (removing one flake)" (Shafer 1969:4).

Multiple Faceted Striking Platform: "A striking platform with two or more facets" (Shafer 1969:4).

Primary Cortex Flake: Flakes which "have the dorsal surfaces covered with cortex; they represent the initial decortication of a core" (Hester and $\mathrm{Hill}$ 1972:46).

Secondary Cortex Flakes: Flakes which "retain some cortex on the dorsal surface, representing further shaping of a core" (Hester and Hi11 1972:46). 
Interior Flakes: Flakes retaining "no cortex on the dorsal surface, indicating their removal from the interior of a core" (Hester and Hill 1972:46).

Convergent Platform: "Striking platform formed by convergent planes" (Hester 1971:106; Hester and Hil1 1972:46).

Crushed (Shattered) Platforms: Flakes which have had their striking platform obliterated during flake removal.

Distal: Farthest from point of attachment for a projectile point. The portion of a biface which morphologically is a point or tip.

Proximal: The base of a projectile point, or the area chipped (modified) for hafting.

Longitudinal: Running lengthwise.

Transverse: Crossing from side to side; crosswise.

Using these terms, a description of the artifacts recorded at Mariposa will be more easily understood.

Artifacts were divided into three major divisions: chipped stone, ground and polished stone, and historic materials. No ceramics or bone tools were collected from testing and excavation activities conducted at Mariposa. Lithic objects culturally modified by chipping activities (Epstein 1962) were placed under the rubric of "chipped stone." Modification may be bifacial or unifacial and the classification presented here was considerd most appropriate for the lithic assemblage at Mariposa.

\section{Chipped Stone}

\section{Utilized Flakes}

Thirty-four flakes are included under this category. Utilization should be distinctly separated from retouch or trimming, another tool category al together. Mallouf, Fox and Briggs (1973:67) provide an excellent contrast between "utilization" and "retouch":

The term "utilization" is used when referring to random flake edges which exhibit irregular minute scarring. Use of this term is based on the observation that flakes freshly removed from a core often possess unidentified edges suitable for scraping or cutting purposes. Subsequent utilization of such an edge in working non-1ithic materials such as antler or wood can, in time, produce a jagged, irregular edge outline.

"Retouch" .. . refers to a process whereby a flake edge is intentionally subjected to modification through the removal of a uniform series of tiny flakes. Retouch may be used as a means of sharpening, shaping, dulling, or otherwise reestablishing a usable edge in place of one which is worn or improperly formed. 
Distinguishing between utilization and retouch is not a clear-cut matter, however. A retouch edge can be produced by utilization methods upon unmodified flakes (Mallouf, Fox and Briggs 1973:67). Any separation of these two different lithic modification techniques, then, is always tenuous.

At Mariposa, two types of utilized flakes are recognized: secondary cortex utilized flakes and interior utilized flakes. Secondary flakes, which retain both cortex and flake scars from core preparation, were utilized, as were interior flakes. Interior flakes retain no cortex and are believed to have been struck from the interior of a core nucleus (Mallouf, Fox and Briggs 1973: 75).

Utilized Secondary Flakes (P1ate 1,a)

Fourteen utilized secondary flakes were recovered from the 1974 field season. About half of these still retain a bulb of force and platform. Two of the utilized secondary flakes appear to have been burned. Chert is the basic lithic material used to manufacture these tools. Area of utilization, in most cases, is limited in extent to between five and ten millimeters along a lateral edge. Limited utilization area may reflect the physical 1 imits of the flakes manufactured, since many of the flakes are small. Intense utilization did not appear on any of the specimens, implying only limited use and discard. Irregular flake shapes comprise the majority of the artifacts and no selected pattern of flake shape is indicated.

\section{Utilized Interior Flakes (Plate $1, b)$}

Fifty-nine percent of the utilized flakes (20 of 34 specimens) were manufactured on interior flakes. Again, no particular type of flake shape appears to have been preferred for utilization processes. Only three flakes are burned (A-10, $A-11$ and $A-38$ ) and one flake shows intensive utilization (A-15). One-third of the utilized interior flakes still retained either the bulb of force or the platform (or both). Significantly, 11 of the 18 flakes $(61 \%)$ were hinge fractured on one or both ends of the flake. Such hinging could have resulted from tool manufacturing "accidents" where bifacial or unifacial reduction blows had been too severe for the material to handle. If such were the case, pieces of rejected or broken tools were obtained for use in different (or similar) activities. Fine-grained quartzite was used as the lithic resource material for one utilized interior flake (A-98) while light tan and brownish chert was used for the remainder of this category.

Metric measurements and provenience data for both categories of utilized flakes are included below. 
Plate 1. Utilized Flakes, Trimmed Flakes and Scrapers. a, secondary cortex utilized flake $(A-94)$; b, interior utilized flake $(A-1)$; $C$, secondary cortex trimmed flake (A-149); d, interior trimmed flake $(A-93) ;$ e, side scraper, one edge $(A-86) ; f$, side scraper, two edges $(A-117) ; g$, end and side scraper $(A-66)$. 


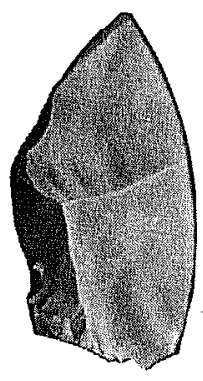

a
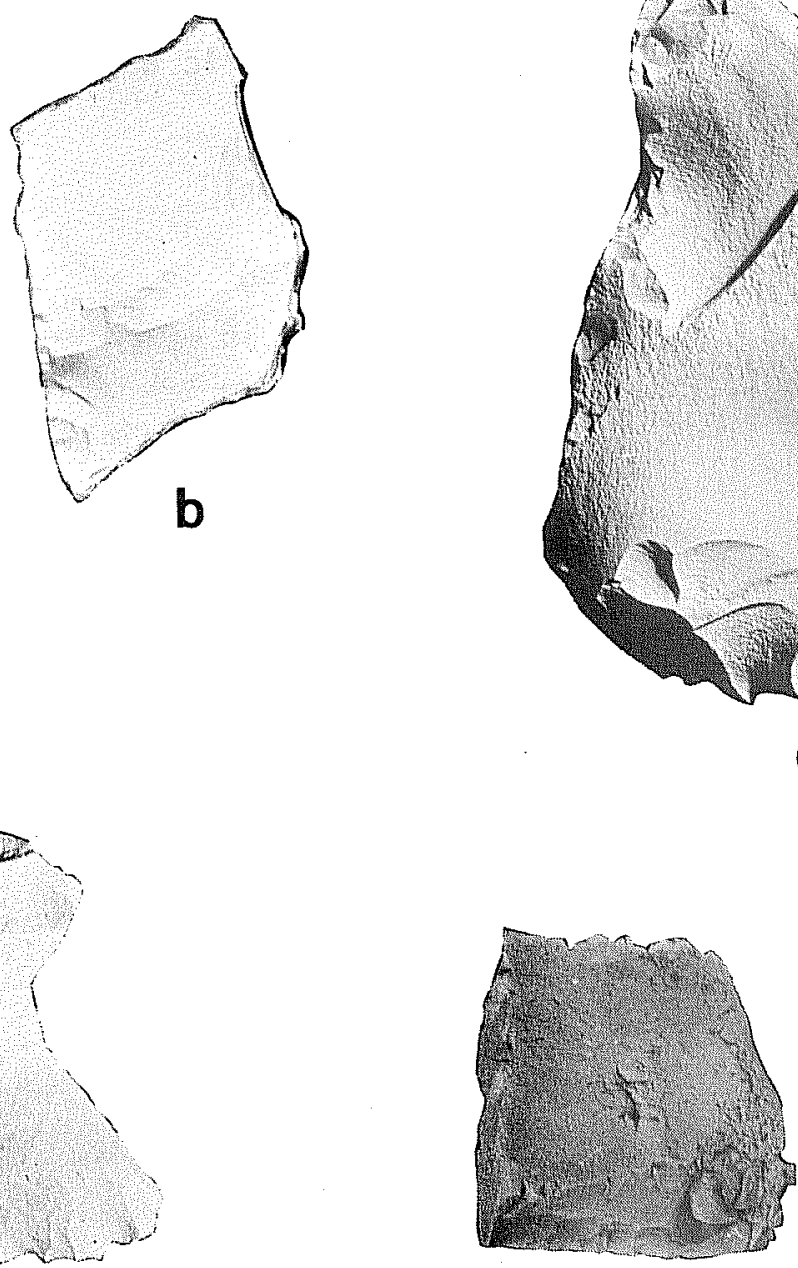

e

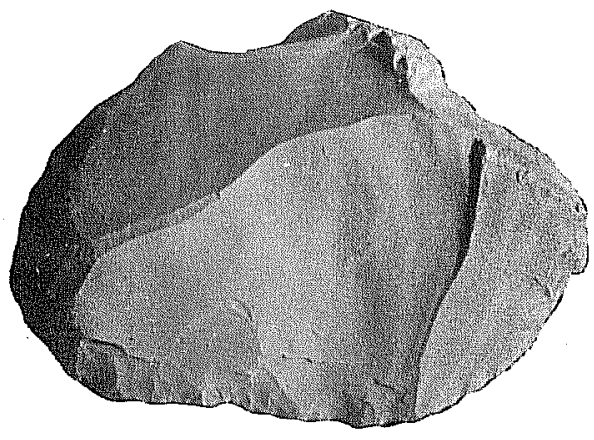

g 
Utilized Flake Metric Data

Secondary

Cortex FTakes

A -5

A-7

A-8

A-13

A-28

A-30

A-31

A-53

A-54

A-56

A-65

A-72

A-94

A-162

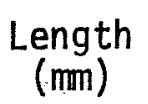

50.15

42.0

26.4

55.0

37.0

43.85

27.5

20.25

27.65

24.15

58.55

29.3

35.0

24.6
Width
$(\mathrm{mm})$

39.2

31.55

8.25

22.4

31.25

25.1

30.35

15.35

26.0

14.35

21.8

28.6

28.2

19.6
Thickness

(mm)

18.3

8.35

4.5

9.55

5.6

10.0

9.1

4.55

9.35

4.3

19.66

10.5

6.15

5.2
Weight

(gm)

30.5

13.1

1.4

11.25

6.1

11.5

19.8

1.3

7.4

1.65

15.2

13.4

3.5

4.0

Interior Flakes

$\begin{array}{llllc}\text { A-1 } & 51.0 & 29.3 & 9.6 & 12.1 \\ \text { A-10 } & 26.55 & 28.0 & 6.35 & 5.3 \\ \text { A-11 } & 25.25 & 17.65 & 6.65 & 3.0 \\ \text { A-15 } & 26.55 & 22.0 & 5.6 & 3.1 \\ \text { A-22 } & 23.8 & 24.05 & 5.3 & 3.25 \\ \text { A-23 } & 61.9 & 35.0 & 8.8 & 11.2 \\ \text { A-29 } & 38.15 & 27.0 & 9.75 & 7.1 \\ \text { A-38 } & 24.0 & 16.1 & 2.8 & 1.4 \\ \text { A-43 } & 22.6 & 20.2 & 6.45 & 2.6 \\ \text { A-60 } & 30.7 & 29.2 & 4.55 & 2.8 \\ \text { A-62 } & 21.0 & 12.3 & 5.55 & 1.65 \\ \text { A-67 } & 18.15 & 15.7 & 6.6 & 1.7 \\ \text { A-80 } & 24.75 & 22.0 & 5.5 & 3.1 \\ \text { A-90 } & 32.9 & 20.55 & 4.75 & 2.25 \\ \text { A-98 } & 56.77 & 46.66 & 18.0 & 51.5\end{array}$




$\begin{array}{ccccc}\text { Interior Flakes } & \begin{array}{c}\text { Length } \\ (\mathrm{mm})\end{array} & \begin{array}{c}\text { Width } \\ (\mathrm{mm})\end{array} & \begin{array}{c}\text { Thickness } \\ (\mathrm{mm})\end{array} & \begin{array}{c}\text { Weight } \\ (\mathrm{gm})\end{array} \\ \text { A-142 } & 22.75 & 14.20 & 13.25 & 3.7 \\ \text { A-148 } & 44.35 & 25.55 & 7.15 & 7.4 \\ \text { A-151 } & 35.65 & 24.6 & 11.4 & 6.4 \\ \text { A-163 } & 22.8 & 16.2 & 5.3 & 3.4 \\ \text { A-166 } & 29.6 & 20.9 & 5.5 & 5.7 \\ \text { - } \ldots \ldots \ldots\end{array}$

Utilized Flake Provenience

Secondary

Cortex FTakes

A-5

A-7

A-8

A-13

A-28

A-30

A-31

A-53

A-54

A-56

A-65

A-72

A-94

A-162

$$
\text { Leve } 1
$$

$2(5-10 \mathrm{~cm})$

$2(5-10 \mathrm{~cm})$

$2(5-10 \mathrm{~cm})$

$3(10-15 \mathrm{~cm})$

$1(0-5 \mathrm{~cm})$

$2(5-10 \mathrm{~cm})$

$2(5-10 \mathrm{~cm})$

$3(10-15 \mathrm{~cm})$

$3(10-15 \mathrm{~cm})$

$4(15-20 \mathrm{~cm})$

$2(5-10 \mathrm{~cm})$

$4(15-20 \mathrm{~cm})$

$2(5-10 \mathrm{~cm})$

$1(0-20 \mathrm{~cm})$
Unit

N38/W2

N38/W2

N38/W2

N38/W2

$\mathrm{N} 40$

N40

N40

N42

N42

N42

N42/W2

N42/W2

N40/E2

Area B
Quadrant

NE

SW

SW

SE

SW

NW

NW

NE

SW

SW

SW

SW

SW

Test 3

Interior Flakes

$\begin{array}{llll}A-1 & 1(0-5 \mathrm{~cm}) & N 38 / \mathrm{W} 2 & \mathrm{SW} \\ A-10 & 3(10-15 \mathrm{~cm}) & \mathrm{N} 38 / \mathrm{W} 2 & \mathrm{NW} \\ A-11 & 3(10-15 \mathrm{~cm}) & \mathrm{N} 38 / \mathrm{W} 2 & \mathrm{NW} \\ A-15 & 4(15-20 \mathrm{~cm}) & N 38 / \mathrm{W} 2 & \mathrm{NE} \\ A-22 & 7(30-35 \mathrm{~cm}) & N 38 / \mathrm{W} 2 & \mathrm{NW} \\ A-23 & 7(30-35 \mathrm{~cm}) & N 38 / W 2 & \mathrm{NW}\end{array}$




\begin{tabular}{|c|c|c|c|}
\hline Interior Flakes & Level & Unit & Quadrant \\
\hline$A-29$ & $1(0-5 \mathrm{~cm})$ & N40 & SE \\
\hline$A-38$ & $1(0-5 \mathrm{~cm})$ & $\mathrm{N} 42$ & NE \\
\hline$A-43$ & $2(5-10 \mathrm{~cm})$ & N42 & NE \\
\hline$A-60$ & $1(0-5 \mathrm{~cm})$ & N42/W2 & NW \\
\hline$A-62$ & $1(0-5 \mathrm{~cm})$ & N42/W2 & SW \\
\hline$A-67$ & $2(5-10 \mathrm{~cm})$ & N42/W2 & SE \\
\hline$A-80$ & $1(0-5 \mathrm{~cm})$ & N42/E2 & SE \\
\hline A-90 & $1(0-5 \mathrm{~cm})$ & N40/E2 & NE \\
\hline A-98 & $2(5-10 \mathrm{~cm})$ & N40/E2 & SE \\
\hline$A-142$ & $3(30-45 \mathrm{~cm})$ & Test 5 & $\mathrm{~S} 1 / 2$ \\
\hline$A-148$ & $3(40-60 \mathrm{~cm})$ & Test 4 & -- \\
\hline$A-151$ & surface & N42/W2 & - \\
\hline$A-163$ & $1(0-5 \mathrm{~cm})$ & N42/E2 & NW \\
\hline$A-166$ & $1(0-5 \mathrm{~cm})$ & N40/E2 & SW \\
\hline
\end{tabular}

Secondary cortex utilized flakes abundantly appear in levels 2 and 3 , where $77 \%$ of these specimens were recorded. Of the nine excavation units, N38/W2, $\mathrm{N} 40$ and N49 contained most of the secondary cortex utilized flakes. Cultural processes which incorporated the use of secondary cortex utilized flakes may be concentrated in these excavated site areas. Utilized flakes with no cortex (interior flakes) were present in greatest quantities in the upper two levels of the site. N42/W2, N42/E2 and N38/W2 appear to be areas where the deposition of interior utilized flakes was preferred, although flakes in N38/W2 occur in deeper levels.

Combining the provenience data for all utilized flakes indicates that loci of utilization processes occurred in N38/W2, N40, N42/E2, N42 and N42/W2, containing almost one-third of the utilized flake specimens.

Trimmed Flakes (Plate $1, c$ and d)

Marginally retouched flakes which exhibit no recognizable tool form or which seem to be primarily chipped in a random pattern with no visible intent toward tool manufacture were termed trimmed flakes. All of these artifacts were constructed on chert flakes and were trimmed (retouched) either unifacially or bifacially. Two subclasses of trimmed flakes are described (below) according to the type of flake used in the artifact preparation. 
Secondary cortex trimmed flakes form the first subclass. Unifacial trimming is exhibited on eight of the nine artifacts in this subclass and is usually confined to one lateral edge. Three of these flakes still retain original striking platforms and bulb of force. Bifacial trimming on one edge characterizes the other secondary cortex trimmed flake. This artifact $(A-64)$ was burned prior to flake removal.

Five artifacts comprise the second subclass of trimmed flakes: interior trimmed flakes. Artifact A-130 was manufactured from fine grained quartzite, while the other four were made from chert. All of the interior trimmed flakes are unifacially flaked on one lateral edge and irregular in outline. In contrast, most of the secondary cortex trimmed flakes retained a great deal of their original "flake" shape.

Trimmed flakes may represent two lithic stages. First, they may represent the rejected initial stages in a flake-tool manufacturing process. On the other hand, trimmed flakes could also represent easily and quickly manufactured cutting tools which may have been used for a relatively short duration (tempora17y) and discarded when the tool edge became ineffective. Conclusions concerning these two sequences are hindered by the small sample size encountered at 41 ZV 83.

Metric data and provenience information for the two subclasses of trimmed flakes follows.

Trimmed Flake Metric Measurements

$\begin{array}{ccccc}\text { Secondary Cortex } & \begin{array}{c}\text { Length } \\ (\mathrm{mm})\end{array} & \begin{array}{c}\text { Width } \\ (\mathrm{mm})\end{array} & \begin{array}{c}\text { Thickness } \\ (\mathrm{mm})\end{array} & \begin{array}{c}\text { Weight } \\ (\mathrm{gm})\end{array} \\ \text { A-19 } & 46.2 & 34.1 & 18.5 & 26.2 \\ \text { A-58 } & 31.35 & 28.35 & 10.6 & 6.35 \\ \text { A-64 } & 40.0 & 28.35 & 13.6 & 10.4 \\ \text { A-89 } & 42.15 & 26.6 & 6.0 & 7.55 \\ \text { A-111 } & 26.35 & 33.85 & 8.0 & 10.1 \\ \text { A-149 } & 76.0 & 45.2 & 17.9 & 75.45 \\ \text { A-169 } & 38.7 & 35.6 & 22.3 & 44.3 \\ \text { A-172 } & 47.5 & 35.1 & 18.3 & 25.3 \\ \text { A-173 } & 34.6 & 25.2 & 16.1 & 15.6\end{array}$

Interior Flakes

$\begin{array}{llllc}\text { A-93 } & 54.3 & 50.6 & 14.35 & 31.55 \\ \text { A-130 } & 58.75 & 26.2 & 14.45 & 18.35 \\ \text { A-154 } & 23.15 & 19.3 & 3.5 & 1.85 \\ \text { A-164 } & 15.7 & 15.1 & 5.2 & 3.5 \\ \text { A-165 } & 33.5 & 32.6 & 11.4 & 14.7 \\ \ldots \ldots \ldots & \ldots \ldots\end{array}$


Trimmed Flake Provenience

\begin{tabular}{cllc} 
Secondary Cortex & \multicolumn{1}{c}{ Leve1 } & \multicolumn{1}{c}{ Unit } & Quadrant \\
\hline A-19 & $5(20-25 \mathrm{~cm})$ & $N 38 /$ W2 & NW \\
$A-58$ & $4(15-20 \mathrm{~cm})$ & $N 42$ & SE \\
$A-64$ & $2(5-10 \mathrm{~cm})$ & $N 42 / W 2$ & NE \\
$A-89$ & $3(10-15 \mathrm{~cm})$ & $N 42 / E 2$ & SE \\
$A-111$ & $2(5-10 \mathrm{~cm})$ & $N 38$ & $N E$ \\
$A-149$ & $3(10-15 \mathrm{~cm})$ & $N 42$ & SE \\
$A-169$ & $3(10-15 \mathrm{~cm})$ & $N 42 / E 2$ & SW \\
$A-172$ & $5(20-25 \mathrm{~cm})$ & $N 42 / W 2$ & NE \\
A-173 & $5(20-25 \mathrm{~cm})$ & $N 42$ & SW
\end{tabular}

Interior Flakes

$\begin{array}{lllc}\text { A-93 } & 2(5-10 \mathrm{~cm}) & \text { N40/E2 } & \text { SW } \\ \text { A-130 } & 1(0-20 \mathrm{~cm}) & \text { Area B } & \text { Test 3 } \\ \text { A-154 } & \text { surface } & \text { N42 } & -- \\ \text { A-164 } & 3(30-45 \mathrm{~cm}) & \text { Test } 5 & \text { NE extension } \\ \text { A-165 } & 1(0-5 \mathrm{~cm}) & \text { N40/E2 } & \text { SW } \\ \ldots \ldots \ldots\end{array}$

Both trimmed flake types occur in levels one through five, although no clustering is readily discernible. Half of the trimmed flakes were recovered from levels two and three at Mariposa.

Unifacial Tools

Excavation and surface collecting at Mariposa produced 21 artifacts which exhibited primary and secondary flaking on one side or face. Classification within this category depended on the finished characteristics of the tool. Marginally flaked unifacial tools which exhibit completeness and a relatively long area of working edge were termed scrapers. Several types of scrapers are represented in the collection, including one-edge side scrapers, two-edge scrapers, end and side scrapers, and scraper fragments. Artifacts lacking distinctive tool finishing were classified as unifacial tool fragments.

Scrapers (Plate $1, e, f, g$, ). While recognizing that "scraper" as a functional description may not reflect the accurate function of this type of artifact, the term is retained due to its almost universal morphological and technological recognition. Stated another way, scrapers are those artifacts which frequently are made from flakes and are unifacially chipped (marginally or totally) to form steep edge angles. Steep edge angles are assumed to have 
performed scraping functions; however, such conclusions cannot be definitely stated without microscopic edge wear analysis and replication experiments. No such studies were attempted, and the artifacts were classified after a macroscopic examination. Eight specimens were excavated during the field season and one specimen was collected from the surface of Area B during the same field season.

The nine specimens were grouped into four classes: side scrapers, one edge and two edge; end-side scrapers; and scraper fragments. According to Crabtree (1972:90), a side scraper is an "implement with beveling on one or more margins of a flake or blade to obtain a strong cutting edge." Three complete scrapers and one scraper fragment can be classified as side scrapers. Two distinct classes of side scrapers can be produced--those with one edge worked and those with two edges worked.

Side Scrapers, One Edge (A-32, A-86, A-112, A-170)--Four examples of this class were excavated at Mariposa, one being a fragment. One specimen (Artifact \#32) was manufactured from a large primary cortex flake. Hard-hammer percussion was the technique utilized to produce this flake. Distinct compression rings are seen on the ventral surface, along with a prominent bulb of force. Platform preparation consisted of removing one flake. The bit of the scraper is convex and the tool outline is oval. Another of the one edge side scrapers is a fragment which still retains cortex on the dorsal surface except on that edge where retouching occurred. What exists of the bit appears to be straight. The third one-edged side scraper is irregular in tool outline and appears to have been made from a core. The retouched edges are quite steep. This specimen is made from fine-grained quartzite, whereas the previous two are made from the locally available chert.

Side Scraper. Two Edges (A-117)--0nly one specimen was classified in this category. Manufactured from a chert primary cortex flake, the artifact was retouched unifacially on one edge and bifacially on the other lateral edge. Cortex almost covers the dorsal face. The bifacial trimming on one edge may be evidence of either platform preparation for subsequent unifacial retouch or further modification of the edge into a bifacial working edge.

End and Side Scrapers (A-120, A-155, A-66)--Excavation revealed three scrapers classified as end-side scrapers. Bifacial retouch is seen on A-120, along with some edge wear. This specimen's end scraping edges are formed on the dorsal face. Cortex is also present on the dorsal face. The remaining two end-side scrapers (A-155, A-66) are thinner in comparison with $A-120$ and are general1y more oval in outline. Both, like A-120, appear to have been manufactured from chert flakes. Artifact \#155 has very steep flaking on the distal end and the overall flaking pattern of the end and two lateral edges is even and marginal. No cortex is present and the scraper retains a hinged fracture on the proximal end. This end exhibits neither retouch nor macroscopic edge wear.

Cortex is present on the proximal end of Artifact \#66. As with A-155, pressure flaking has produced a fine working edge on this specimen. In longitudinal cross section, Artifacts \#66 and 155 reveal lenticular outlines. 
Scraper Fragment--One scraper fragment was recovered at Mariposa. While it appears to have been an end scraper, it is impossible to tell whether one, both or neither of the lateral edges were also marginally flaked in a unifacial fashion to produce a scraper edge. Along with steep edge angles, this artifact also retains cortex on the dorsal face and appears to have been burned.

Metric attributes and provenience for the eight scrapers are given below. Classification divisions are labeled.

Scraper Metric Measurements

\begin{tabular}{ccccc} 
Side Scraper & $\begin{array}{c}\text { Length } \\
(\mathrm{mm})\end{array}$ & $\begin{array}{c}\text { Width } \\
(\mathrm{mm})\end{array}$ & $\begin{array}{c}\text { Thickness } \\
(\mathrm{mm})\end{array}$ & $\begin{array}{c}\text { Weight } \\
\text { One Edge }\end{array}$ \\
\hline A-32 & 88.6 & 54.5 & 2.94 & 98.5 \\
A-86 & 32.15 & 31.8 & 8.2 & 11.25 \\
A-112 & 54.0 & 32.0 & 25.65 & 46.0 \\
A-170 & 55.6 & 39.1 & 13.2 & 34.0
\end{tabular}

Side Scraper Two Edge
A-117
78.0
35.55
14.55
43.4

End-Side Scraper

$\begin{array}{lllcl}\text { A }-66 & 70.0 & 41.0 & 9.25 & 25.2 \\ \text { A-120 } & 62.4 & 40.0 & 28.15 & 51.1 \\ \text { A-155 } & 43.3 & 35.7 & 9.7 & 16.7\end{array}$

Scraper Fragment

A-27

33.45

28.55

1.1

10.5

Scraper Provenience

Side Scraper

$\begin{array}{cllc}\frac{\text { One Edge }}{\text { Ond }} & \text { Level } & \text { Unit } & \text { Quadrant } \\ \text { A-32 } & 2(5-10 \mathrm{~cm}) & \text { N40 } & \text { NE } \\ A-86 & 3(10-15 \mathrm{~cm}) & \text { N42/E2 } & \text { NE } \\ A-112 & 2(5-10 \mathrm{~cm}) & \text { N38 } & \text { SE } \\ A-170 & 1(0-5 \mathrm{~cm}) & \text { N42/W2 } & \text { NW }\end{array}$

Side Scraper Two Edge 


\begin{tabular}{cccc} 
End-Side Scraper & Level & Unit & Quadrant \\
\cline { 1 - 3 }$A-66$ & $2(5-10 \mathrm{~cm})$ & N42/W2 & SW \\
$A-120$ & i surface & Area B & - \\
$A-155$ & $2(5-10 \mathrm{~cm})$ & N42/W2 & NE
\end{tabular}

Scraper Fragment

A-27 $1(0-5 \mathrm{~cm}) \quad \mathrm{N} 40 \quad \mathrm{NW}$

Scrapers recovered from excavated contexts were found primarily in levels 2 and 3 , where $75 \%$ of the specimens were recorded. One distinct concentration can be observed. End and side scrapers were found only in level 2 of N42/W2 and on the surface of Area B. Because N42/W2 is somewhat on the margin of the 1974 excavation area, adjoining unexcavated units need excavation at least to the second level before adequate assessment can be made. It may be that a specialized activity area of unknown dimensions is indicated by end and side scrapers in N42/W2.

Unifacial Tools: Fragments (Plate 2, a and b). A total of 12 unifacial tool fragments were recovered from both surface and subsurface inveatigations at Mariposa. All but one are marginally chipped both primarily and secondarily. Other than the completely worked unifacial artifact $(A-61)$, which has been formed into a recognizable shape (rectangular), no other tool "forms" or types were recorded. Artifact \#61 is actually a fragment, as one end is a hinge fracture. While the two lateral edges and worked end indicate some edge wear and/or utilization, no wear appears on the fractured end.

The remainder of the unifaces are flaked marginally and can be further classified as secondary cortex unifaces or interior unifaces, depending on whether cortex is present or absent on the dorsal face.

Secondary Cortex Unifaces--Since the unifaces recovered were manufactured from flakes, secondary cortex unifaces, like secondary cortex flakes, retain some cortex on their dorsal surface. Presence of cortex on such flakes indicates that the flake has been struck from a partially decorticate core (Mallouf, Fox and Briggs 1973:68). One-half of the unifaces collected fall under this category. A11 utilize chert as the lithic resource material. One specimen appears to have been burned $(A-152)$. Cortex covers all but the worked areas on the dorsal surface on two of the marginal secondary cortex unifaces, A-39 and A-127. Interesting $7 y$, both of these are also hinge fractured on the proximal end. The lateral edges and end of the specimen were worked producing an almost oval working edge. Careful workmanship is lacking on most specimens. Bulbs of force and striking platforms still exist on four of the six specimens $(66.6 \%)$.

Interior Unifaces--The remaining five marginal unifaces were produced on flakes devoid of nodular cortex. Such flakes are manufactured "subsequent to primary and secondary decortication" (Mallouf, Fox and Briggs 1973:75). Eighty percent 


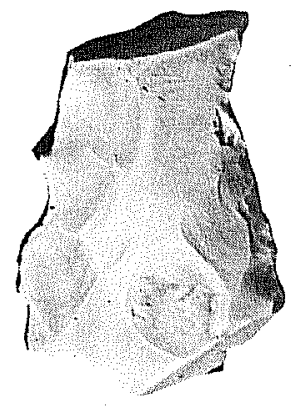

a

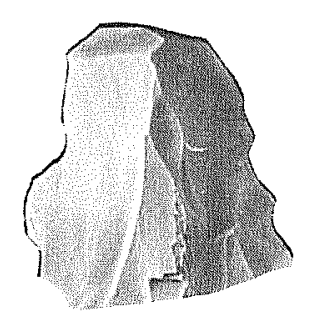

b

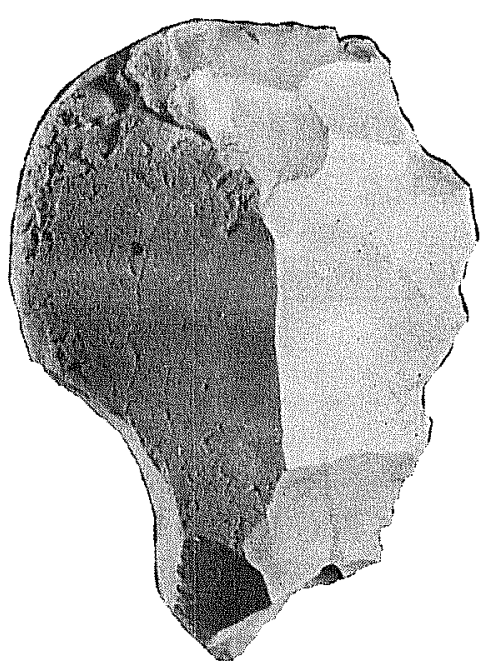

C
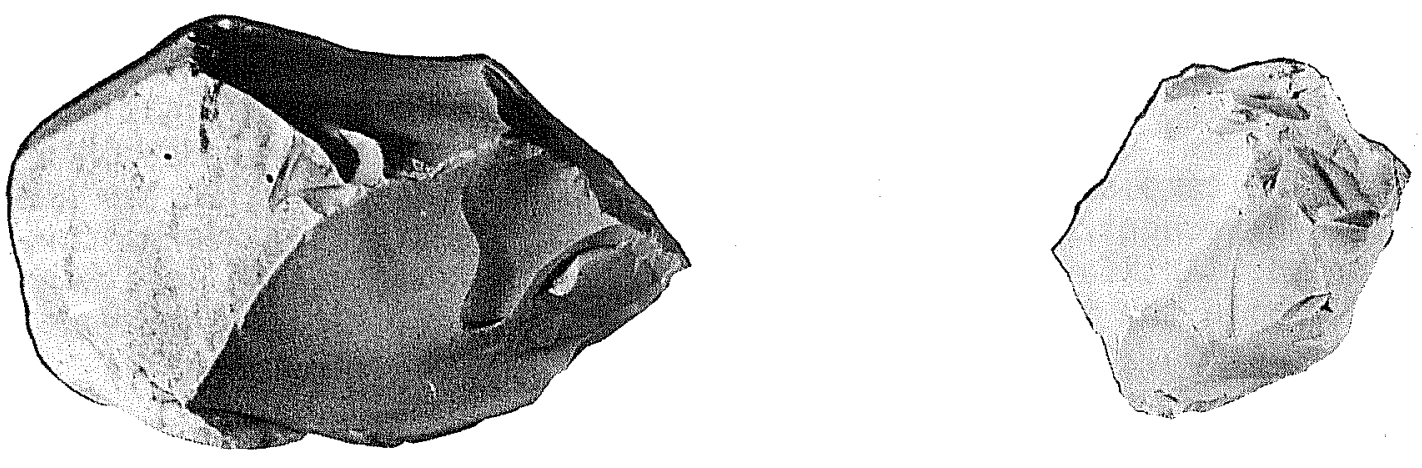

e
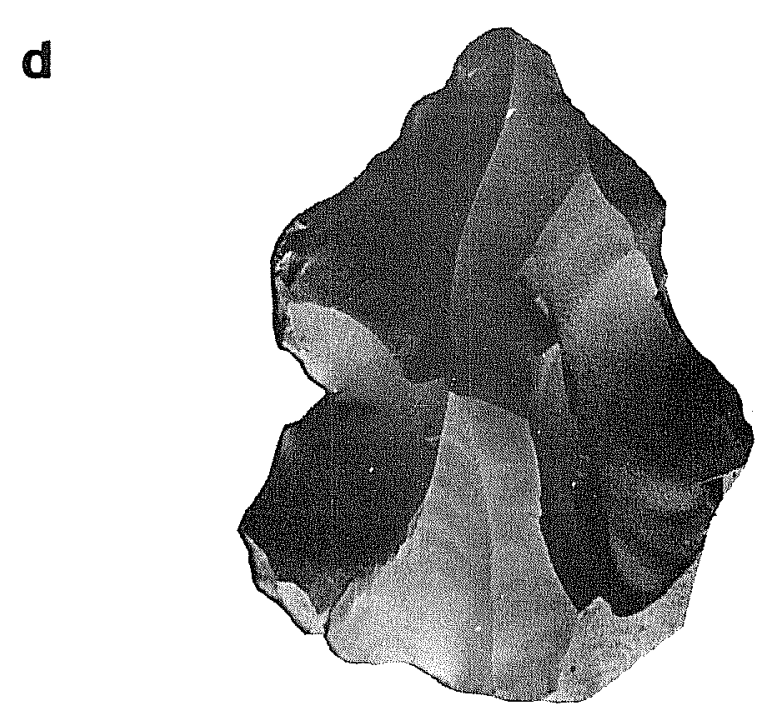

f

Plate 2. Unifaces and Cores. a, secondary cortex uniface $(A-152)$; $b$, interior uniface $(A-59) ; c$, group II core $(A-100)$; $d$, group III core $(A-12)$; $e$, group IV core $(A-17) ; f$, group $V$ core $(A-44)$. 
(four or five) retain hinge fractures on at least one end. A11 are irregular in shape and one specimen (A-57) is burned. All are unifacially worked on one lateral edge and two of these still retain their bulb of force and striking platform (all single faceted).

No distinct pattern of unifacial tool manufacture is seen in the Mariposa collection. Instead, a picture of random modification using lithic debris for tools is perceived. Hinging on many of these artifacts may also indicate tool breakage during tool manufacturing processes. Edge wear in the form of small step fracturing can be seen on a majority of the unifaces described above. Describing uniface function would only be speculation without some accompanying microscopic edge analys is and replication. Provenience and metric data are listed below.

Unifacial Tool Metric Data

$\begin{array}{ccccc}\text { Uniface Fragment } & \begin{array}{c}\text { Length } \\ (\mathrm{mm})\end{array} & \begin{array}{c}\text { Width } \\ (\mathrm{mm})\end{array} & \begin{array}{c}\text { Thickness } \\ (\mathrm{mm})\end{array} & \begin{array}{c}\text { Weight } \\ (\mathrm{gm})\end{array} \\ \text { A-61 } & 48.15 & 27.0 & 8.4 & 14.45\end{array}$

Secondary Cortex Unifaces

$\begin{array}{lllcr}\text { A-39 } & 39.0 & 33.0 & 8.35 & 11.0 \\ \text { A-103 } & 55.1 & 35.55 & 28.3 & 35.1 \\ \text { A-121 } & 30.0 & 25.5 & 8.0 & 7.1 \\ \text { A-128 } & 66.45 & 45.65 & 18.45 & 46.2 \\ \text { A-145 } & 70.0 & 39.0 & 15.25 & 38.5 \\ \text { A-152 } & 41.0 & 31.55 & 15.15 & 16.9\end{array}$

Interior Unifaces

$\begin{array}{lllcc}\text { A-21 } & 30.6 & 10.55 & 7.0 & 1.5 \\ \text { A-45 } & 22.65 & 15.0 & 4.75 & 2.05 \\ \text { A-57 } & 27.6 & 23.4 & 15.0 & 10.3 \\ \text { A-81 } & 18.6 & 17.0 & 5.0 & 1.8 \\ \text { A-85 } & 37.35 & 23.55 & 8.6 & 6.8 \\ \ldots \ldots & \ldots \ldots \ldots\end{array}$

Unifacial Tool Provenience

$\begin{array}{cccc}\text { Uniface Fragment } & \text { Leve1 } & \text { Unit } & \text { Quadrant } \\ \text { A-61 } & 1(0-5 \mathrm{~cm}) & \text { N42/W2 } & \text { SW }\end{array}$




$\begin{array}{cccc}\text { Secondary Cortex } & \text { Leve1 } & \text { Unit } & \text { Quadrant } \\ \text { A-39 } & 1(0-5 \mathrm{~cm}) & \text { N42 } & \text { NE } \\ A-103 & 1(0-5 \mathrm{~cm}) & \text { N38/E2 } & \text { NE }\end{array}$

Secondary Cortex Unifaces

$\begin{array}{llll}\text { A-121 } & \text { surface } & \text { Area B (1974) } & -- \\ \text { A-128 } & \text { surface } & \text { Area B (1975) } & - \\ \text { A-145 } & 1-2(0-30 \mathrm{~cm}) & \text { Test } 5 & \text { NE extension } \\ \text { A-152 } & 3(10-15 \mathrm{~cm}) & \text { N42/E2 } & \text { SW (hearth) }\end{array}$

Interior Unifaces

\begin{tabular}{|c|c|c|c|}
\hline$A-21$ & $6(25-30 \mathrm{~cm})$ & N38/W2 & NW \\
\hline$A-45$ & $2(5-10 \mathrm{~cm})$ & N42 & SW \\
\hline$A-57$ & $4(15-20 \mathrm{~cm})$ & $\mathrm{N} 42$ & SE \\
\hline$A-81$ & $2(5-10 \mathrm{~cm})$ & N42/E2 & NW \\
\hline$A-85$ & $3(10-15 \mathrm{~cm})$ & N42/E2 & NW \\
\hline
\end{tabular}

A large amount (5) of the unifacial tool fragments were recovered from the surface and first excavated level at Mariposa. The remaining seven unifacial tool fragments are concentrated in levels two and three. No single area seems to have been favored for the deposition of these tool fragments since only one unit, N42/E2, contained two unifacial tool fragments in a particular level.

Formal Bifaces

Bifaces which do not exhibit evidence of any hafting modification were classified as "formal bifaces." A total of 24 specimens, including fragments, have been recovered from Mariposa. Further classification of these artifacts depended on one set of characteristics: those bifaces which still retained evidence of being manufactured on flakes (i.e., bulb of force, striking platform, rings of force) were termed "flake bifaces" and those bifaces which did not exhibit such evidence were termed "non-flake bifaces." Subsequent classification of formal bifaces depended on the observable morphological characteristics of the artifacts. A11 collected bifaces exhibited the characteristic sinuous edge when viewed perpendicular to the faces.

Flake Bifaces. Nine flake bifaces, constituting $37.5 \%$ of the formal biface category, were recognized as having some or a 11 flake characteristics still present. Within this category, three groups can be recognized: (a) distal fragments (3); (b) proximal fragments (2); and (c) complete specimens (4). 
Distal fragments of the flake bifaces are fairly thin and made of light tan to cream colored chert. All are biconvex in the transverse section and their proximal ends are hinge fractured.

The two proximal flake biface fragments are considerably thicker in cross section than the distal flake biface fragments and are plano-convex in the transverse section. Again, the lithic material is 1 ight tan or cream colored chert. Basal edges are straight to slightly concave, and both specimens' lateral edges taper towards the base. Only marginal primary and secondary chipping is seen on the flat side (or ventral face of the original flake).

Triangular or roughly trianguloid outlines are seen in the complete flake bifaces. Marginal chipping is seen on both faces in three of the four specimens. Cortex, which is found on one specimen $(A-87)$, is actually part of the original flake striking platform. Artifact A- 150 has been thermally altered prior to flaking activities on its lateral edges and end (opposite original striking platform). Except for the burned specimen, all of the complete flake bifaces are made of light tan to cream colored chert. The distal end of one specimen (A-146) is beveled.

To facilitate some idea of the variation in the metric attributes of length, width, thickness and weight within each category, tables listing this information will be subheaded for each category discussed, both for the flake bifaces and the following non-flake bifaces. Before describing the non-flake formal biface, one should consider where the flake bifaces "fit" into the cores and the artifact manufacturing sequence. Complete flake bifaces recovered here could only have come from relatively large cores, assuming that the representative bifaces in the collection were ultimately derived from flakes approximately twice the size of the flake tool. Only large Group I, II and III cores, and possibly Group IV and V cores (see below), are physically able to produce larger flakes. These flakes might also have to be relatively thick, given the thickness of the proximal flake biface fragments also present in the collection.

Non-Flake Bifaces. Bifaces without both hafting modification and still present flake attributes are classified as non-flake bifaces. Numerous subgroups appear within the 15 non-flake bifaces. (62.5\% of the formal biface category). Two subcategories of completed bifaces, oval and triangular, together with proximal and distal fragments, a burinated biface, "thick" bifaces, and "core-tools" combine to form the category non-flake formal bifaces.

Both proximal and distal fragments are represented in the sample. The three proximal (basal) fragments are hinge fractured and are made of light tan to cream chert. Artifact A-140 exhibits straight edges, while the other two (both are larger and thicker than A-140) have slightly convex lateral edges. Cortex is present on one face of A-140 (a very large specimen) and all of the proximal fragments are biconvex in transverse outline. Extensive primary and secondary flaking is seen on these specimens.

Four distal fragments of non-flake bifaces are fairly thick and exhibit primary and secondary flaking. Half of these specimens are cream colored, while the remaining two appear to have been heat treated. No pattern of preferred morphological shape appears, aside from the fact that all are shaped to produce a 
point (or tip). Biconvex transverse sections occur in all specimens. Fine secondary flaking is exhibited by one of the thermally altered specimens $(A-25)$, while rough flaking (random) characterizes the remainder of the distal fragments.

Complete specimens were grouped by their morphological and technological attributes. Of the smaller and completely chipped specimens, two basic shapes appear: ovoid and triangular. The ovoid specimen $(A-45)$ exhibits sinuous edges with primary and secondary flaking on both faces. No edge wear is apparent (macroscopically); however, step fractures are seen on one face. While the ovoid nonflake biface is made of pink chert with grey splotches, the triangular specimen is cream-colored chert. Edges of this artifact $(A-138)$ are slightly convex and the distal tip is not well formed. Rough primary and secondary flaking is seen on all of the edges (lateral and basal). In the transverse section, both the ovoid and triangular non-flake bifaces are roughly biconvex.

One of the bifaces (A-109) is a special specimen, thus forming its own category. Basically subtrianguloid in shape with rough primary and secondary flaking on one lateral edge, the unique attribute of the artifact is seen on the other lateral edge. Apparently this biface was used to produce a burin spal1, as evidenced by the long longitudinal flake scar forming the lateral edge (see Fig. 4). Only this one artifact, termed a "burinated biface," appears from the Mariposa assemblage. This artifact was subjected to extensive wear (i.e., "nibbling" or small step fractures) on one of the edges produced by the detachment of the burin spa11.

The remaining five non-flake formal blfaces can be divided into two categories: "core tool" and thick bifaces. Two "core tools" were identified, primarily on the basis of clearly observable edge wear. Without this characteristic edge wear, such "bifaces" would probably have been classified as Group VII cores (bidirectional cores). Fine grained quartzite and chert were used for manufacturing these bifaces. The function of this category of tools can only be guessed; the heavy abrasional evidence may indicate heavy chopping. Cortex remains on the faces of both specimens.

Finally, two "thick bifaces," one of light tan chert, the other a vitreous purple (heat treated), form their own category. Rough primary and secondary flaking have produced sinuous edges. The flaking dominates one face of each specimen and some cortex is still remaining on the artifacts. Both are ovoid in shape and thickly plano-convex in the transverse section.

Formal Biface Metric Data

FLAKE BIFACES

$\begin{array}{ccccc}\text { Distal Fragments } & \begin{array}{c}\text { Length } \\ (\mathrm{mm})\end{array} & \begin{array}{c}\text { Width } \\ (\mathrm{mm})\end{array} & \begin{array}{c}\text { Thickness } \\ (\mathrm{mm})\end{array} & \begin{array}{c}\text { Weight } \\ (\mathrm{gm})\end{array} \\ \text { A-16 } & 23.25 & 15.0 & 3.2 & 1.0 \\ \text { A-47 } & 27.15 & 26.65 & 4.4 & 3.5 \\ \text { A-105 } & 23.25 & 18.6 & 4.55 & 2.1\end{array}$


Proximal Fragments Length

(mm)

Width

(mm)

Thickness

(mm)

Weight

19.6

8.0

(gm)

A-69

33.2

34.0

8.5

5.8

40.65

33.35

27.9

5.6

4.6

A-87

44.35

28.4

5.25

5.45

A-146

33.55

9.55

24.4

A- 150

35.4

24.0

7.6

6.25

NON-FLAKE BIFACES

Distal Fragments

$\begin{array}{llllr}\text { A-9 } & 29.5 & 28.25 & 7.75 & 5.7 \\ \text { A-25 } & 46.0 & 27.8 & 6.5 & 11.6 \\ \text { A-59 } & 43.55 & 38.35 & 9.0 & 12.65 \\ \text { A-743 } & 43.25 & 20.7 & 7.0 & 4.5\end{array}$

Proximal Fragments

$\begin{array}{cllll}A-126 & 33.6 & 34.25 & 9.8 & 12.65 \\ A-129 & 59.0 & 54.2 & 8.1 & 23.4 \\ A-140 & 24.4 & 13.25 & 3.2 & 0.8\end{array}$

Complete, Ovoid

$$
\text { A-46 }
$$

47.0

37.0

10.65

17.3

Complete, Triangular

$$
\text { A-138 }
$$

73.2

36.0

8.2

25.2

Burinated Biface
A-109
62.55
33.4
15.5
37.2

Core Tools
A-127
87.65
58.65
29.7
192.45
A-141
74.7
26.45
30.6
48.5

Thick Bifaces
A-136
58.0
52.0
22.0
57.2
A-137
62.0
41.6
22.5
54.7 
Formal Biface Provenience Data

FLAKE BIFACES Leve 1

Unit

Quadrant

Distal Fragments

$\begin{array}{llll}A-16 & 4(15-20 \mathrm{~cm}) & \text { N38/W2 } & \text { SW } \\ A-47 & 2(5-10 \mathrm{~cm}) & \text { N42 } & \text { SW } \\ A-105 & 1(0-5 \mathrm{~cm}) & N 38 / E 2 & \text { NE }\end{array}$

Proximal Fragments

A-69

A-131

Complete

$$
\text { A-4 }
$$

A-67

A-146

A-150
$3(10-15 \mathrm{~cm})$

$1(0-20 \mathrm{~cm})$
N42/W2

Area B

N38/W2

N42/W2

Test 5

N42
NW

Test 3

NON-FLAKE BIFACES

Distal Fragments

A-9

A-25

A-59

A-143
$2(5-10 \mathrm{~cm})$

$2(5-10 \mathrm{~cm})$ $(0-60 \mathrm{~cm})$

$3(10-15 \mathrm{~cm})$

$$
\begin{aligned}
& \text { NW } \\
& \text { SE } \\
& \text { SE Extension } \\
& \text { SE }
\end{aligned}
$$

N38/W2

SW

N38/W2

N42

N1/2

$10(60 \mathrm{~cm})$

$5(20-25 \mathrm{~cm})$

Test 5

NW

$1-2(0-30 \mathrm{~cm})$

NE Extension

Proximal Fragments

$\begin{array}{lllc}\text { A-126 } & \text { surface } & \text { Area B } & -- \\ \text { A-129 } & 1(0-10 \mathrm{~cm}) & \text { Area B } & \text { Test 2 } \\ \text { A-140 } & 1(0-15 \mathrm{~cm}) & \text { Test } 5 & \mathrm{~N} 1 / 2\end{array}$

Complete, Ovoid
A-46
$2(5-10 \mathrm{~cm})$
N42
SE

Complete, Triangular

$$
\text { A-138 }
$$

$2(20-40 \mathrm{~cm})$

Area B

Test 3

Burinated Biface

$$
\text { A-109 }
$$

$2(5-10 \mathrm{~cm})$

N38/E2

SW 


\begin{tabular}{ccrc} 
Core Tools & Level & Unit & Quadrant \\
\hline$A-127$ & surface & Area B & $-\overline{\mathrm{N}}$ \\
$\mathrm{A}-141$ & $3(30-45 \mathrm{~cm})$ & Test 5 & $\mathrm{~N}$
\end{tabular}

Thick Bifaces
A-136
$1(0-20 \mathrm{~cm})$
Area B
Test 3
A-137
$1(0-20 \mathrm{~cm})$
Area B
Test 3

Combining provenience information for the flake and non-flake bifaces, 16 of 23 (or 70\%) of the specimens were recovered from Area A (all excavation units and test pits). Considering only flake bifaces, $89 \%$ ( 8 of 9 ) were found in Area $A$. On the other hand, only $57 \%$ ( 8 of 14 ) of the non-flake bifaces were located in Area A. Flake bifaces were found primarily in levels two and three, with some specimens much deeper. Four excavation units--N38/W2, N42, N38/E2 and N42/W2-and one test pit contained flake biface specimens in Area A. Non-flake bifaces excavated in Area $A$ were evenly divided between lower contexts (greater than 15 $\mathrm{cm}$ below the surface) and upper contexts (0 to $15 \mathrm{~cm}$ below the surface). Level two exhibited more formal bifaces than any other single level, however. Three of the nine excavation units (N38/W2, N38/E2 and N42) and Test 5 were the Area A grid proveniences at Mariposa where non-flake bifaces were present. Half of the non-flake bifaces were found in Area $A$ and half were found in Area $B$ at Mariposa. The majority (83\%) from Area $B$ were recorded on the surface to a depth of $20 \mathrm{~cm}$.

Lack of flake bifaces in Area B at Mariposa is an important point to remember. The fact that projectile points recovered from Area B context typologically date to Archaic times (see section on projectile points) combined with the lack of flake bifaces may possibly indicate that different lithic technologies were occurring at different times at Mariposa. Much more research must be sustained, however, before this possibility can be verified.

\section{Cores}

The process of removing one or more flakes from a suitable cobble or nodule necessarily forms a core. Usually this reduction process is intended to produce either flakes destined to be further worked into flake tools or the process can be one of reducing the core itself into a tool (core-tool). These two processes can be divided into separate industries if the tool reduction process has not obliterated distinctions which exist in the initial stages of the two processes.

One objective of this study is to determine, if possible, which 1 ithic process (flake-tool or core-tool) can be associated with those peoples who inhabited the Mariposa site. Great care, therefore, in distinguishing the different types of cores present is a necessary step in deciding which industry occurred. Previous work (Hester 1975b) makes this aspect appreciably easier. 


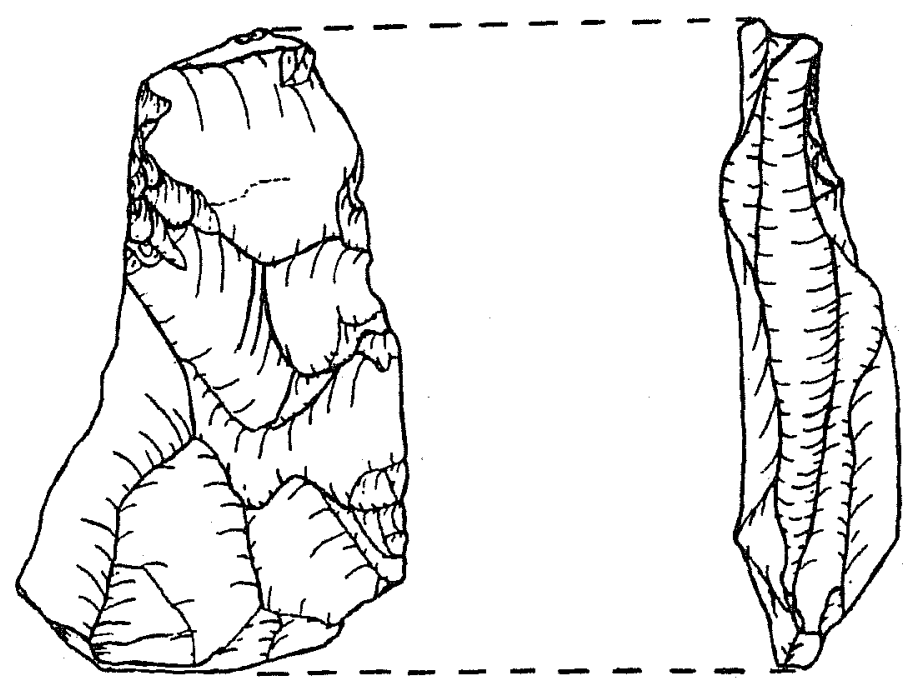

Figure 4. Burinated Biface, A-109. 
Four criteria or attributes are recognized as being important in core classification: (1) direction of flake remova 1; (2) number of preparation platforms; (3) amount of suitable lithic material existing on the core; and (4) the physical "suitability" of the core (cores with step fractures and flaws--hinging fracture--are not perceived as "suitable").

Recognizing evidence that two industries (flake-tool and core-tool) existed in the Late Prehistoric context, Hester (1975b) constructed a preliminary model for Tithic industries on the Rio Grande Plain. Each industry, theoretically, produces characteristic core and tool types. For the flake industry, several core types are possible: (1) roughly conical polyhedral cores, flaked unidirectionally; (2) multi-faceted (two or more flake removals form the platform) with "horizontal" platforms (sides form an 80-degree angle); (3) multi-faceted with "oblique platforms" (sides form angles between 50 and 60 degrees); (4) "ovate bifacial" cores characterized by either apparent bifacial reduction or random multi-directional flaking; and (5) cores which are flaked from natural or unprepared platforms (Hester 1975b:215-217).

Tool forms produced on flakes detached from these cores are usually small projectile points, scrapers, gravers and perforators. Marginally trimmed flakes were also produced as tools. Regional Late Prehistoric sites commonly exhibit materials associated with the flake tool industry, although flake tools and cores also occur in Archaic contexts (Hester 1975b:217).

Following Hester (1975b:217), the other lithic industry "involves the manufacture of tools through the bifacial reduction of cobbles, and can be termed either a core-tool or cobble industry." Tool by-products of this industry include larger projectile points, chopping tools (core choppers) and knives. Cores associated with this industry are not well defined, but thin, tabular cores are believed necessary as the initial core morphological type (Hester 1975b:217). Data from Mariposa indicate such to be the case. Three subsequent cores have also been recognized. Using the relatively flat surface of the tabular core, flakes may be peeled off unidirectionally, forming a downward peak on the flaked face. Tabular cores may also be angularly struck on one end to prepare a platform. Subsequent reduction would peel off flakes by striking perpendicularly the prepared face. Finally, striking the initially tabular core on both ends at acute angles to the end would bifacially reduce the core (similar to flake-tool core type above).

Admittedly, the core-reduction sequence is similar to the flake-tool industry's core. Core thickness does, to some degree, indicate the relative thickness of the initial core. Those cores associated with the core-tool industry are thinner, comparatively speaking, than those produced by the flake tool industry.

Both industries can be recognized from the recovered cores collected at Mariposa. More significant, the two industry sequences can be related to each other to form one lithic core process (see Fig. 5). Prior to describing the overal1 process, each type of core will be briefly discussed. 
(III)

FACETED PLATFORM

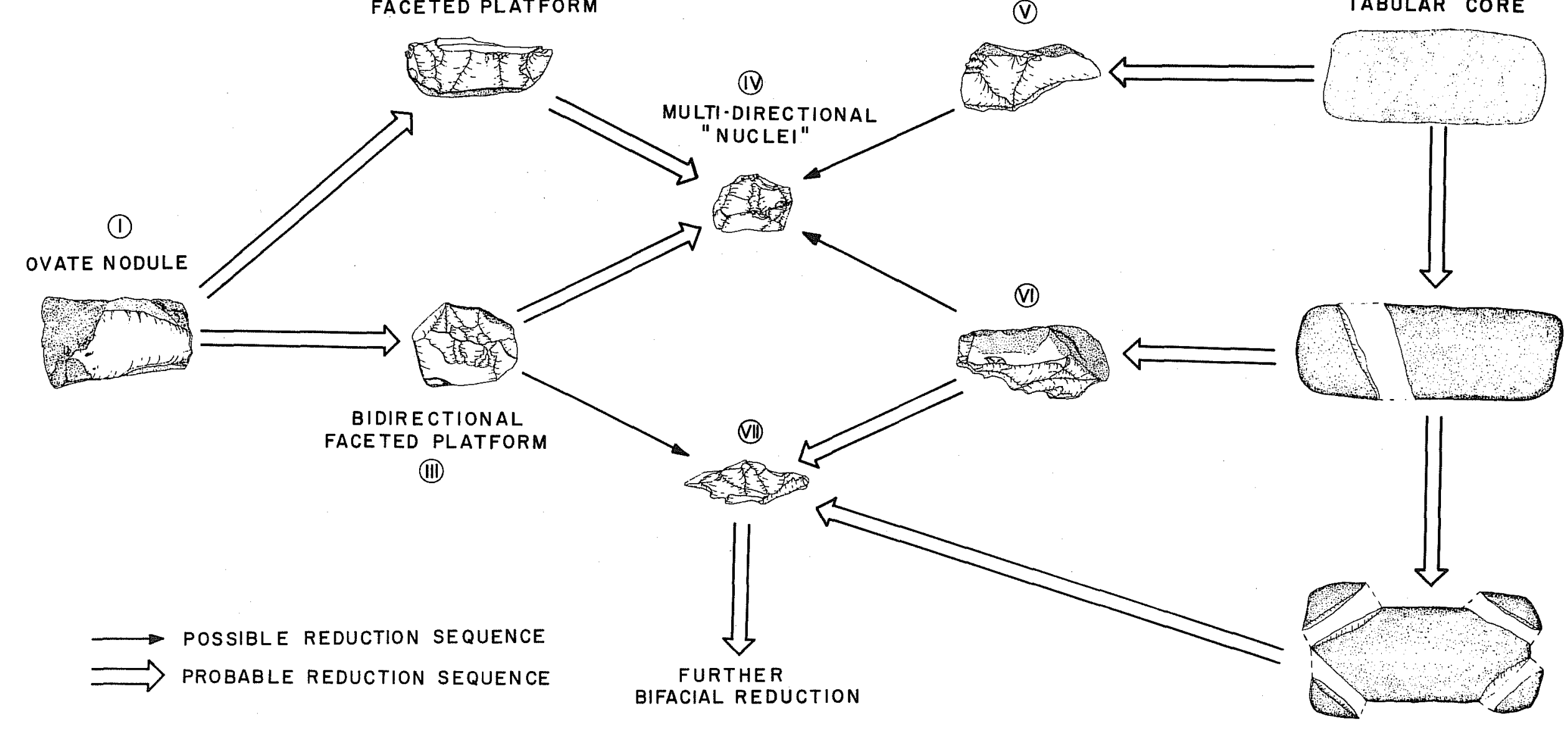

Figure 5. Core Reduction Sequence at the Mariposa Site, $41.2 \mathrm{~V} 83$. 
Group I Cores (one specimen, 3.2\% of core sample)

This is a thickly oyate core with one flake detached indicating core testing or platform preparation. Since no further work on the core exists, it is probable that a flaw in the material was detected, with the core being rejected. The flake produced could have been formed into a small tool. Group I cores are quite similar to Hester's 5 (above).

Group II Cores (Plate 2,c. Five specimens, 16.1\% of core sample)

Platforms are formed by the removal of one flake (single-faceted) and subsequent flakes are detached unidirectionally and perpendicular to the single-faceted platform. All are somewhat oval in outline and retain cortex on the face opposite the platform. These are morphologically similar to Hester's 2 (above).

Group III Cores (Plate $2, d$. Two specimens, $6.5 \%$ of core sample)

These cores are faceted in two directions. Sinuous edges and denticulate outlines characterize the working edge. Cortex is present opposite the edge which was flaked. Both specimens exhibit roughly oval outlines.

Group IV Cores (Plate 2,e. 13 specimens, $41.9 \%$ of core sample)

Multi-faceting and multi-directional flake removal characterize Group IV cores. Many of the cores are faceted in four or more directions. Roughly angular outlines predominate. Artifact $\mathrm{A}-71$ is a fine-grained quartzite, while the remaining five specimens are made of chert. Cortex is relatively absent.

Group V Cores (P1ate 2,f. Three specimens, 9.7\% of core sample)

Unidirectional flake removal on a natural (cortex) platform shapes these cores. Both utilize chert as the lithic resource material. A pyramid shape is indicated, with the peak being formed at the point where many flake scars converge. These cores lie flat on the cortex face, indicating a tabular shape prior to flake removal.

Group VI Cores (Plate 3,a. Two specimens, 6.5\% of core sample)

Platforms of Group VI cores are single-faceted subsequent to flake removal, oblique to perpendicular with respect to platform. Flake removal can proceed on either face or both. One specimen has been greatly reduced (A-104), and both are made of chert. Group VI cores are identical to Hester's 3 (above).

Group VII Cores (Plate 3,b. Two specimens, $16.1 \%$ of core sample)

The last category of cores is formed by bifacial reduction of tabular core material. Artifact \#24 has been thermally altered. Bifacial reduction of these cores follows a multi-directional pattern which may be random or symmetrical at acute angles to the sides. This type of core is Hester's 4 (above). 

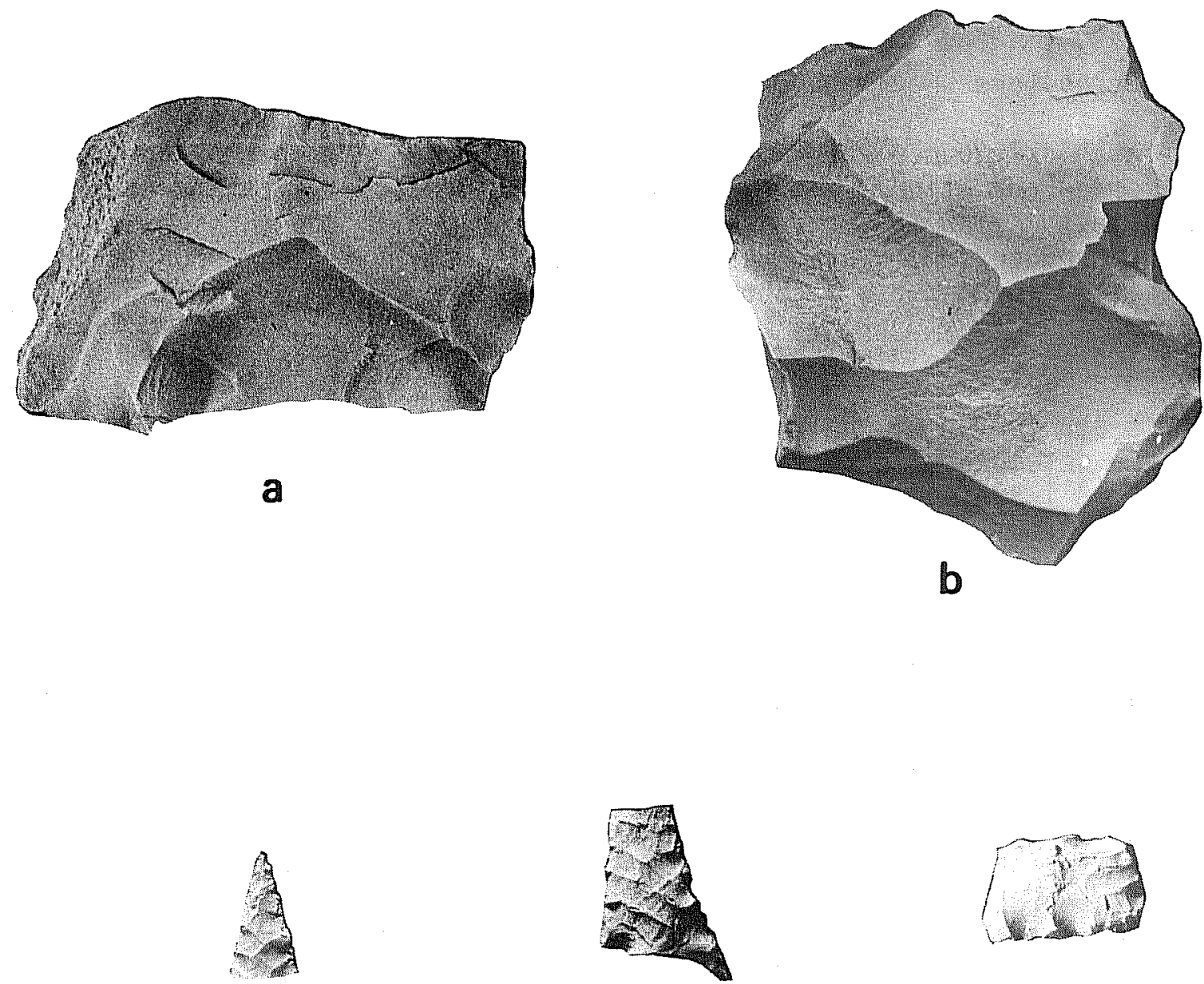

C

d

e

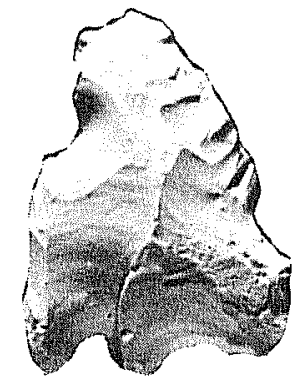

f

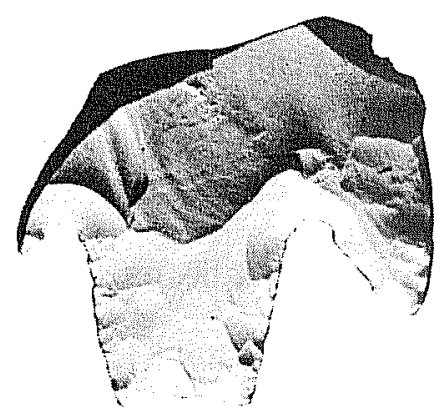

g

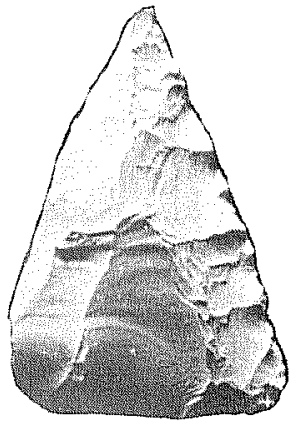

h

Plate 3. Cores and Projectile Points. $a$, group VI core $(A-52) ; b$, group VII core $(A-33)$; $C$, distal fragment $(P-28)$; $d$, medial fragment $(P-46)$; $e$, basal fragment $(P-44) ; f$, preform $(P-4) ; g$, Langtry fragment $(P-35) ; h$, Tortugas point $(P-31)$. 
Core Overshot Flake

One core overshot flake (A-119) was recognized at Mariposa. This unique form of flake resembles (morphologically) biface overshot flakes "in which the thinning flake unintentionally carries across the biface and detaches a portion of the opposite edge" (Hester 1975b:218; see also Skinner 1971). The large size (relative to biface thinning overshot flakes), its degree of cortex coverage (including the striking platform), and prominent bulb of force all point to the fact that this specimen is the result of the reduction of a core which bears one edge of the original core. Gentle curvature of the remaining original core edge indicates a nodular core was the initial core shape.

Group I

A-107

Group II

A-18

A-74

A-100

A-135

A-144

Group III

67.0

60.65

67.55

53.0

66.0

49.7

42.0

Core Metric Data

Length Width

(mm)

56.55

48.2

40.7

44.1

34.65

22.65

45.55

39.4

36.15

32.4

144.0

A-55

Group IV

A-17

32.8

32.15

24.6

34.3

A-37

30.4

17.6

17.7

8.2

A-68

56.4

48.7

47.55

50.0

47.7

29.65

45.4

33.15

23.65

38.25

49.55

39.6

27.65

56.2

13.15

39.15

40.2

27.45

72.75

46.1

51.9

37.4

34.65

68.4

33.6

10.92

25.35

22.15

22.25

37.5

16.0

10.7

41.65

121.5

11.2

6.3

27.25

105.45

16.0

17.6

A-118

47.25

152.6

A-160

26.7

38.9 
Group V

A-44

A-123

A-161

Group VI

$A=33$

A-104 $\underset{(\mathrm{mm})}{\text { Length }}$

63.6

65.35

59.6

64.3

68.0

Group VII

A-24

A-52

A-116

A-125

A-139

55.6

70.5

45.65

74.55

70.25
Width

(mm)

47.6

51.35

42.4
Thickness

(mm)

27.1

30.8

26.6

26.4

82.3

20.55

42.4
Weight

(gm)

74.2

76.1

82.4

Core Overshot Flake

A-119

40.75

15.75

35.9

49.7

27.0

110.2

29.4

15.25

21.5

66.65

16.6

99.2

68.25

38.7

180.3

Core Provenience Metric Data

Artifact

Group I

A-107

Group II

A-18

A-74

A-100

A-135

A-144

Group III

A-12

A-55
Leve1

$1(0-5 \mathrm{~cm})$

$4(15-20 \mathrm{~cm})$

$5(20-25 \mathrm{~cm})$

$3(10-15 \mathrm{~cm})$

$1(0-20 \mathrm{~cm})$

$1-2(0-30 \mathrm{~cm})$

$3(10-15 \mathrm{~cm})$

SW

$4(15-20 \mathrm{~cm})$
N38/W2

Unit

N38/E2

N38/W2

N42/W2

N40/E2

Test 4

Test 5

N42
Quadrant

SE

SW

NE

NE

Area B

NE Extension

130.8 
\begin{tabular}{r} 
Group IV \\
\hline$A-17$ \\
$A-37$ \\
$A-68$ \\
$A-71$ \\
$A-88$ \\
$A-96$ \\
$A-101$ \\
$A-108$ \\
$A-110$ \\
$A-113$ \\
$A-114$ \\
$A-118$ \\
$A-160$
\end{tabular}

Group V
Leve1

$4(15-20 \mathrm{~cm})$

$5(20-25 \mathrm{~cm})$

$2(5-10 \mathrm{~cm})$

$3(10-15 \mathrm{~cm})$

$3(10-15 \mathrm{~cm})$

$2(5-10 \mathrm{~cm})$

$3(10-15 \mathrm{~cm})$

$2(5-10 \mathrm{~cm})$

$2(5-10 \mathrm{~cm})$

$3(10-15 \mathrm{~cm})$

$3(10-15 \mathrm{~cm})$

$3(10-15 \mathrm{~cm})$

$3(30-45 \mathrm{~cm})$
Unit

N38/W2

N40

N42/W2

N42/W2

N42/E2

N40/E2

N40/E2

N38/E2

N38

N38

N38

N38

Test 5
Quadrant

SW

SW

SE

NE

NE

SW

NE

NW

NE

NW

NE

SW

$\mathrm{N} 1 / 2$
A-44

A-123

A-161
$2(5-10 \mathrm{~cm})$

surface

$1(0-10 \mathrm{~cm})$
N42

Area B

(1974)

Test 2

Area B

Group VI

$$
\text { A-33 } 104
$$

Group VII

A-24

A-52

A-116

A-125

A-139

$2(5-10 \mathrm{~cm})$

$1(0-5 \mathrm{~cm})$

$8(35-40 \mathrm{~cm})$

$3(10-15 \mathrm{~cm})$

$3(10-15 \mathrm{~cm})$

surface

$1(0-20 \mathrm{~cm})$
N40

N38/E2

N38/W2

N42

N38

Area B

(1974)

Test 4

(1974)
NE
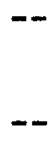

Core Overshot Flake

$$
\text { A-119 } 3(10-15 \mathrm{~cm}) \quad \text { N38 }
$$


Taken together, the cores, (Groups I-VII) excavated at Mariposa are primarily from Area $A$ and occur most frequently in levels two and three, where $55 \%$ of the specimens were recoyered. This trend is best illustrated in the 13 Group IV core specimens, all but two of which occur in levels two and three. Group IV cores also represent the most prevalent core type recovered. Examination of core proveniences indicates that most cores are equally distributed in seven of the nine excavation units at Mariposa. Possible clusters of Group IV cores may be in N42/W2 and N38, but the specimen sample size is presently not adequate for definite statements. The clustering in N38, however, is especially strong. This unit may have been a locus for the deposition (discard) of exhausted Group IV core nuclei. These cores represent specimens which are physically not functional as core material (i.e., for the manufacture of appropriately sized flakes). Indirectly, since this unit seems to be a favored core discard area, a core preparation or use area may be located in the similar or adjacent areas.

All seven groups of cores can be technologically related in such a way as to describe the core reduction sequence practiced by the aboriginal inhabitants of Mariposa (see Fig. 4). The two different arrows indicate the (hypothetical) strength of association between core groups. This sequence has not been demonstrated to occur by replication; core group relationships are presented on the basis of inferred sequential core modifications. Two general morphological types of core resource material are available, nodular (or round) and tabular. Reduction of either type of core produced large flakes capable of use as tools (utilized, trimmed, uniface, biface, projectile point). Thus flakes were produced by the reduction of Group I (nodular) cores into either Group II and/or Group III cores and by the reduction of tabular resource material into Group V, VI and/or Group VII cores. Core overshot flakes, such as the one excavated, are also possible by-products.

Further reduction of Groups II, III, V, VI and VII cores would produce smaller cores as one end product, as well as flakes, though these flakes would be smaller than flakes initially produced. If large enough, generated flakes from this reduction could have possibly been trimmed into or utilized as tools. They also could have been finished into flake tools (unifaces and bifaces). Reduction of Group II and Group III cores would result in Group IV cores. Group VII cores will be produced from the continued reduction of Group VI cores, although they also could have been reduced into Group IV cores as we11.

Certain cores (III, VII) could have easily been reduced into bifacial tools. It seems probable that most other cores were directed toward the manufacture of flakes and, ultimately, flake tools. Moving toward the center of Fig. 5 indicates that more and more smaller flakes are being removed from cores. The net result of this process is the generation of multi-directional core nuclei (Group IV cores). Physical conditions here also dictate that the smaller cores will produce smaller flakes, and the centrally located Group IV cores are the smallest core group based on their recorded metric attributes. Core nuclei were discarded when it became physically impossible to extract flakes large enough for tool production. 


\section{Projectile Points}

Artifacts bifacially worked into thin specimens with hafting modification are classified as projectile points. Fragments presumed to be included within this category are done so based on observable (and predictable) attributes which the classifier readily recognized, based on field and laboratory experience. From Mariposa, a total of 47 projectile points and fragments were excavated.

Point Fragments ( $P$ late $3, c, d, e, f$ ). Of the total collected sample, 12 specimens (28.6\%) were fragments which could not be classified as to type with any degree of certainty. In most cases (six specimens) the fragment was the extreme distal fragment of a point. Two specimens were identified as medial fragments. Cortex is present on approximately 10\% of one side and one lateral edge of a barb. While the specimen is essentially triangular in outline, it seems that attempts to thin the artifact into a final "point" form failed and the artifact was rejected. It is also apparent that on one lateral edge, an indention or "grooved area" shows signs of utilization.

In addition to the distal and medial fragments previously noted, four basal fragments were identified as probable portions of projectile points (Points 13, 20, 24 and 37). These fragments are al1 thin and wel1 worked by secondary retouch pressure flaking. All show hinge fractures on their distal end. Parallel thinning by longitudinal flakes is seen on two of the fragments. Point 13 shows evidence of being burned, probably subsequent to manufacture. Three of these fragments are plano-convex in transverse section; the other is roughly biconvex. Longitudinally, a 11 are plano-convex. Chert was used as the lithic raw material for these artifacts.

\section{Provenience of Projectile Point Fragments}

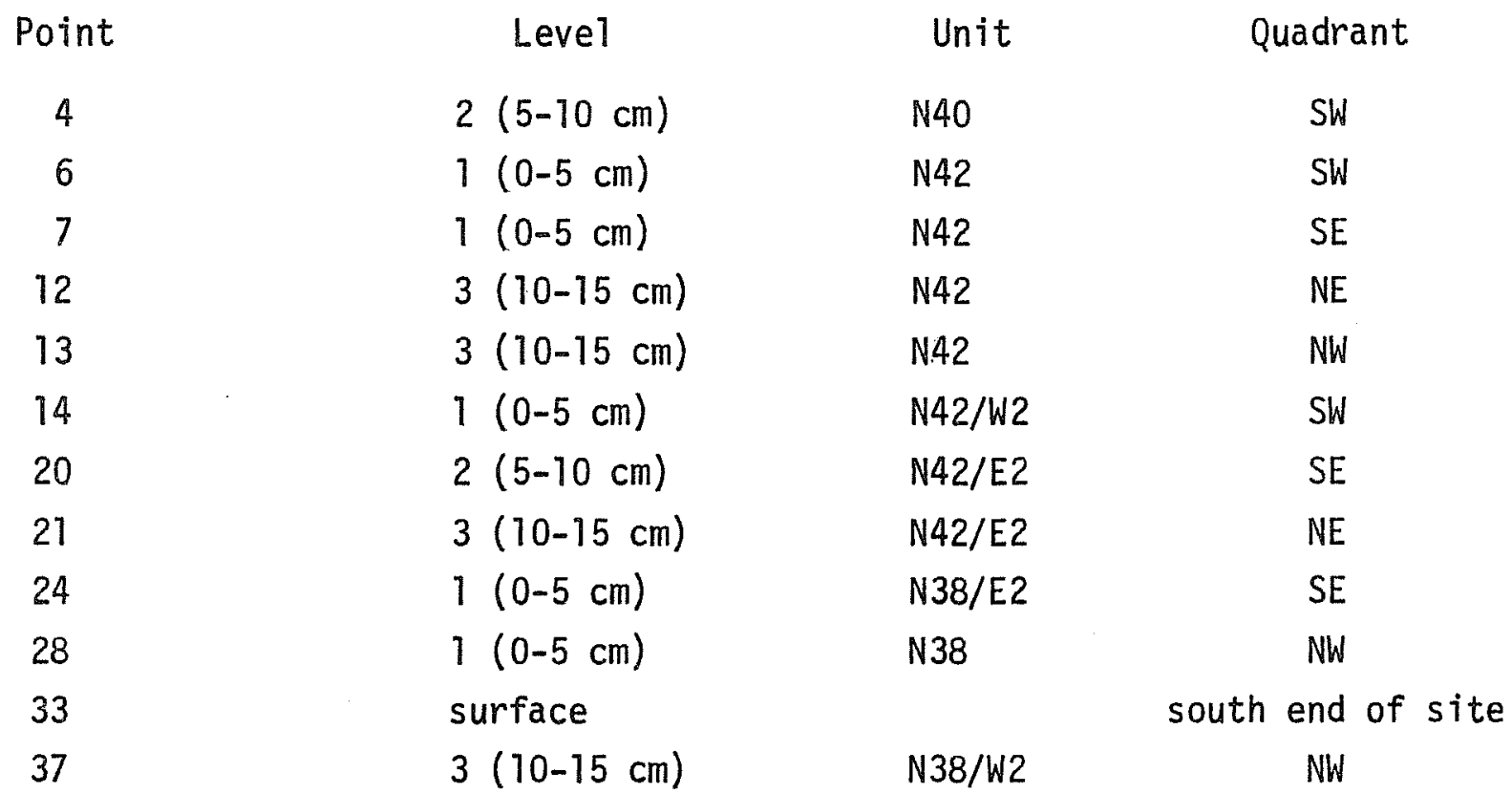


Dart Points (Plate $3, g, h$. Plate $4, a)$. Of the recovered points, five specimens were readily identified as belonging to the general category of dart points. Temporally, these artifacts are usually associated with the Archaic Period, but can persist into later Neo-American occupations. All but two of the specimens were recovered from the surface near the gully cut in Area B of $\mathrm{CH}-28$. Due to this unique spatial distribution, it is assumed that these three dart points have eroded from the lower level of the gully cut. Additionally, all three dart points recovered from this area are basal fragments. Dart points are recognized to be morphologically distinct from arrow points (1arger, heavier).

These three basal fragments are identified as specimens of the Langtry type (see Plate $3, g$ ), as described by Suhm and Jelks (1962). The shoulders of the specimens are well defined, the stems contract slightly, and the bases are concave. A11 are made from chert which ranges in color from greyish-brown to pinkish-brown. Workmanship as a whole is not well refined and the distal hinge fracture on all of the fragments indicates that the points were broken during the latter stages of the manufacturing sequence and subsequently discarded.

Another dart point was excavated within the confines of the controlled test excavation number four at a depth of 20 to $40 \mathrm{~cm}$ below the present surface. This specimen is a complete Tortugas (see Plate $3, \mathrm{~h}$ ) made of light tan chert with a rose strip along one lateral edge. As is characteristic of the Tortugas type (Suhm and Jelks 1962:249), this point is stemless with a triangular blade, straight to slightly convex edges, and a straight base. Alternate beveling combined with fine secondary retouch pressure flaking on the edges has produced a very "striking" artifact. In cross section, this point exhibits a planoconvex outline and, due to the beveling, a triangular form is seen in the transverse section. The base has been thinned on only one face by removal of one longitudinal flake. Dimensions of the Tortugas point follow:

$$
\begin{aligned}
& \text { Length } \mathrm{mm}-45.2 \\
& \text { Width } \mathrm{mm}-16.8 \\
& \text { Thickness mm }-2.60 \\
& \text { Weight gm }-1.3
\end{aligned}
$$

According to Suhm and Jelks (1962:249), this type of dart point is "a major type - . of the Falcon Focus, continuing into the Mier Focus" and is "a minor type of the Aransas Focus, the Edwards Plateau Aspect and the Pecos River Focus." While frequently occurring with Neo-American materials, the Tortugas dart point is usually associated with the Archaic and has been dated at 4000 B.C. to A.D. 1000 (Suhm and Jelks 1962:249).

The remaining dart point is the smallest one in terms of overall size and weight and was recovered from the first level of Unit N38/E2 (NE quadrant) (Plate $4, a)$. This translucent grey point is a corner-notched, triangular point which has been fashioned from a flake. In the transverse section, the point exhibits a thick, roughly plano-convex outline, and longitudinally it shows asymmetric biconvexity. While not a "large point," this specimen does have thick, wide edges which are slightly concave and a concave base. One face of this point is almost flat and on the other face both edges have been beveled. 


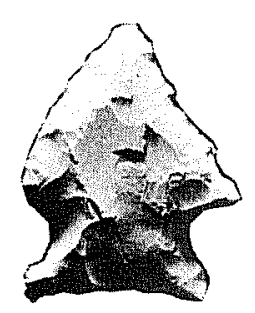

a

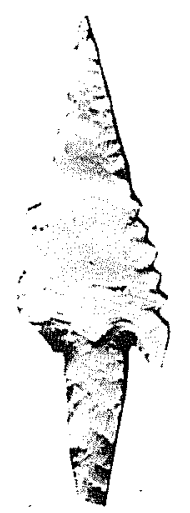

b

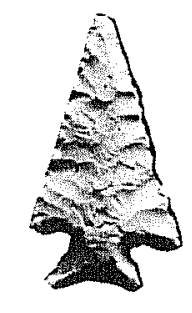

c

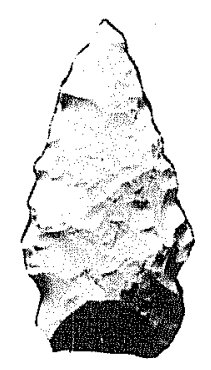

d

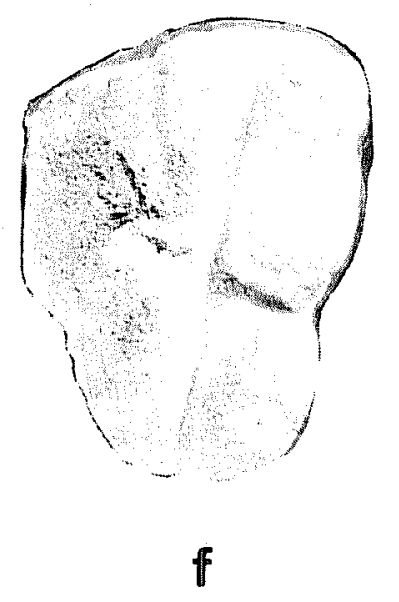

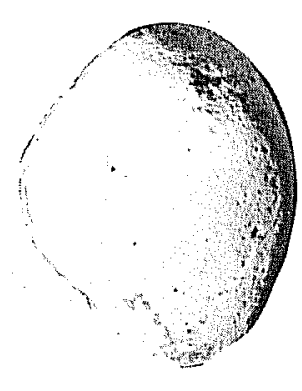

e

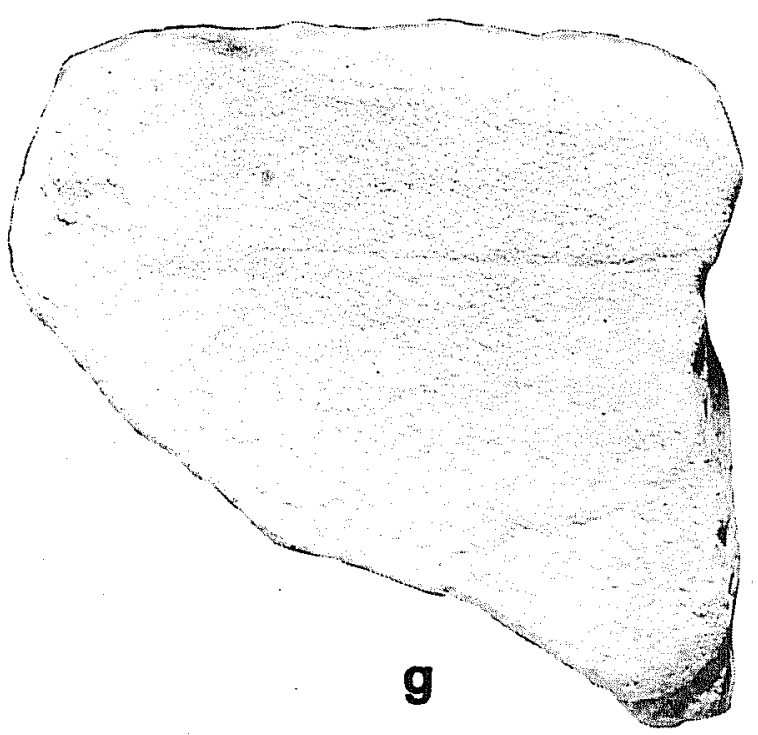

Plate 4. Projectile Points, Battered Stone and Ground Stone. a, Edgewood point $(P-23) ; b$, Perdiz point $(P-40) ; C$, Scallorn point $(P-5)$; d, Zavala point $(P-3) ; e$, hammerstone fragment $(A-26) ; f$, grooved sandstone $(A-102) ; g$, scratched sandstone $(A-106)$. 
Both faces show extensive flaking. Interestingly, one edge has been retouched with pressure flaking while the other edge reveals multiple step fractures occurring in the same direction. Edge reworking (reshaping) may account for this.

Morphologically, the described point could be an Ellis or Edgewood. Due to basal convexity, this specimen was classified as an Edgewood point (Suhm and Jelks 1962:183). Edgewood has been noted to occur in components of the East Texas Aspect, Archaic Stage, and less consistently, in the Edwards Plateau Aspect. Edgewood types have been dated to the later stages of the Archaic period in Texas, around A.D. 1 (Suhm and Jelks 1962:183).

Metric data concerning this one point are:

$$
\begin{aligned}
& \text { Length } \mathrm{mm}-27.0 \\
& \text { Width } \mathrm{mm}-17.0 \\
& \text { Thickness mm }-50.0 \\
& \text { Stem Width mm }-18.3 \\
& \text { Stem Length mm }-7.4 \\
& \text { Weight } \mathrm{gm}-3.3
\end{aligned}
$$

Provenience of Dart Points

\begin{tabular}{clll}
$\begin{array}{c}\text { Point } \\
23\end{array}$ & $\begin{array}{c}\text { Leve1 } \\
1(0-5 \mathrm{~cm})\end{array}$ & $\begin{array}{c}\text { Unit } \\
\text { N38/E2; NE1/4 }\end{array}$ & $\begin{array}{c}\text { Type } \\
\text { (Suhm and Jelks 1962) } \\
\text { Edgewood }\end{array}$ \\
31 & $2(20-40 \mathrm{~cm})$ & Test 4 & $\begin{array}{c}\text { Tortugas } \\
34\end{array}$ \\
35 & surface & Area B, Gully & Langtry, Basal fragment \\
43 & surface & Area B, Gully & Langtry, Basal fragment \\
\hline & surface & Area B & Langtry, Basal fragment
\end{tabular}

Arrow Points. Dominating the recovered projectile point category are arrow points. Generally, these projectile points appear in archaeological contexts after dart points and are indicators of the Late Prehistoric (temporal) period. Several types, most notably Perdiz, Scalzorm and Zavala points, form the bulk of the arrow point category. Twenty-five specimens (59.5\% of the total sample) were typed following descriptions published by Suhm and Jelks (1962) and Hester (1971). These will be described under the appropriate subheadings (types) and provenience data will follow the descriptions.

Perdiz Points (Plate 4,b)--Eight projectile points and fragments were classified according to the published criteria of Suhm and Jelks (1962) as Perdiz. One point appears to be resharpened, since it is very sma11. From $\mathrm{CH}-28$, the Perdiz points have generally slender, triangular blades with straight concave edges. 
Barbs are prominent on almost all of the points. The characteristic contracting stem of Perdiz points is present and the stem edge is stralght or convex. Serrated blade edges are quite distinct on two of the specimens.

Plano-convex and biconvex longitudinal sections predominate the sample; where the point was plano-convex, it could be determined that the point was prepared from a flake. One of the specimens exhibiting plano-convexity in the longitudinal section appears to be burned (cf. Hester and Collins 1974) and was recovered in two fragments. This specimen, Point 40, was burned after manufacture, perhaps being left in a kill and "cooked" with the meat. In the transverse cross section, biconvex outlines formed the majority, while planoconvex outlines were associated with those points manufactured from flakes.

Point 32 possesses some unique characteristics. In addition to having the longest blade of the Perdiz specimens $(4.52 \mathrm{~mm})$, the edges in transverse section change from plano-convex in the basal portion to bi-triangular on the distal end, due to alternate beveling. This specimen exhibits bifacial pressure secondary retouching on both edges and the stem has been broken. On the remaining points, the degree of secondary retouch varies from extensive to nil. The smaller points probably have been resharpened.

According to Suhm and Jelks (1962:283), the Perdiz projectile point type is dated from A.D. 1000 to A.D. 1560 and has been associated with many Late Prehistoric complexes in Texas. Geographically, Perdiz points have been found in most areas of Texas. Metric data for these eight points will be summarized in table form (see next page) and their respective proveniences follow.

Scazzorn Points (Plate 4,C)--A total of ten arrow points and fragments, $21 \%$ of the total projectile point sample, were recognized as belonging to the Scallorn type. More than $70 \%$ (seven of ten) of the ScaZzorn sample were at 1east $90 \%$ complete. Within this category, a fairly wide range of morphological variation was encountered. Two of the points (numbers 30 and 36 ) have been extensively reworked/reshaped to produce very small points.

Scallorn points are characterized by "[broad] to slender triangular blades with edges straight to convex, occasionally concave" (Suhm and Jelks 1962: 285). These corner-notched points exhibit various barb shapes and notch angles. One of the collected points exhibits serrated lateral edges. Some of the stem bases are concave or slightly concave (four of ten), while straight bases are present on the majority of the points.

Point 19 is another example of a burned arrow point. Potlids are present on both faces and color is a translucent dark red-brown. The base of Point 19 has been thinned on both faces. One edge of the stem, as well as the distal end (tip), is missing from this artifact specimen.

Morphologically, a majority of the Scallorm specimens are plano-convex in longitudinal section, while some are biconvex. There is a slight curvature when examined longitudinally, indicating that many of these points were manufactured from flakes. Two general outlines are seen in these specimens when viewed in transverse section: plano-convex and biconvex. Technologically, 
Perdiz Points Metric Data

\begin{tabular}{ccccccc} 
Point & Length mm & Width mm & Thickness mm & $\begin{array}{c}\text { Stem } \\
\text { Width } \mathrm{mm}\end{array}$ & $\begin{array}{c}\text { Stem } \\
\text { Length mm }\end{array}$ & Weight gm \\
8 & 17.0 & 13.2 & 2.4 & 5.0 & 3.2 & 0.35 \\
10 & 18.2 & 15.1 & 2.6 & 17.7 & -- & 0.55 \\
16 & 25.7 & 19.7 & 3.4 & 6.0 & 8.6 & 1.1 \\
25 & 27.8 & 16.4 & 5.0 & 6.6 & 4.4 & 1.55 \\
32 & 45.2 & 16.8 & 2.6 & -7.5 & 1.3 \\
38 & 27.6 & 12.6 & 3.0 & 4.0 & 4.7 & 0.7 \\
39 & 34.7 & 20.0 & 3.8 & 7.6 & 4.6 & 1.35 \\
\hline
\end{tabular}

Perdiz Points Provenience

\begin{tabular}{cllc} 
Point & \multicolumn{1}{c}{ Level } & Unit & Quadrant \\
8 & $2(5-10 \mathrm{~cm})$ & $N 42$ & NW \\
10 & $2(5-10 \mathrm{~cm})$ & $N 42$ & SE \\
16 & $2(5-10 \mathrm{~cm})$ & $N 42 / W 2$ & SE \\
25 & $1(0-5 \mathrm{~cm})$ & $N 38 / E 2$ & SE \\
32 & surface & $N 40 / W 2$ & Northern $1 / 2$ \\
38 & $3(10-15 \mathrm{~cm})$ & $N 38 / W 2$ & NE \\
39 & $3(10-15 \mathrm{~cm})$ & $N 38 / W 2$ & SE \\
40 & $2(5-10 \mathrm{~cm})$ & $N 40$ & NW \\
47 & $4(15-20 \mathrm{~cm})$ & $N 40$ & NE
\end{tabular}


Scalzorn examples all present secondary retouch flaking. All but one of the points (number 17) show good workmanship, with controlled flaking on all faces.

Chert was utilized (in flake form) as the lithic material for all the artifacts examined. Color of the specimens varies from shades of light grey to pink with one dark red-brown specimen (the burned point mentioned above).

The Scazlom projectile point is a Late Prehistoric point which shows strong relationships (cultural?) to the Central Texas Aspect as well as Late Prehistoric foci of other Texas areas (Henrietta and Rockport Foci) (Suhm and Jelks 1962:285). Chronologically, Suhm and Jelks (1962:285) place the ScaZzorn before the occurrence of Perdiz points; they believe that the occurrence of Scazzom points in Texas spans 700 years, from A.D. 500 to A.D. 1200 . Metric measurements and provenience data for the Scalzorn points are included on the next page.

Zavala Points (Plate 4,d)--Relatively recent work in south Texas has revealed the presence in the Neo-American horizon of a small "stubby" dart-like point (Hester and Hill 1975b). A typological name, Zavaza, has been given to this projectile point. It is still unclear whether the zavala actually functioned as a dart point or an arrow point. Morphologically, this type seems to fall somewhere between dart points and arrow points. First, its length is generally smaller than dart points, but its thickness and rough flaking cast some doubt on whether it can be classified as an arrow point. Temporally, this point is found both in Neo-American and Late Archaic contexts. Zavaza points, as a group, are manufactured on flakes and are side notched. Base edges range from slightly convex to straight and to slightly concave. Basal thinning has been noted for many specimens.

A very similar point from the Trans-Pecos area has been described by Johnson (1964:36). At Devi7's Mouth, 61 Figueroa points were recovered whose dimensions are very similar to the Zavala type. Johnson's (1964:37) qualitative observations reveal other similarities:

The small size of these points may indicate that they were used as arrowheads, al though they show the typical attributes of most dart points, viz., relative great thickness and crude percussion chipping.

Concerning the geographical and temporal boundaries, Johnson (1964:37) felt that his Figueroa was a major point type of the Late Archaic in a large portion of central and west-central Texas.

From the Mariposa site, seven specimens of the Zavaza type were excavated. Two of these points (Point 18 and Point 27) are burned. These points have a11 three types of bases, with one being basal7y notched (Point 22). As mentioned above, Zavala points are roughly trianguloid with straight to convex blade edges. Expanding stem types form the majority of the excavated sample. Three of the specimens are basally thinned, and all of the points show secondary retouch flake scars of the expanding variety. Seen in the longitudinal section, five specimens are roughly biconvex in outline and two are plano-convex. One of the Zavala points exhibits a plano-trianguloid outline in the transverse section; the rest are biconvex to rough biconvex. 
Scazzorn Points Metric Data

\begin{tabular}{|c|c|c|c|c|c|c|}
\hline Point & Length mm & Width mm & Thickness mm & $\begin{array}{c}\text { Stem } \\
\text { Width } \mathrm{mm}\end{array}$ & $\begin{array}{l}\text { Stem } \\
\text { Length mm }\end{array}$ & Weight gm \\
\hline 5 & 27.0 & 15.4 & 2.6 & 10.2 & 5.7 & 1.0 \\
\hline 9 & 17.6 & 13.6 & 3.2 & 12.5 & 2.0 & 0.65 \\
\hline 14 & 20.0 & 13.1 & 2.4 & 7.6 & 4.6 & 0.50 \\
\hline 17 & 25.7 & 17.8 & 4.6 & 11.7 & 4.3 & 1.80 \\
\hline 19 & 22.0 & 11.8 & 2.9 & 8.7 & 6.3 & 0.75 \\
\hline 29 & 27.0 & 15.4 & 4.4 & 13.4 & 5.0 & 1.50 \\
\hline 30 & 18.7 & 15.3 & 3.8 & 13.7 & 5.4 & 1.0 \\
\hline 36 & 17.0 & 13.7 & 3.5 & 13.3 & 4.3 & 0.60 \\
\hline 41 & 27.6 & 16.2 & 3.8 & 8.1 & 4.3 & 1.40 \\
\hline 47 & 23.6 & 15.4 & 3.7 & 7.6 & 2.4 & \\
\hline
\end{tabular}

ScazZorn Points Provenience

\begin{tabular}{|c|c|c|c|c|c|c|c|}
\hline Point & Leve1 & Unit & Quadrant & Point & Level & Unit & Quadrant \\
\hline 5 & I $(0-5 \mathrm{~cm})$ & N42 & NW & 29 & $2(5-10 \mathrm{~cm})$ & N38 & NW \\
\hline 9 & $2(5-10 \mathrm{~cm})$ & N42 & NW & 30 & $1(0-20 \mathrm{~cm})$ & Area B & Test 3 \\
\hline 14 & $1(0-5 \mathrm{~cm})$ & N42/W2 & SW & 36 & $2(5-10 \mathrm{~cm})$ & N38/W2 & SE \\
\hline 17 & $3(10-15 \mathrm{~cm})$ & N42/W2 & SE & 41 & $3(10-15 \mathrm{~cm})$ & $N 40$ & NW \\
\hline 19 & $2(5-10 \mathrm{~cm})$ & N42/E2 & NE & 47 & $4(15-20 \mathrm{~cm})$ & N40 & NE \\
\hline
\end{tabular}




\section{ZavaZa Points Metric Data}

$\begin{array}{ccccccc}\text { Point } & \text { Length mm } & \text { Width mm } & \text { Thickness } \mathrm{mm} & \begin{array}{c}\text { Stem } \\ \text { Width mm }\end{array} & \begin{array}{c}\text { Stem } \\ \text { Length mm }\end{array} & \text { Weight gm } \\ 2 & 41.6 & 18.4 & 8.1 & 16.6 & 7.0 & 5.7 \\ 3 & 33.3 & 17.0 & 5.9 & 14.6 & 8.3 & 3.4 \\ 18 & 34.6 & 28.3 & 5.0 & 15.2 & 7.2 & 3.2 \\ 22 & 31.5 & 16.8 & 5.0 & 17.0 & 5.4 & 2.7 \\ 26 & 24.2 & 16.7 & 6.7 & 15.6 & 6.3 & 2.65 \\ 27 & 30.4 & 20.7 & 7.3 & 18.0 & 5.0 & 4.1 \\ 42 & 34.6 & 17.0 & 6.8 & 15.0 & 6.3 & 4.3\end{array}$

Zavala Points Provenience

$\begin{array}{cllc}\text { Point } & \text { Level } & \text { Unit } & \text { Quadrant } \\ 2 & 5(20-25 \mathrm{~cm}) & \text { N38/W2 } & \text { SW } \\ 3 & 6(25-30 \mathrm{~cm}) & \text { N38/W2 } & \text { NW } \\ 18 & 3(10-15 \mathrm{~cm}) & \text { N44 } & \text { SE } \\ 22 & 1(0-5 \mathrm{~cm}) & \text { N38/E2 } & \text { NE } \\ 26 & 2(5-10 \mathrm{~cm}) & N 38 / E 2 & \text { NE } \\ 27 & 1(0-5 \mathrm{~cm}) & \text { N38 } & \text { NW } \\ 42 & 3(10-15 \mathrm{~cm}) & N 40 & \text { SE }\end{array}$


As can be noted from the provenience table on page 86 zavaza points occur in almost all levels, with the smaller specimens occurring in the upper two levels. The preceding metric information indicates the variability present in the Zavaza sample.

The majority of dart points recovered from Martposa were confined to the surface of Area B and in deep levels of Area A. Only one example occurred in the upper level of an Area A excavation unit. On the other hand, only one (of 25) arrow point, a Scazzorn occurred in Area B. It is immediately obvious that this dichotomy has important implications. Area B seems to be an Archaic locality, temporally distinct from Area A. The Mariposa site seems to have been a favored occupation area from at least Archaic times through the Late Prehistoric. Elaboration of the nature of the Archaic occupations at Mariposa cannot be presented until lower levels of the site are more completely revealed. Both the surface evidence in Area $B$ and the deep hearth in Test 5 (Area A) indicate that Mariposa probably embodies an Archaic component in addition to the recorded Late Prehistoric component.

Perdiz points are present in great frequency in the upper three levels (and surface) of Mariposa, as $89 \%$ of the sample are recorded there. Six of the nine excavated units contained Perdiz points, with N42 and N38/W2 having more than one specimen in a level. As for scazlorn points, a similar $89 \%$ of these projectile points are situated in the upper three levels of the site. Of the six excavation units containing Perdiz points, four also contained Scalzorn points. While the majority $(71 \%)$ of Zavala points present at Mariposa occurred in levels one through three, two examples were recovered from much deeper contexts. However, since only two excavation units penetrated at least six levels, one cannot say that this pattern is useful for the entire site. Both examples from levels five and six occur in N38/W2. The fact that Zavala points occur in quite different excavation units than both Perdiz and Scalzorn may be significant.

In summary, Perdiz and Scazzorn projectile points occur with quite similar frequencies in the upper three levels of Mariposa. Zavala points, while occurring in similar archaeological contexts as both Perdiz and Scalzorn, seem to appear before these types. This picture is quite in line with data from other Late Prehistoric sites in the vicinity of Mariposa (Hester and Hil1 $1975 \mathrm{~b}$ ). Due to the late $\mathrm{C}-14$ determination for Mariposa, the temporal parameters for the existence of these point types must be expanded, at least to A.D. 1650 .

Ground, Battered, and Polished Stone

Analysis concerning this category of lithic artifacts offered surprising results. While most Late Prehistoric sites in this area contain numerous hammerstones (Hester and Hill 1975b:9), very few (two) were recovered from Mariposa, and one of these is a fragment $(A-26$; Plate 4,e). Smoothed sandstone slabs, not usually reported from south Texas sites, were relatively frequent. Five specimens were excavated from Mariposa. One of these specimens, Artifact $\# 41$, consisted of three fragments, two of which fit together. All four of these fragments were located in level $1(0-5 \mathrm{~cm})$ of the southwestern quadrant of Unit N42. Well-worn corners are evident on the two fragments which 
could be joined. One unidentified ground stone with rounded corners was recorded from the same provenience.

Artifact \#106 is smoothed on both faces and one face exhibits a longitudinal scratch. The artifact is stained with a dark black substance (unknown origin).

Scratches and grooving occurred on four hematite specimens and six sandstone rocks. Taken together, these artifacts form the largest class of ground stone materials. Generally, such grooves and scratches (the majority of which are longitudinal) are associated with arrow shaft straightening activities (Hester and $\mathrm{Hill}$ 1975b:9); these implements may also have been used to grind and prepare platforms on artifacts for ease of manufacture (see Plate 4, $f$ and $g$ ).

Four fragmentary manos and one complete mano were also found at Mariposa. A11 faces and edges are uniformly worn. Limestone was the favorite working material for these grinding implements, as all but one of the manos (a fragment) consisted of this material. Interestingly, the one mano fragment which was not limestone was made of quartzite and stained with hematite (see Plate 5).

Polished stone was rare, with only one quartzite fragment (polished on one face) being recovered (Artifact \#97).

A11 of the artifacts described above were excavated during the 1974 field season. In 1975, testing at Mariposa revealed the presence of a large hearth located approximately $60 \mathrm{~cm}$ below the surface (Montgomery, Moffat and Richie 1975). A hearth at such a deep level is significant in itself but careful observations revealed additional information. Nine incised stones, all located in the central portion of the hearth and relatively close in proximity to each other, were recorded in the field and were removed for further examination.

A11 but one of the specimens are incised on one face only. Incising on the majority of the sandstone artifacts consisted of longitudinal lines running roughly parallel. As few as two and as many as five lines were present. In a few cases, the longitudinal lines were crossed by a perpendicular transverse line. On one specimen, Artifact \#159-8, a longitudinal incision was crossed by four transverse lines. While most of the specimens had parallel longitudinal incised lines, no other recurring pattern persists in the sample. Approximately half of the sandstone artifacts are rectanguloid in outline, while the remainder of the sample are irregular. Some of the specimens are quite large (e.g., A-159-8) but a few are significantly smaller (e.g., A-159-1).

Problems associated in determining the function of incised stone are numerous (Hester and Hill 1975b:13). Compounding these problems at Mariposa is the fact that sandstone rocks rather than limestone cobbles were used as raw material and that such incised rock appears in an oriented pattern within the deep hearth. Such circumstances as those at Mariposa have yet to be reported from other sites. 


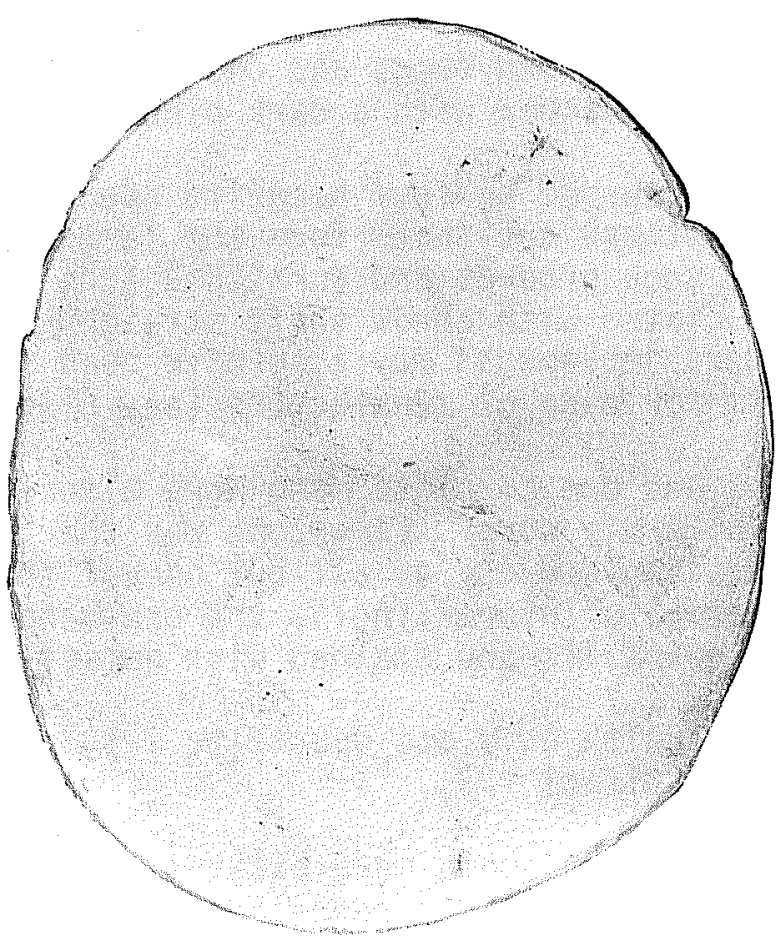

a

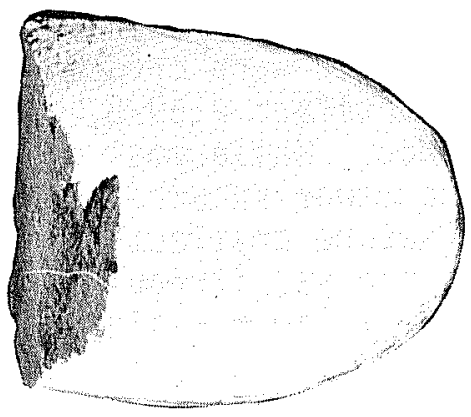

b

Plate 5. Ground Stone. $a, 1$ imestone mano $(A-20)$; b, mano fragment (A-171). 
Ground, Battered or Polished Stone Metric Data

$\begin{array}{ccccr}\text { Artifact } & \begin{array}{c}\text { Length } \\ (\mathrm{mm})\end{array} & \begin{array}{c}\text { Width } \\ (\mathrm{mm})\end{array} & \begin{array}{c}\text { Thickness } \\ (\mathrm{mm})\end{array} & \begin{array}{c}\text { Weight } \\ (\mathrm{gm})\end{array} \\ \begin{array}{c}\text { Hammerstones } \\$\cline { 1 - 2 } \text {$A-25 }\end{array} & & & & \\ \text { A-78 } & 33.75 & 27.15 & 20.7 & 20.4 \\ & 52.6 & 40.4 & 58.0 & 224.4\end{array}$

Smoothed Sandstone Slabs

$\begin{array}{lcllc}\text { A-36 } & 69.6 & 57.5 & 24.6 & 152.1 \\ \text { A-40 } & 6.8 & 13.35 & 16.4 & 5.1 \\ \text { A-41 (3) } & 47.7 & 29.65 & 16.7 & 33.85 \\ & 63.3 & 57.7 & 17.4 & 74.9 \\ & 33.0 & 28.0 & 16.3 & 25.3 \\ \text { A-106 } & 87.15 & 67.3 & 28.75 & 132.25 \\ \text { A-153 } & 115.0 & 98.4 & 37.65 & 626.6\end{array}$

Scratched and Grooved Sandstone

\begin{tabular}{|c|c|c|c|c|}
\hline$A-73$ & 46.45 & 29.55 & 22.55 & 26.75 \\
\hline$A-79$ & 19.55 & 13.25 & 3.25 & 1.2 \\
\hline$A-83$ & 57.4 & 30.0 & 35.65 & 76.45 \\
\hline$A-84$ & 52.85 & 38.65 & 14.45 & 42.55 \\
\hline$A-102$ & 43.45 & 28.0 & 36.2 & 45.1 \\
\hline$A-1115$ & 71.5 & 62.0 & 43.35 & 269.7 \\
\hline
\end{tabular}

Polished Stone Quartzite

$\begin{array}{lllll}A-97 & 34.0 & 20.35 & 21.35 & 15.0\end{array}$

Manos and Mano Fragments

$\begin{array}{llllc}A-20 & 86.0 & 72.7 & 42.1 & 385.1 \\ A-34 & 43.2 & 36.75 & 37.85 & 68.75 \\ A-99 & 57.0 & 44.0 & 19.9 & 55.8 \\ A-124 & 74.55 & 38.0 & 45.55 & 182.1 \\ A-171 & 60.2 & 25.7 & 36.9 & 77.1\end{array}$

Smoothed Hematite

$\begin{array}{lllll}\text { A-156 } & 18.0 & 17.3 & 6.7 & 3.1\end{array}$




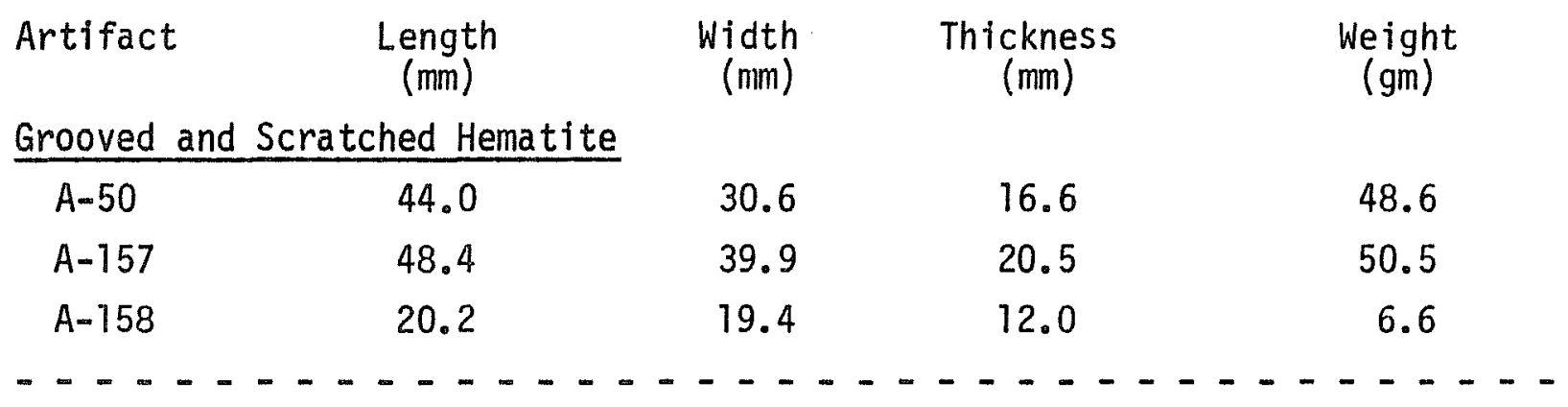

$$
\begin{gathered}
\text { Ground, Pecked, or Pol ished Stone } \\
\text { Provenience }
\end{gathered}
$$

Artifact

Level

Unit

Quadrant

Hammerstones
A-25
$10(55-65 \mathrm{~cm})$
N38/W2
$\mathrm{N} 1 / 2$
$A-78$
$4(15-20 \mathrm{~cm})$
N44
SW

Smoothed Sandstone Slabs

$\begin{array}{lllc}A-36 & 5(20-25 \mathrm{~cm}) & N 40 & \mathrm{SW} \\ A-40 & 1(0-5 \mathrm{~cm}) & N 42 & \mathrm{SW} \\ A-41 & 1(0-5 \mathrm{~cm}) & N 42 & \mathrm{SW} \\ A-106 & 1(0-5 \mathrm{~cm}) & N 38 / E 2 & S E \\ A-153 & \text { surface } & \text { Area B } & \begin{array}{c}\text { West of } \\ \text { Excavations }\end{array}\end{array}$

Scratched and Grooved Sandstone

$\begin{array}{llll}A-73 & 4(15-20 \mathrm{~cm}) & \text { N42/W2 } & \text { SE } \\ A-79 & 1(0-5 \mathrm{~cm}) & \text { N42/E2 } & \text { SW } \\ A-83 & 2(5-10 \mathrm{~cm}) & \text { N42/E2 } & \text { NE } \\ A-84 & 2(5-10 \mathrm{~cm}) & N 42 / E 2 & \text { SE } \\ A-102 & 3(10-15 \mathrm{~cm}) & N 40 / E 2 & \text { SW } \\ A-115 & 3(10-15 \mathrm{~cm}) & N 38 & \text { NE }\end{array}$

Polished Stone Quartzite
A-97
$2(5-10 \mathrm{~cm})$
N40/E2
SE

Manos and Mano Fragments

$\begin{array}{llll}A-20 & 5(20-25 \mathrm{~cm}) & N 38 / W 2 & \text { NE } \\ A-34 & 2(5-10 \mathrm{~cm}) & \text { N40 } & \text { SW } \\ A-99 & 2(5-10 \mathrm{~cm}) & \text { N40/E2 } & \text { SE } \\ A-125 & \text { surface } & \text { Area B }(1974) & -- \\ A-171 & 2(5-10 \mathrm{~cm}) & \text { N42 } & \text { SW }\end{array}$


Artifact

Level

Unit

Quadrant

Smoothed Hematite

$\begin{array}{llll}\text { A-156 } & 4(15-20 \mathrm{~cm}) & \text { N38/W2 } & \text { SE } \\ A-20 & 5(20-25 \mathrm{~cm}) & \text { N38/W2 } & \text { NE } \\ \text { A-34 } & 2(5-10 \mathrm{~cm}) & \text { N40 } & \text { SW } \\ \text { A-99 } & 2(5-10 \mathrm{~cm}) & \text { N40/E2 } & \text { SE } \\ \text { A-124 } & \text { surface } & \text { Area B } & --\end{array}$

Grooved and Scratched Hematite

\begin{tabular}{llll} 
A-50 & $2(5-10 \mathrm{~cm})$ & $N 42$ & $\mathrm{NE}$ \\
A-157 & $6(25-30 \mathrm{~cm})$ & $\mathrm{N} 38 / \mathrm{W} 2$ & $\mathrm{NW}$ \\
A-158 & $2(5-10 \mathrm{~cm})$ & $\mathrm{N} 40$ & $\mathrm{NE}$ \\
\hline
\end{tabular}

A11 nine excavation units at Mariposa contained some form of ground or polished stone. Most of these artifacts were obtained from the surface of the site to the third excavation level. Both of the hammerstones came from deeper contexts (levels four and ten). Smoothed sandstone slabs came mainly from the first level and surface of the site, with $N 42$ containing two specimens in the first 1eve1. Scratched and grooved sandstone frequency is highest in the first three levels of the site, and levels one and two of N42/E2 contained half of the site's specimens. Smoothed hematite as well as grooved and scratched hematite occurs in upper contexts, especially in level two and in lower levels (levels four, five and six). Several units (N38/W2, N40, N42, N40/E2) contained four or more specimens of various types of ground stone. Those artifacts in N38/W2 were recovered primarily from deeper contexts.

\section{Historic Materials}

A single lead bullet, Artifact \#133, represents the only historic material recovered from Mariposa. The bullet (probably .45 caliber) measures $16.2 \mathrm{~mm}$ in length, the width and thickness are both $11.2 \mathrm{~mm}$, and it weighs $13.6 \mathrm{gm}$. Provenience of the artifact indicates that it came from the first level of a test pit (Test 4) in Area B. Since Area B has been the focus of recent road-cutting operations and erosional processes, the lead bullet is undoubtedly intrusive.

\section{Flake Analysis}

Analysis of the unmodified (unaltered) flake material from Mariposa provides insight into many aspects of prehistoric behavior. Theoretically, flake analyses help determine the kinds of tool manufacturing activities at a site, the "structure" or the outlined model of reduction techniques, and temporal changes in technology, Where the data exist, comparison of technologies can 
also be undertaken. The data herein are the outcome of reviewing the literature concerning debitage analysis with and near the Rio Grande Plain. Definition of terms generally follows Shafer's (1969) study at Robert E. Lee Reservoir Basin (in west central Texas) along with work of $\mathrm{Hill}$ and Hester (1971), Hester and Hill (1972) and Hester (1975b) in south Texas.

Those flakes which are completely covered with cortex on the dorsal surface are termed Primary Cortex Flakes. Technologically, the attribute of complete cortex coverage indicates that these flakes result from the initial decortication of a core (Hester and Hill 1972:46). Subsequent reduction of a core produces flakes which retain some dorsal cortex. These are termed Secondary Cortex Flakes. Further core reduction yields Interior Flakes which are devoid of cortex on the dorsal surface.

In addition to the three types of flakes manufactured as by-products of core reduction, another type of flake can be readily identified. Lipped flakes, or bifacial thinning flakes, are, as the second name implies, evidence for the bifacial reduction technique. Thought to be produced by soft hammer percussion (Epstein 1964:64; Shiner 1970:31), bifacial thinning flakes have attributes which consistently occur. According to Shiner (1970:32), these attributes are:

1) Oval platform; 2) platforms between about 40 and 60 degrees to bulbar surface; 3) faceted platform; 4) diffuse bulb without the tiny flake near the center of the bulb; 5) a narrowing and thinning of the flake before it widens out and sometimes thickens again; 6) a curvature of the flake itself.

The overhanging "7ip" on the ventral surface is the easiest attribute to observe on these flakes. Flake specimens which lack an identifiable striking platform or bulb of percussion are categorized as flake fragments.

Concomitant with the study of flake attributes, classification of platforms reinforces statements concerning lithic technology. Five platform types are most commonly recognized (cf. Hester and Hill 1972). These are: (1) cortex platforms, whose striking platform has been unmodified; (2) single faceted platforms, formed by removal of one flake to prepare the striking platform; (3) multifaceted platforms constructed by the detachment of several faceting flakes; (4) convergent platforms ( 1 -shaped), caused by removing flakes lying relative to each other in convergent planes (Hester 1971:106,5), and (5) crushed (shattered) platforms (Hester and Hill 1972:46-48).

Analysis of the Mariposa flake sample follows the lines of Hester and Hill (1972). Separate tabulation of flake types and flake platform types both in number and in relative frequency are prepared for the overall sample by level and in each unit of each level respectively. Metric dimensions are not included. Hester and Hill (1972:48) have prepared range dimensions of length, width and thickness for the four main types of flakes (primary cortex, secondary cortex, interior, and biface thinning flakes). 


\section{Flake Types}

As stated above, five flake types were recorded from materials excavated at Mariposa. These are presented, by unit and level provenience, in Table 2. Similar information, obtained from less exact methods (i.e., Test Pits), are provided in Table 3. This information is summarized, by level, in Table 4 where relative percentage is the quantity recorded (this is only for 1974 excavations).

Centering on material excavated in 1974, an overall statement of the flake types represented at Mariposa can be formulated. Here, all levels and units are combined to show the following breakdown, by number and percent, of the five flake types:

\begin{tabular}{|c|c|c|}
\hline & $\begin{array}{c}\text { Number } \\
\text { Recovered }\end{array}$ & $\begin{array}{l}\text { Percentage of } \\
\text { Flake Category }\end{array}$ \\
\hline Primary Cortex Flakes & 45 & 2.0 \\
\hline Secondary Cortex Flakes & 319 & 13.9 \\
\hline Interior Flakes & 289 & 12.6 \\
\hline Biface Thinning Flakes & 247 & 10.8 \\
\hline Flake Fragments & 1,397 & 60.8 \\
\hline Total & 2,297 & 100.0 \\
\hline
\end{tabular}

If one removes the flake fragment category from the above information, the following numbers of specimens, and their relative frequency, by type, are generated:

\begin{tabular}{|c|c|c|}
\hline & $\begin{array}{c}\text { Number } \\
\text { Recovered }\end{array}$ & $\begin{array}{l}\text { Relative } \\
\text { Percentage }\end{array}$ \\
\hline Primary Cortex Flakes & 40 & 4.4 \\
\hline Secondary Cortex Flakes & 321 & 35.7 \\
\hline Interior Flakes & 291 & 32.3 \\
\hline Biface Thinning Flakes & 248 & 27.6 \\
\hline Total & 900 & 100.0 \\
\hline
\end{tabular}

Secondary cortex flakes, interior flakes, and biface thinning flakes contribute $95 \%$ of the identifiable flake types, with secondary cortex flakes being the most frequent. Interior flakes occur the second most frequently, followed by biface thinning flakes. Ramifications for these results are discussed in Chapter VIII (Lithic Technology).

The other attributes observed on flakes recovered from Mariposa may be grouped as flake striking platform types. Five categories here were also analyzed: single facet platforms, multi-facet platforms, crushed or shattered platforms, cortex platforms and convergent platforms. For the sake of brevity, all the data have been compiled in Table 5. Here each platform type is quantified by 
TABLE 2

FLAKE PROVENIENCE AND COUNT: EXCAVATED UNITS (1974) MARIPOSA SITE

\begin{tabular}{|c|c|c|c|c|c|c|c|c|c|c|c|c|c|c|c|c|c|}
\hline \multirow[b]{2}{*}{ FLAKES } & \multicolumn{12}{|c|}{ N38/W2 } & \multicolumn{5}{|c|}{ N40 } \\
\hline & 1 & 2 & 3 & 4 & 5 & 6 & 7 & 8 & 9 & 10 & 11 & 12 & 1 & 2 & 3 & 4 & 5 \\
\hline $\begin{array}{l}\text { Primary } \\
\text { Cortex } \\
\text { Flakes }\end{array}$ & -- & 3 & 1 & 2 & -- & 2 & 1 & -- & - & -- & -- & -- & 1 & 2 & 3 & 3 & 1 \\
\hline $\begin{array}{l}\text { Secondary } \\
\text { Cortex } \\
\text { Flakes }\end{array}$ & 4 & 10 & 8 & 9 & 13 & 4 & 7 & 4 & 1 & 4 & 1 & 1 & 5 & 26 & 10 & 16 & 14 \\
\hline $\begin{array}{l}\text { Interior } \\
\text { Flakes }\end{array}$ & 8 & 11 & 6 & 7 & 3 & 2 & 8 & 2 & 2 & 1 & 1 & 1 & 3 & 10 & 10 & 9 & 13 \\
\hline $\begin{array}{l}\text { Flake } \\
\text { Fragments }\end{array}$ & 13 & 63 & 42 & 29 & 45 & 34 & 33 & 20 & 5 & -- & 9 & 4 & 9 & 56 & 23 & 32 & 53 \\
\hline
\end{tabular}


TABLE 2 (continued)

\begin{tabular}{|c|c|c|c|c|c|c|c|c|c|c|c|c|c|c|c|c|}
\hline \multirow[b]{2}{*}{ FLAKES } & \multicolumn{6}{|c|}{$\mathrm{N} 42$} & \multicolumn{5}{|c|}{$\mathrm{N} 42 / \mathrm{W} 2$} & \multicolumn{5}{|c|}{ N44 } \\
\hline & 1 & 2 & 3 & 4 & 5 & 6 & 1 & 2 & 3 & 4 & 5 & 1 & 2 & 3 & 4 & 5 \\
\hline $\begin{array}{l}\text { Primary } \\
\text { Cortex } \\
\text { Flakes }\end{array}$ & -- & 1 & 3 & -- & $\cdots$ & -- & -- & -- & -- & -- & 1 & 1 & -- & -- & -- & -- \\
\hline $\begin{array}{l}\text { Secondary } \\
\text { Cortex } \\
\text { Flakes }\end{array}$ & 9 & 7 & 5 & 9 & -- & 1 & 5 & 7 & 5 & 3 & 9 & 7 & 7 & 4 & 2 & 3 \\
\hline $\begin{array}{l}\text { Interior } \\
\text { Flakes }\end{array}$ & 11 & 10 & 11 & 11 & 6 & 1 & 9 & 13 & 10 & 8 & 9 & 4 & 2 & 2 & 2 & 2 \\
\hline $\begin{array}{l}\text { Biface } \\
\text { Thinning } \\
\text { Flakes }\end{array}$ & 4 & 4 & 7 & 4 & -- & 1 & 4 & 4 & 3 & 7 & 12 & 5 & 5 & 3 & 3 & 10 \\
\hline $\begin{array}{l}\text { Flake } \\
\text { Fragments }\end{array}$ & 37 & 57 & 52 & 35 & 21 & 4 & 15 & 31 & 29 & 40 & 32 & 17 & 20 & 8 & 12 & 12 \\
\hline
\end{tabular}


TABLE 2 (continued)

\begin{tabular}{|c|c|c|c|c|c|c|c|c|c|c|c|c|c|}
\hline \multirow[b]{2}{*}{ FLAKES } & \multicolumn{3}{|c|}{ N42/E2 } & \multicolumn{3}{|c|}{ N42/E2 } & \multicolumn{3}{|c|}{ N42/E2 } & \multicolumn{3}{|c|}{ N38 } & \multirow[b]{2}{*}{ TOTAL } \\
\hline & 1 & 2 & 3 & 1 & 2 & 3 & 1 & 2 & 3 & 1 & 2 & 3 & \\
\hline $\begin{array}{l}\text { Primary } \\
\text { Cortex } \\
\text { Flakes }\end{array}$ & 2 & 2 & -- & 3 & -- & 2 & 2 & 1 & -- & 2 & 1 & 2 & 40 \\
\hline $\begin{array}{l}\text { Secondary } \\
\text { Cortex } \\
\text { Flakes }\end{array}$ & 4 & 12 & 6 & 5 & 13 & 6 & 16 & 7 & 5 & 6 & 20 & 3 & 321 \\
\hline $\begin{array}{l}\text { Interior } \\
\text { Flakes }\end{array}$ & 7 & 10 & 3 & 6 & 8 & 7 & 9 & 9 & 3 & 4 & 11 & 6 & 291 \\
\hline $\begin{array}{l}\text { Biface } \\
\text { Thinning } \\
\text { Flakes }\end{array}$ & 5 & 12 & 4 & 7 & 7 & 7 & 12 & 11 & 9 & 7 & 14 & 8 & 248 \\
\hline $\begin{array}{l}\text { Flake } \\
\text { Fragments }\end{array}$ & 30 & 58 & 31 & 37 & 49 & 35 & 41 & 53 & 37 & 17 & 102 & 27 & 1,409 \\
\hline
\end{tabular}


TABLE 3

FLAKE PROVENIENCE AND COUNT: TEST PITS

\begin{tabular}{|c|c|c|c|c|c|c|c|c|c|c|c|c|c|c|c|c|}
\hline \multirow[b]{3}{*}{ FLAKES } & \multicolumn{15}{|c|}{ MARIPOSA SITE } & \multirow{3}{*}{$\begin{array}{c}\text { Test } 3 \\
1974 \\
\text { Area B } \\
1\end{array}$} \\
\hline & \multicolumn{5}{|c|}{ Test 11970} & \multicolumn{7}{|c|}{ Test 21970} & \multicolumn{3}{|c|}{$\begin{array}{l}\text { Test } 2 \\
1974 \\
\text { Area B }\end{array}$} & \\
\hline & 1 & 2 & 3 & 4 & 5 & 1 & 2 & 3 & 4 & 5 & 6 & 7 & 1 & 2 & 3 & \\
\hline $\begin{array}{l}\text { Primary } \\
\text { Cortex } \\
\text { Flakes }\end{array}$ & 2 & -- & -- & -- & 1 & 1 & 2 & -- & -- & -- & -- & -- & -- & -- & -- & -- \\
\hline $\begin{array}{l}\text { Secondary } \\
\text { Cortex } \\
\text { Flakes }\end{array}$ & 3 & 5 & 3 & 2 & 2 & 18 & 12 & 5 & 4 & 5 & 1 & -- & 4 & 1 & -- & -- \\
\hline $\begin{array}{l}\text { Interior } \\
\text { Flakes }\end{array}$ & 18 & 5 & 4 & 2 & 4 & 31 & 11 & 6 & 6 & 2 & 1 & -- & -- & -- & 2 & 2 \\
\hline $\begin{array}{l}\text { Biface } \\
\text { Thinning } \\
\text { Flakes }\end{array}$ & 4 & 3 & 1 & 1 & -- & 6 & 3 & 3 & 1 & -- & -- & -- & 5 & 2 & 1 & -- \\
\hline $\begin{array}{l}\text { Flake } \\
\text { Fragments }\end{array}$ & 32 & 16 & 12 & 6 & 9 & 52 & 29 & 22 & 13 & 8 & -- & 1 & 19 & 10 & 1 & 16 \\
\hline
\end{tabular}


TABLE 3 (continued)

\begin{tabular}{|c|c|c|c|c|c|c|c|c|c|c|c|c|}
\hline \multirow[b]{2}{*}{ FLAKES } & \multirow[t]{2}{*}{$\begin{array}{c}\text { Test 4 } \\
1974 \\
\text { Area B }\end{array}$} & \multicolumn{3}{|c|}{$\begin{array}{l}\text { Test } 1 \\
1974 \\
\text { Area B }\end{array}$} & \multicolumn{4}{|c|}{$\begin{array}{l}\text { Test } 5 \\
1975 \\
\text { Area A }\end{array}$} & \multicolumn{2}{|c|}{$\begin{array}{c}\mathrm{NE} \\
\text { Exten- } \\
\text { sion }\end{array}$} & \multirow{2}{*}{$\begin{array}{c}\text { SE } \\
\text { Exten- } \\
\text { sion } \\
1 \\
1\end{array}$} & \multirow[b]{2}{*}{ TOTAL } \\
\hline & & 1 & 2 & 3 & 1 & 2 & 3 & 4 & $1-2$ & $3-4$ & & \\
\hline $\begin{array}{l}\text { Primary } \\
\text { Cortex } \\
\text { Flakes }\end{array}$ & -- & -- & -- & -- & 2 & -- & -- & -- & 1 & -- & -- & 9 \\
\hline $\begin{array}{l}\text { Secondary } \\
\text { Cortex } \\
\text { Flakes }\end{array}$ & $\therefore$ & -- & 2 & -- & 4 & 2 & 4 & 1 & 12 & 4 & 1 & 103 \\
\hline $\begin{array}{l}\text { Interior } \\
\text { Flakes }\end{array}$ & 4 & 1 & 1 & -- & 3 & 5 & 4 & 1 & 8 & 2 & 2 & 125 \\
\hline $\begin{array}{l}\text { Biface } \\
\text { Thinning } \\
\text { Flakes }\end{array}$ & 5 & 2 & 3 & -- & 9 & 7 & 8 & 2 & 15 & 2 & -- & 83 \\
\hline $\begin{array}{l}\text { Flake } \\
\text { Fragments }\end{array}$ & 33 & 3 & 3 & 1 & 33 & 37 & 40 & 8 & 63 & 16 & 1 & 484 \\
\hline
\end{tabular}




\section{TABLE 4}

FLAKE TYPE RELATIVE PERCENTAGE BY EXCAVATION LEVEL (1974)

Primary

Cortex

Flakes

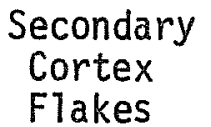

Flakes

\author{
Interior
Flakes \\ Interior
Flakes
}

33.3

39.6

28.9

37.9

38.2

27.8

30.4

66.7

33.3

66.7

16.7

33.3
33.3

30.5

33.5

35.9

32.4

16.7

34.8

33.3

66.7

16.7

16.7

33.3
Biface

Thinning

Flakes
Leve1 11

Level 12
27.3

26.2

30.6

21.4

29.4

44.4

30.4

0

0

16.7

66.7

33.3 
TABLE 5

FLAKE STRIKING PLATFORM TYPE RELATIVE PERCENTAGE BY LEVEL

\begin{tabular}{llccccc} 
& $\begin{array}{c}\text { Single Facet } \\
\text { Platform }\end{array}$ & $\begin{array}{c}\text { Multi-Facet } \\
\text { Platform }\end{array}$ & $\begin{array}{c}\text { Crushed/ } \\
\text { Shattered }\end{array}$ & Convergent & Cortex \\
\hline Level & 1 & 44 & 31.9 & 7.1 & 3.8 & 13.2 \\
Leve1 & 2 & 51.3 & 27.3 & 7.3 & 3 & 11.3 \\
Leve1 & 3 & 46.4 & 35.5 & 6.6 & 0.6 & 10.8 \\
Leve1 & 4 & 47.1 & 28.4 & 8.8 & 5.9 & 9.8 \\
Leve1 & 5 & 47.4 & 31.6 & 8.4 & 2.1 & 10.5 \\
Leve1 & 6 & 33.3 & 44.4 & 5.6 & 5.6 & 11.1 \\
Leve1 & 7 & 13 & 43.5 & 30.4 & 8.7 & 4.3 \\
Level & 8 & 66.7 & 0 & 16.7 & 0 & 16.7 \\
Leve1 & 9 & 66.7 & 33.3 & 0 & 0 & 0 \\
Level & 10 & 50 & 16.7 & 16.7 & 0 & 16.7 \\
Level & 11 & 16.7 & 66.7 & 0 & 0 & 16.7 \\
Level 12 & 50 & 50 & 0 & 0 & 0
\end{tabular}


showing relative percentage of each type in each level. Table 6 presents data compiled for all excavation levels and units initiated in 1974 and assumed to represent the overall site assemblage. Each flake striking platform type is quantified and then converted to relative percentage. Results of this brief analysis are detailed in Chapter VIII (Lithic Technology).

\section{TABLE 6}

\section{NUMBER RECOVERED AND RELATIVE PERCENTAGE OF \\ FLAKE STRIKING PLATFORMS FROM \\ THE MARIPOSA SITE}

\begin{tabular}{lcc} 
Single Facet Platform & $\begin{array}{c}\text { Number } \\
\text { Recovered }\end{array}$ & $\begin{array}{c}\text { Relative } \\
\text { Percentage }\end{array}$ \\
Multi-Facet Platform & 416 & 46.2 \\
Crushed/Shattered Platform & 285 & 31.7 \\
Cortex Platform & 72 & 8.0 \\
Convergent Platform & 100 & 11.1 \\
$\quad$ TOTAL & 27 & 3.0 \\
\cline { 2 - 3 } & 900 & 100.0
\end{tabular}

One note of caution: below level five at Mariposa, the flake sample becomes quite small in quantity, making inferences concerning flake attributes below this level highly suspect.

\section{Uniface Retouch Flakes}

Flakes which "possess remnants of unifacially trimmed edges" (Shafer 1970:480) were provided a special category: uniface retouch flakes. Following Shafer (1970), morphological attributes of flake removal from the original uniface provide a convenient classification of these flakes. The first attribute consists of flake removal from the uniface by striking a lateral edge parallel to the uniface's ventral surface. Another attribute is the apparent removal of the flake by striking the uniface "on the ventral surface near the" tool "edge" (Shafer 1970:480). A third removal technique, striking the uniface on the dorsal surface near the edge, also removes a uniface retouch flake. Removal of the uniface tool edge ("retouching") is considered to be functionally useful, since it removes worn, steep beveled edges which probably hinder maximum tool efficiency (Shafer 1970:480-481). Detailed information concerning this process may be found in Shafer (1970).

Two uniface retouch flakes ( $10.5 \%$ of the category) were produced by the lateral edge striking method. Flakes removed from unifaces by the second method, ventra1 blows, accounted for $26.3 \%$ (five of nineteen specimens) of the Mariposa sample. These flakes also tended to be smallest in overall size. Twelve uniface retouch flakes (63.2\% of the sample) were produced by striking the dorsal 
surface of the uniface near the edge. Dorsal struck uniface retouch flakes tended to be larger than the ventral struck flakes. Metric dimensions and provenience information are given below.

Uniface Retouch Flakes Metric Dimensions

Artifact

$$
\underset{(\mathrm{mm})}{\text { Length }}
$$

$$
\begin{array}{r}
\text { Width } \\
(\mathrm{mm})
\end{array}
$$

(mm)

Weight

Laterally Struck

$\begin{array}{lllll}A-21 & 30.6 & 10.55 & 7.0 & 1.5 \\ A-180 & 33.1 & 10.6 & 8.2 & 5.0\end{array}$

Ventrally Struck

\begin{tabular}{|c|c|c|c|c|}
\hline$A-167$ & 17.7 & 16.0 & 8.7 & 4.0 \\
\hline$A=168$ & 19.5 & 12.1 & 5.0 & 2.8 \\
\hline$A-176$ & 17.5 & 15.4 & 5.0 & 2.8 \\
\hline$A=184$ & 19.6 & 16.1 & 4.6 & 2.8 \\
\hline$A-186$ & 21.2 & 13.0 & 7.7 & 3.5 \\
\hline$A=187$ & 16.5 & 10.6 & 2.9 & 2.2 \\
\hline$A=188$ & 21.4 & 20.9 & 5.7 & 3.6 \\
\hline$A-189$ & 19.5 & 14.0 & 4.5 & -- \\
\hline
\end{tabular}

$\begin{array}{lllll}\text { A-174 } & 20.0 & 18.0 & 7.9 & 4.3 \\ \text { A-175 } & 20.6 & 15.5 & 4.4 & 3.4 \\ \text { A-177 } & 15.7 & 10.5 & 3.7 & 2.6 \\ \text { A-178 } & 14.6 & 12.2 & 3.2 & 2.4 \\ \text { A-179 } & 17.1 & 14.6 & 6.3 & 2.8\end{array}$

Dorsally Struck

Uniface Retouch Flakes Provenience

Artifact

Level

Unit

Quadrant

Laterally Struck
A-21
$6(25-30 \mathrm{~cm})$
N38/W2
NW
A-180
$4(15-20 \mathrm{~cm})$
N40
NE 


\begin{tabular}{|c|c|c|c|}
\hline Artifact & Level & Unit & Quadrant \\
\hline \multicolumn{4}{|c|}{ Ventrally Struck } \\
\hline$A-174$ & $1(0-20 \mathrm{~cm})$ & Test 3 & Area B \\
\hline$A-175$ & $5(20-25 \mathrm{~cm})$ & N42/W2 & SW \\
\hline$A-177$ & $2(5-10 \mathrm{~cm})$ & N42 & NE \\
\hline$A-178$ & $2(5-10 \mathrm{~cm})$ & N42 & NW \\
\hline A-179 & $2(5-10 \mathrm{~cm})$ & N42 & NW \\
\hline \multicolumn{4}{|c|}{ Dorsally Struck } \\
\hline$A-167$ & $4(15-20 \mathrm{~cm})$ & N44 & SW \\
\hline$A-168$ & $2(5-10 \mathrm{~cm})$ & N38/E2 & SW \\
\hline$A-176$ & $1(0-5 \mathrm{~cm})$ & N40/E2 & SE \\
\hline$A-184$ & $3(10-15 \mathrm{~cm})$ & N42 & SW \\
\hline$A-186$ & $1(0-5 \mathrm{~cm})$ & N42 & $N E$ \\
\hline$A-187$ & $5(20-25 \mathrm{~cm})$ & N42 & NE \\
\hline$A-188$ & $3(10-15 \mathrm{~cm})$ & N40/E2 & NW \\
\hline$A=189$ & $2(5-10 \mathrm{~cm})$ & N38/W2 & SW \\
\hline$-\cdots$ & $\ldots$ & -- & -- \\
\hline
\end{tabular}

Over half $(52.6 \%, 10$ of 19) of the uniface retouch specimens occur in the upper three levels of Mariposa. More significantly, a distinct clustering of ventrally struck uniface retouch flakes was found in the second level of excavation unit N42. This appears to be a locus for uniface rejuvenation activities, i.e., where worn or dull steep uniface bevels were removed to prepare more efficient tools (Shafer 1970).

\section{Burned Rock}

A11 examples of burned rock were collected during the 1974 excavations. This material was recorded and cataloged for each quadrant of every excavation unit. The majority (numerically) of the burned material was sandstone, but occasional specimens of quartzite and flint were recovered. Both the number of burned rock recorded in each excavation unit and the total weight (in grams) of the collected burned rock (again in each excavation unit) are presented in Tables 7 and 8 , respectively. Combining the information provided by these two tables gives the number of grams per burned rock for each excavation unit level (Table 7). An "average" burned rock weight for each level is also indicated in Table 8. Because no other quantitative information was undertaken in the burned rock analysis, no idea of the variability in the burned rocks can be presented. Tables 7 and 8 provide an initial view of the average variability 
between the first three excavated levels and present the variability of quantity and weight of recovered burned rocks per level between excavation units.

Examination of Table 7 shows that the number of burned rocks is highly variable both between excavation units in particular levels and between levels. Levels six through twelve are not discussed since less than five excavation units penetrated these levels. Levels two and five showed the highest number of burned rocks per level. The third level contained the lowest number of burned rocks. These data may indicate the levels (two and five) most heavily used or occupied at Mariposa, if one assumes that scattered burned rocks reflect intensity of occupation. Two separate occupations may have also occurred. Within the first five excavated levels at Mariposa, some excavation units consistently provided either high or low burned rock counts. N44, through the initial five levels, contained uniformly low numbers of burned rocks. High burned rock counts are observed in excavation units $N 42$ and $N 42 / W 2$. This pattern is also seen in Table 8, where the data are weight rather than number of burned rocks. Again, N44 has low values through the first five levels, but here N38/W2 and N40 contained the highest weights (instead of $N 42$ and N42/W2). Turning to Table 9 , one gains an idea of the relative size (here measured as average grams per rock) of the burned rock recovered. Level three shows the largest values, with levels four and five (11.6 grams/rock and 12.0 grams/rock, respectively) also containing large values. Inspection of the individual excavation units indicates a different pattern from the previous tables. Low values, probably indicative of "smaller" burned rocks, are obtained consistently from two excavation units-N42 and N42/W2. Highest values are seen in N40 and N38/E2, while the overal1 level itself averaged the lowest values compared to the remaining upper four levels.

Conclusions from the above burned rock information must remain tenuous. While nine excavation units were cleared to three levels (15 cm below the surface), only five were excavated to five levels and two to level six. Excavation unit N38/W2 was the only unit which was excavated greater than six levels. Consequently, valid inferences concerning the significance of variability between levels and between excavation units within levels can only be proposed for those units excavated to five levels. If one assumes that number of burned rocks is an indicator of site usage, then this evidence from Mariposa points to maximum occupational activity at level two and level five. This same possibility arises when one considers the weight of burned rock recovered. While many areas revealed strong indicators of hearth activity, in one specific area-excavation unit N44--unusually low values were recorded from the first two tables. However, the significance of this focus of low activity is not clear. This uncertainty is compounded further when one considers the third table (Table 9). Here the low values of number of burned rocks and weight of burned rock are combined and indicate relatively fewer but larger burned rocks.

Overal1, the recording of burned rock recovered from the 1974 excavations at Mariposa reflects that the density of burned rocks is greatest in two levels, when one considers the number and weight of burned rocks. One unit which recorded low amounts of number and weight of burned rocks at the same time had relatively large pieces of burned rock within it. 
TABLE 7

NUMBER OF BURNED ROCKS RECOVERED

\begin{tabular}{|c|c|c|c|c|c|c|c|c|c|c|c|c|}
\hline & & N38/W2 & $\mathrm{N} 40$ & $\mathrm{~N} 42$ & N42/W2 & N44 & N42/E2 & N40/E2 & N38/E2 & N38 & Average & Total \\
\hline Leve] & 1 & 103 & 99 & 166 & 96 & 106 & 63 & 115 & 192 & 125 & 118.3 & 1065 \\
\hline Level & 2 & 237 & 156 & 193 & 172 & 82 & 186 & 167 & 146 & 271 & 178.9 & 1610 \\
\hline Level & 3 & 107 & 82 & 147 & 148 & 29 & 97 & 103 & 71 & 213 & 110.8 & 997 \\
\hline Level & 4 & 121 & 184 & 203 & 248 & 39 & --- &.- & $-\cdots$ & --- & 159.0 & 795 \\
\hline Leve1 & 5 & 175 & 224 & 249 & 315 & 79 & -- & -.. & -- & -- & 208.4 & 1042 \\
\hline Level & 6 & 161 & --- & 49 & -- & -- & -- & -- & -- & --- & 105.0 & 210 \\
\hline Level & 7 & 145 & --- & --- & --- & --- & $\cdots$ & $\cdots$ & -- & -- & 145.0 & 145 \\
\hline Level & 8 & 146 & --- & -- & --- & --- & --- & $\cdots$ & -- & --- & 146.0 & 146 \\
\hline Level & 9 & 20 & --- & -- & --- & -- & --- & -- & --- & --- & 20.0 & 20 \\
\hline Leve 1 & 10 & 48 & --- &.-- & --- & 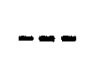 & -.- & -- & $\ldots$ & --- & 48.0 & 48 \\
\hline Level 1 & 11 & 161 & --- & -.- & -- & --- & -- & --- & -- & --- & 161.0 & 161 \\
\hline Level 1 & 12 & 44 & --- & -- & --- & --- & --- & -- & -- & --- & 44.0 & 44 \\
\hline TOTAL & & 1468 & 745 & 1007 & 979 & 335 & 346 & 385 & 409 & 609 & 122.0 & 6283 \\
\hline
\end{tabular}


GRAMS OF BURNED ROCK RECOVERED

\begin{tabular}{|c|c|c|c|c|c|c|c|c|c|c|c|c|}
\hline & & N38/W2 & N40 & N42 & N42/W2 & N44 & N42/E2 & N40/E2 & N38/E2 & N38 & Average & Total \\
\hline Leve1 & 1 & 789.6 & $1,561.3$ & 1308.2 & 371.5 & 610.8 & 536.0 & 787.9 & 2518.0 & 938.1 & 1046.8 & $9,421.4$ \\
\hline Leve1 & 2 & $2,608.0$ & $1,800.8$ & 1402.3 & 1545.5 & 505.9 & 1630.8 & 2638.7 & 1675.1 & 3241.4 & 1894.3 & $17,048.5$ \\
\hline Leve1 & 3 & $2,819.2$ & $1,217.6$ & 820.8 & 1585.2 & 544.2 & 1339.4 & 2286.8 & 1278.8 & 2949.7 & 1649.1 & $14,841.7$ \\
\hline Level & 4 & $1,644.9$ & $2,625.6$ & 1623.7 & 2287.7 & 509.9 & --- & --- & --- & --- & 1738.4 & $8,691.8$ \\
\hline Leve1 & 5 & $3,507.4$ & $3,237.1$ & 1338.4 & 2954.7 & 838.1 & --- & --- & --- & --- & 2375.1 & $11,875.7$ \\
\hline Leve1 & 6 & $2,146.0$ & --- & 115.2 & --- & --- & --- & --- & --- & --- & 1130.6 & $2,261.2$ \\
\hline Leve 1 & 7 & $3,257.3$ & --- & --- & -- & -- & --- & -- & -- & -- & 3257.3 & $3,257.3$ \\
\hline Leve] & 8 & $2,287.0$ & -- & -- & --- & -- & --- & --- & --- & --- & 2287.0 & $2,287.0$ \\
\hline Level & 9 & 630.7 & --- & --- & --- & --- & --- & --- & --- & -- & 630.7 & 630.7 \\
\hline Level & 10 & $1,071.2$ & --- & --- & --- & --- & --- & --- & --- & --- & 1071.2 & $1,071.2$ \\
\hline Leve1 & 11 & $4,850.8$ & --- & --- & --- & --- & --- & --- & -- & --- & 4850.8 & $4,850.8$ \\
\hline Leve1 & 12 & $1,213.5$ & -- & --- & --- & -- & --- & -- & -- & --- & 1213.5 & $1,213.5$ \\
\hline
\end{tabular}

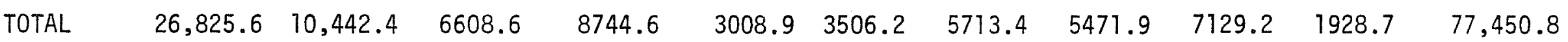


TABLE 9

GRAMS PER BURNED ROCK RECOVERED

\begin{tabular}{|c|c|c|c|c|c|c|c|c|c|c|c|c|}
\hline & & N38/W2 & $N 40$ & $\mathrm{~N} 42$ & N42/W2 & N44 & N42/E2 & N40/E2 & N38/E2 & N38 & Average & Total \\
\hline Level & 1 & 7.7 & 15.8 & 7.9 & 3.9 & 5.8 & 8.5 & 6.9 & 13.1 & 7.5 & 8.6 & 77.1 \\
\hline Leve1 & 2 & 11.0 & 11.5 & 7.3 & 9.0 & 6.2 & 8.8 & 15.8 & 11.5 & 12.0 & 10.3 & 93.1 \\
\hline Level & 3 & 26.3 & 14.8 & 5.8 & 10.7 & 18.8 & 13.8 & 22.2 & 18.0 & 13.8 & 16.0 & 144.2 \\
\hline Level & 4 & 13.6 & 14.3 & 8.0 & 9.2 & 13.0 & -- & -- & -- & -- & 11.6 & 58.1 \\
\hline Level & 5 & 20.0 & 14.5 & 5.4 & 9.4 & 10.6 & -- & -- & -- & -- & 12.0 & 59.9 \\
\hline Level & 6 & 13.3 & -- & 2.4 & - & -- & -- & -- & $-=$ & -- & 7.9 & 15.7 \\
\hline Level & 7 & 22.5 & -- & -- & -- & -- & -- & -- & -- & -- & 22.5 & 22.5 \\
\hline Level & 8 & 15.7 & -- & - & -- & -- & - & -- & -- & -- & 15.7 & 15.7 \\
\hline Leve1 & 9 & 31.5 & -- & -- & -- & - & -- & -- & -- & -- & 31.5 & 31.5 \\
\hline Leve1 & 10 & 22.3 & -- & -- & -- & -- & -- & -- & -- & -- & 22.3 & 22.3 \\
\hline Leve1 & 11 & 30.1 & -- & -- & -- & -- & -- & -- & -- & -- & 30.1 & 30.1 \\
\hline Level & 12 & 27.6 & -- & - & -- & -- & -- & -- & -- & -- & 27.6 & 27.6 \\
\hline
\end{tabular}




\section{Non-Lithic Material}

Faunal Remains

Almost all levels and units excavated at Mariposa contained bone materials. The vast majority of these were unidentifiable fragments. Levels one and two retained the lowest amount of bone, while higher numbers were recovered in the remaining levels, especially level three. Faunal remains are conspicuously absent from the first three levels of N40, N42/W2 and N40/E2.

Identifiable remains are limited to a calcaneus first and second phalange of the white-tailed deer (Odocoizeus virginianus). Four second phalanges and a third phalange (claw) attributed to a medium size mammal (coyote?) were all excavated from level five of $\mathrm{N40}$, in the northwest quadrant. A possible human lower lateral incision was also recorded from this provenience.

Identification of the faunal remains was aided by Gilbert (1973) and Bass (1971). Further statements concerning the bone remains at Mariposa are hindered by a general lack of identifiable material, although several bone fragments were burned to charred.

\section{Invertebrate Remains}

Remains of both freshwater and land gastropods, along with freshwater mussels, were recovered from excavation at Mariposa. Land gastropods from the site include Rabdotus sp. and Polygyra sp. Helisoma sp. Were the freshwater gastropods recovered from archaeological contexts at Mariposa, and Unio sp. represent the freshwater mussels present at the site. Statements concerning areal environments and possible aboriginal subsistence preferences are usually applied to the invertebrate fauna associated with archaeological sites (Suhm 1957; Clark 1973; Allen and Cheatum 1961; Hester 1975d; Hester and Hil1 1975a, 1975b), although other applications have been suggested (cf. Allen and Cheatum 1961).

Preferred habitats of the land gastropods recovered from Mariposa reflect present environmental conditions. Rabdotus sp. gastropods are at home in semiarid climates where brush exists and Polygyra sp. gastropods are commonly found in either sparsely wooded areas or deep woodlands (Allen and Cheatum 1961:294295). Permanent streams with vegetation, whose flow may be sluggish to rapid, are the preferred habitat of Helisoma sp. All these conditions--semi-arid climate, brush, wood-1ined creeks with permanent water--occur today at Mariposa, and the presence of these gastropods in archaeological contexts strongly suggests that the present environmental conditions at Mariposa have not radicaliy changed since Late Prehistoric occupations at the site. In addition to environmental statements, possible subsistence patterns have been postulated by various investigators to account for the large amounts of recovered gastropod material (Suhm 1957; Hester 1975d; Hester and Hi11 1975a, 1975b).

of the 5,182 gastropod specimens recovered from Mariposa, 4,983 were identified as Rabdotus sp. Rabdotus sp. accounts for $96 \%$ of the collected gastropods. Considering the large number of Rabdotus sp. specimens present and the fact that 
many of these were large adult specimens, it is highly probable that these gastropods represent a food item exploited by the Late Prehistoric occupants. Since practically none of the Rabdotus sp. shells were burned, extraction after boiling may have occurred (Hester and Hill 1975a). Ethnographic accounts referring to gastropod exploitation by Indian groups in southern Texas strengthen arguments that these invertebrates were an aboriginal food item in the past.

Examination of Table 10 points to the fact that maximum deposition of Rabdotus sp. occurred in levels two and three of Mariposa. Similar conclusions can be reached when considering all gastropod remains excavated at the site (see Table 11). Level one of Mariposa contains the lowest number of recovered gastropods. Some loci of intense Rabdotus sp. Utilization appear to center in excavation units N42, N40/E2 and N38 of levels two and three. In levels two and three, relatively small numbers of Rabdotus sp. specimens occur in N40 and N42/E2. Areas of Mariposa appear to have been differentially utilized with respect to the deposition of Rabdotus sp. The relatively small number of excavated Polygyra sp. and Helisoma sp. specimens does not allow safe inferences concerning their depositional characteristics. More information concerning possible spatial patterning of gastropods will be discussed in a later section. Recorded quantity and provenience of Rabdotus sp., Polygyra sp., and Helisoma $\mathrm{sp}$. gastropods are given in Tables 10,12 , and 13 respectively. Combined totals and associated provenience are presented in Table 11.

Freshwater mussels of the Unio sp. variety were also recorded at Mariposa. These bivalves represent a food source readily accessible in Turkey Creek. Unio sp. may have been extracted for food or as ornamental items (Hester and Hil1 1975b) by aboriginal populations. Only Unio sp. fragments, most of them quite sma11, were recovered from archaeological contexts. Table 14 illustrates Unio sp. fragment quantity and associated provenience at Mariposa.

of the 338 excavated fragments, $70 \%$ (235) were situated in levels two and three. Large numbers of fragments, possibly representative of Unio processing 1oci, are seen at N38/E2 in level one. Level two, which contained the largest level count, contained four excavation units exhibiting over 20 recovered fragments: N38/W2, N42/E2, N32/E2 and N38. Counts of 20 or more fragments in level three occur in N42/E3 and N40/E2. In leve1 four, N38/W2 represents a loci of possible Unio sp. utilization. No excavation unit illustrated high counts through all excavated levels; N42/E2 and N38/E2 tended to have high numbers of fragments in levels two and three. The fragments of Unio sp. indicate that loci of possible processing are randomiy scattered, temporally, with no preferred location being utilized during the aboriginal occupation(s). However, in level two, the Unio sp. fragments occur in greatest quantity in four contiguous excavation units forming the southern margin of the 1974 excavation area. Further excavations must be awaited before assessing the significance of this pattern.

\section{Features}

Four hearths and one burned rock concentration were recorded during the 1974 excavation and the 1975 testing of Mariposa. The burned rock concentration 
TABLE 10

RABDOTUS SP. SPECIMENS RECOVERED BY UNIT LEVEL

N38/W2 N40 N42 N42/W2 N44 N42/E2 N40/E2 N38/E2 N38 Average Total

\begin{tabular}{|c|c|c|c|c|c|c|c|c|c|c|c|c|}
\hline Leve 1 & 1 & 37 & 8 & 58 & 38 & 12 & 7 & 4 & 43 & 14 & 18.4 & 221 \\
\hline Level & 2 & 90 & 91 & 204 & 56 & 105 & 88 & 161 & 150 & 241 & 98.8 & 1186 \\
\hline Level & 3 & 206 & 24 & 179 & 102 & 54 & 71 & 181 & 135 & 237 & 99.1 & 1189 \\
\hline Level & 4 & 179 & 96 & 236 & 162 & 133 & - & -- & -- & -- & 161.2 & 806 \\
\hline Level & 5 & 204 & 186 & 325 & 155 & 106 & -- & -- & -- & -- & 195.2 & 976 \\
\hline Level & 6 & 113 & -- & 46 & -- & -- & -- & -- & -- & -- & 79.5 & 159 \\
\hline Level & 7 & 118 & -- & -- & -- & -- & -- & -- & -- & -- & 118.0 & 118 \\
\hline Leve1 & 8 & 137 & -- & -- & -- & -- & $-\infty$ & -- & -- & -- & 137.0 & 137 \\
\hline Leve1 & 9 & 54 & -- & -- & -- & -- & -- & -- & -- & -- & 54.0 & 54 \\
\hline Level & 10 & 32 & -- & -- & -- & -- & -- & -- & -- & -- & 32.0 & 32 \\
\hline Level & 11 & 60 & -- & -- & -- & -- & -- & -- & -- & -- & 60.0 & 60 \\
\hline Level & 12 & 45 & -- & -- & -- & -- & -- & -- & -- & -- & 45.0 & 45 \\
\hline
\end{tabular}

\begin{tabular}{llllllllllll}
\hline TOTAL & 1275 & 405 & 1048 & 513 & 410 & 166 & 346 & 328 & 492 & 71.5 & 4983
\end{tabular}


TABLE 11

LAND GASTROPODS RECOVERED BY UNIT LEVEL

N38/W2 N40 N42 N42/W2 N44 N42/E2 N40/E2 N38/E2 N38 Average Tota1

\begin{tabular}{lrrrrrrrrrrrr} 
Leve1 & 1 & 39 & 8 & 66 & 39 & 14 & 7 & 4 & 44 & 15 & 26.2 & 236 \\
Leve1 & 2 & 93 & 96 & 221 & 56 & 108 & 95 & 163 & 162 & 261 & 139.4 & 1255 \\
Leve1 & 3 & 212 & 24 & 189 & 103 & 54 & 77 & 191 & 141 & 242 & 137.0 & 1233 \\
Leve1 & 4 & 182 & 96 & 247 & 162 & 133 & -- & -- & -- & -- & 164.0 & 820 \\
Leve1 & 5 & 208 & 186 & 338 & 163 & 106 & -- & -- & -- & -- & 200.2 & 1001 \\
Leve1 & 6 & 114 & -- & 46 & -- & -- & -- & -- & -- & -- & 80.0 & 160 \\
Leve1 & 7 & 120 & -- & -- & -- & -- & -- & -- & -- & -- & 120.0 & 120 \\
Leve1 & 8 & 137 & -- & -- & -- & -- & -- & -- & -- & -- & 137.0 & 137 \\
Leve1 & 9 & 59 & -- & -- & -- & -- & -- & -- & -- & -- & 59.0 & 59 \\
Leve1 10 & 38 & -- & -- & -- & -- & -- & -- & -- & -- & 38.0 & 38 \\
Leve1 11 & 71 & -- & -- & -- & -- & -- & -- & -- & -- & 71.0 & 71 \\
Leve1 & 12 & 52 & -- & -- & -- & -- & -- & -- & -- & -- & 52.0 & 52 \\
\hline
\end{tabular}

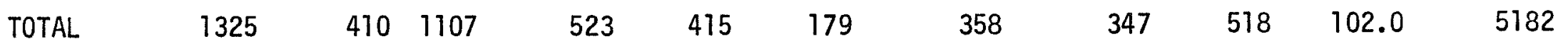


TABLE 12

POLYGYRA SP. SPECIMENS RECOVERED BY UNIT LEVEL

N38/W2 N40 N42 N42/W2 N44 N42/E2 N40/E2 N38/E2 N38 Average Total

\begin{tabular}{|c|c|c|c|c|c|c|c|c|c|c|c|c|}
\hline Level & 1 & 1 & -- & 1 & -- & -- & - & -- & -- & -- & 0.2 & 2 \\
\hline Level & 2 & 1 & 3 & -- & -- & 1 & 3 & 1 & 6 & 11 & 2.9 & 26 \\
\hline Level & 3 & 2 & -- & 2 & -- & -- & 2 & 4 & 5 & 2 & 1.9 & 17 \\
\hline Leve1 & 4 & 1 & -- & 9 & -- & -- & -- & -- & -- & -- & 2.0 & 10 \\
\hline Level & 5 & 2 & -- & 12 & 7 & -- & -- & -- & -- & -- & 4.2 & 21 \\
\hline Level & 6 & -- & -- & -- & -- & -- & -- & -- & -- & -- & -- & -- \\
\hline Level & 7 & 1 & -- & -- & -- & -- & -- & -- & -- & -- & 1.0 & 1 \\
\hline Level & 8 & -- & -- & -- & -- & -- & -- & -- & -- & -- & -- & -- \\
\hline Level & 9 & 2 & -- & -- & -- & -- & -- & -- & -- & -- & 2.0 & 2 \\
\hline Level & 10 & 6 & -- & -- & -- & -- & -- & -- & -- & -- & 6.0 & 6 \\
\hline Level & 11 & 11 & -- & -- & -- & -- & $=-$ & -- & -- & -- & 11.0 & 11 \\
\hline Level & 12 & 7 & -- & -- & -- & -- & -- & -- & -- & -- & 7.0 & 7 \\
\hline
\end{tabular}


TABLE 13

HELISOMA SP. SPECIMENS RECOVERED BY UNIT LEVEL

N38/W2 N40 N42 N42/W2 N44 N42/E2 N40/E2 N38/E2 N38 Average Total

\begin{tabular}{|c|c|c|c|c|c|c|c|c|c|c|c|c|}
\hline Level & 1 & 1 & -- & 7 & 1 & 2 & -- & -- & 1 & 1 & 1.4 & 13 \\
\hline Level & 2 & 2 & 2 & 17 & -- & 2 & 4 & 1 & 6 & 9 & 4.8 & 43 \\
\hline Level & 3 & 4 & -- & 8 & 1 & -- & 4 & 6 & 1 & 3 & 3.0 & 27 \\
\hline Level & 4 & 2 & -- & 2 & -- & -- & -- & -- & -- & -- & 0.8 & 4 \\
\hline Level & 5 & -- & -- & 1 & 1 & -- & -- & -- & -- & -- & 0.4 & 2 \\
\hline Level & 6 & 1 & -- & -- & -- & -- & -- & -- & -- & -- & 0.5 & 1 \\
\hline Level & 7 & 1 & -- & -- & -- & -- & -- & -- & -- & -- & 1.0 & 1 \\
\hline Level & 8 & -- & -- & -- & -- & -- & -- & -- & -- & -- & -- & -- \\
\hline Level & 9 & 3 & -- & -- & -- & -- & -- & -- & -- & -- & 3.0 & 3 \\
\hline Level & & -- & -- & -- & -- & -- & -- & -- & -- & -- & -- & -- \\
\hline Level & & -- & -- & -- & -- & -- & -- & -- & -- & -- & -- & -- \\
\hline Level & 12 & -- & -- & -- & -- & -- & -- & -- & -- & -- & -- & -- \\
\hline
\end{tabular}


TABLE 14

UNIO SP. FRAGMENTS RECOVERED BY UNIT LEVEL

N38/W2 N40 N42 N42/W2 N44 N42/E2 N40/E2 N38/E2 N38 Average Tota1

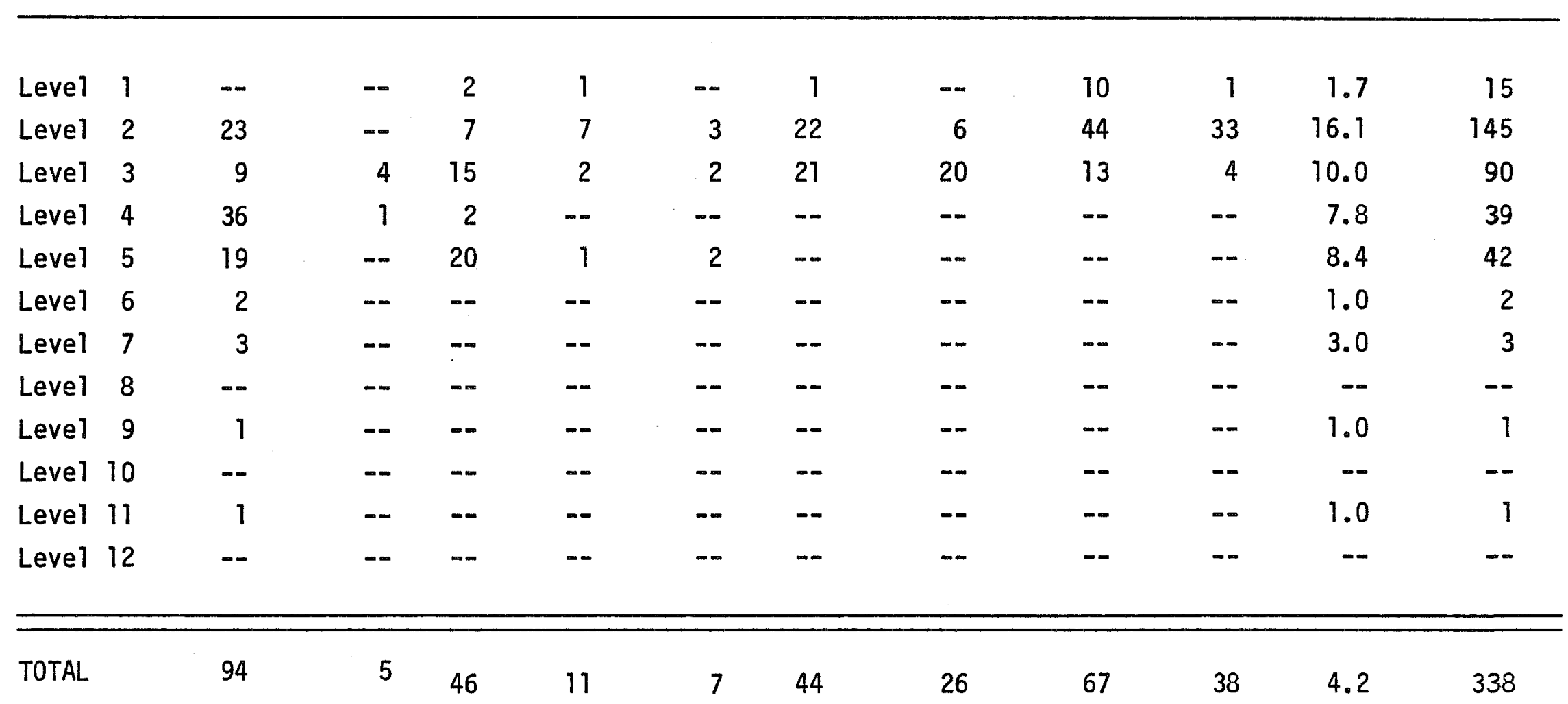


was excavated from the first level $(0-5 \mathrm{~cm}$ below the surface) of unit $\mathrm{N} 42$. Lying in the southeast quadrant of the excavation unit, this small concentration of burned rock contained four snails associated with a few flakes and a baked clay lump. No associated charcoal was recorded (see Montgomery, Moffat and Richie 1975).

Level two (5-10 $\mathrm{cm}$ below the surface) contained two hearths in two excavation units. In N38/E2, a small ovate hearth with burned spall fragments in situ was observed in the southwest quadrant of the unit (Plate 3). A more substantial hearth containing significant quantities of charcoal was recorded in the southwest quadrant of N42/E2, also in level two.

Test 4 in the 1974 investigations at Mariposa encountered a probable hearth situated $50.5 \mathrm{~cm}$ beneath the present ground surface. A charcoal sample was collected from this hearth, and a sketch map prepared. Three large hearth stones (burned) were situated in a roughly $25 \times 35 \mathrm{~cm}$ concentration of charcoal. A Tortugas point (Plate 3 ) was recovered from the overlying level of Test 4.

In 1975, Test 5 at Mariposa revealed a large hearth $60 \mathrm{~cm}$ deep. Charcoal, burned rock, gastropod shells, flint flakes and nine incised burned rocks were obtained once the hearth was cleared. Information gathered from this hearth and test has been prepared (Montgomery, Moffat and Richie 1975).

The features recorded above are distinct locations of prehistoric hearth activity, which are separate from the scattered burned rocks found in every excavation unit at the site. While the scattered burned rocks recovered from Mariposa are indicators of past occupational activities, the features allow one to make more concrete statements concerning the nature of such activities. At Mariposa, the features recorded in the upper two levels of the site are sma11, tightly clustered hearth foci. Charcoal was recovered from one of these loci. An ovate outline is also seen in one of the hearths. In contrast, the two deepest features, assumed to be earlier (temporally) quite large concentrations of burned rock and charcoal, were recorded. Based on the significantly higher concentration of charcoal in one of these hearths and the higher density of burned rock seen in the second hearth, possible differences in function/usage of the features may be postulated.

The earlier features may represent hearths which were possibly maintained for long periods of time, while the smaller hearths from the upper levels may indicate overnight camps and/or hearths maintained only a few times (maybe only once). Without further information, the above proposition cannot be verified. This should, however, be tested at other south Texas sites. 


\title{
VII. INTRASITE PATTERNS
}

\author{
Introduction
}

Careful field recording of artifacts, flint flakes, burned rocks, and faunal remains (snail shell concentrations, mussel shell concentrations, and faunal bone fragments) allows one to prepare horizontal "distribution" maps for each excavated level at Mariposa. Such maps, it was hoped, would generate significant cultural patterns as expressed by the depositional provenience of the archaeological specimens mentioned previously. During the 1974 field season, nine excavation units were opened to at least three levels. While several units were excavated much deeper, the upper three levels were chosen for analysis here. This was done to achieve the most reliable results, since patterns will probably be most evident in those levels containing the greatest amount of horizontally cleared spatial areas. It would not be logical to attempt analyses of artifact depositional patterns in a two-meter-square area as compared to a horizontal area encompassing 18 square meters.

The analysis attempted here must also rely on the recorded field data only. While a number of artifacts and faunal remains were recovered on the $1 / 4-i n c h$ screen during excavations (or retrieved during the subsequent cataloging process). their exact horizontal provenience cannot be reconstructed, except to a $2 \times 2$ meter square, five centimeters deep. Those artifacts and faunal materials located in situ were recorded on grid paper in a field notebook for each unit and leve1. All unit maps within a level were connected into a larger grid map which utilized all excavation units. These maps formed the basis for the maps presented as Maps 5 through 16. In order to express the data most clearly, maps of four categories--artifacts, flakes, burned rock, and faunal material--were individually prepared for each of the first three levels. Thus we have 12 maps to consider for analysis.

Visual interpretation of the distribution maps will be employed. Time did not permit more quantitative spatial analyses employing rigorous statistical tests of asssociation. Such analyses, which include nearest neighbor analysis, spatial analysis of variance, trend analysis, and others, should be employed in future and more specialized archaeological studies in the area (see Whallon 1973, 1974; Dacey 1973; Feder 1976). No attempt will be made to defend the visual interpretation when compared to the other types of spatial analyses. Such being the case, conclusions reached from this analys is must remain tentative until other methods are used on this kind of data.

The following analysis will proceed by individual levels. Within each level, distribution maps of artifacts, flakes, burned rock, and faunal material will be described. An overall statement of the level will provide a brief summary and possible correlations in depositional characteristics between the four types of data.

Level One

( $0-5$ centimeters below the surface)

Artifacts (Map 5)

Of the 12 artifacts recorded in the field, most are scattered somewhat evenly over the nine excavation units. Two concentrations of artifacts were 


\section{$412 V 83$}

Mariposa Site

Level I

ARTIFACTS

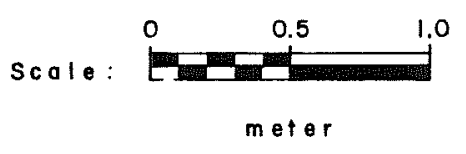

N44

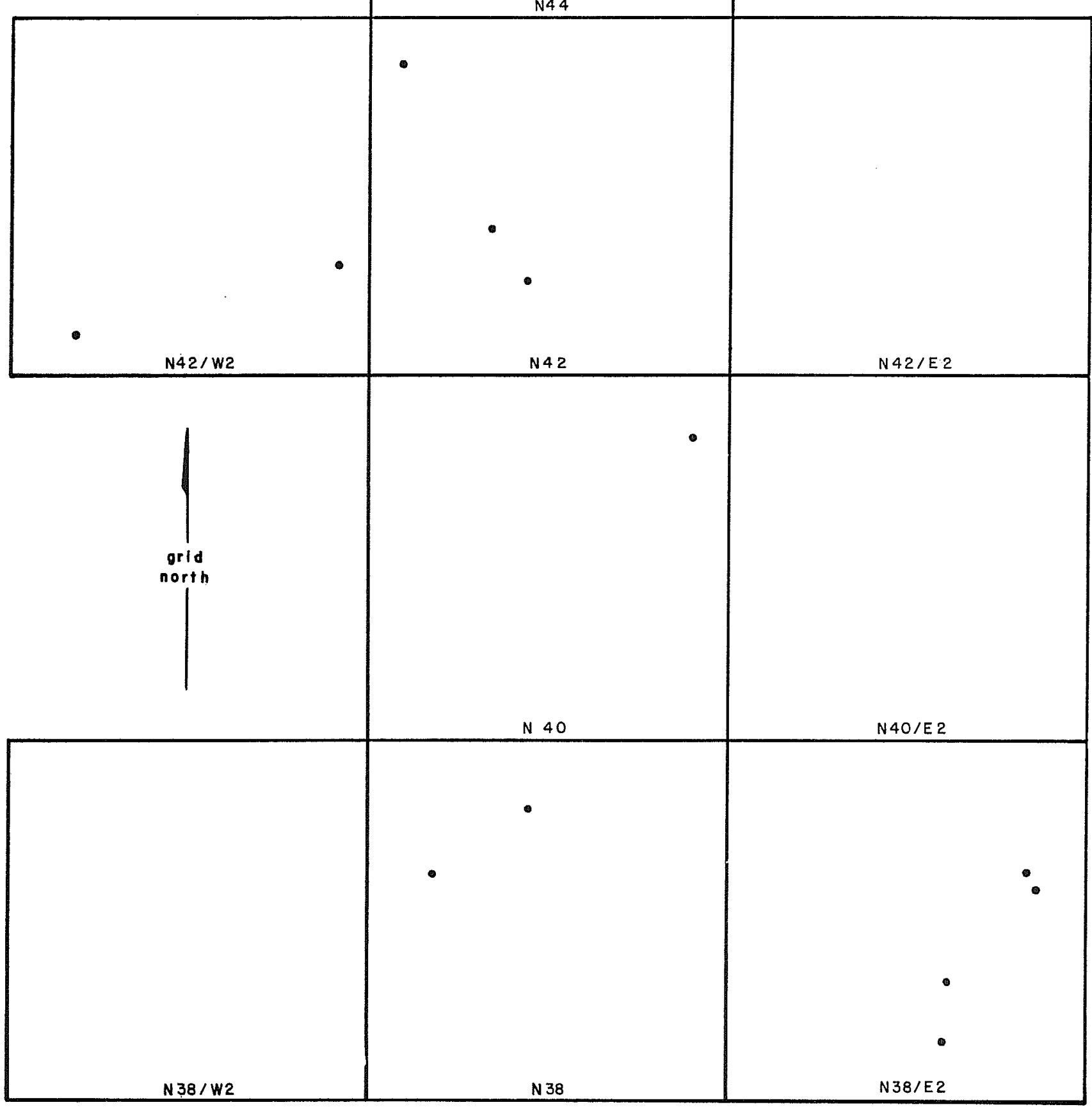

Map 5. Distribution Map of Artifacts, Level One. 
recognized. The first lies in the eastern half of N38/E2, where four artifacts were recovered. The western half of excavation unit $\mathrm{N} 42$ contained three artifacts, two of which were located in the southwest quadrant of the unit. Both clusters (or concentrations) were arrow points.

\section{Flakes (Map 6)}

Except for the southwest quadrant, unit N38/E2 appears to be a distinct cluster of flake material. The central portion of $\mathrm{N} 40$ also seems to be a locus of flake deposition. Less intensive clusters are noted in N42/W2, N42/E2, and the northeast quadrant of $\mathrm{N} 38 / \mathrm{W} 2$. A11 these areas were probably foci for 1 ithic manufacturing activities.

\section{Burned Rock (Map 7)}

Clusters of burned rock, probably indicative of past hearths, can be observed in almost all excavation units to some degree. Relatively concentrated remains are indicated in N38/E2, N38, and N42. Some clustering is possible in N40 and N42/W2. Smal1 discrete clusters, composed of five to eight burned rocks, appear in $N 42, N 42 / W 2$, and N38/W2. $N 44$ is removed from hearth activity, as is the southwest quadrant of N38/W2 and the northwest quadrant of N42/W2. Charcoal recovered from this level lies at the extreme northeastern corner of N38/E2 and is a likely indicator of a hearth in that unit.

\section{Faunal Remains (Map 8)}

Land gastropods are tightly clustered in N38/E2. Vertebrate and invertebrate remains are also concentrated together in the northern half of N42. Outside these areas, isolated bone fragments and scattered remains of all fauna occur, seemingly at random.

\section{Summary}

Excavation unit $N 44$ appears to be removed from 1 ithic manufacturing and subsistence activities. Burned rock and artifact concentrations are associated in N38/E2, N42, and N38. Flakes and burned rock occur together only in N38/E2. Co-occurrence of burned rock with faunal materials is seen in N38/E2 and N42. N38/E2 also represents the area where faunal remains occur with flake materials. Faunal material and artifacts occur together in N38/E2, N42, and N38. Lithic manufacturing materials and finished products (flakes and artifacts) co-occur only in N38/E2. Excavation unit N38/E2 seems to have contained a hearth where subsistence remains and 1 ithic activities both occurred together. Flakes tended to be removed from the depositional areas of artifacts, but they seem to occur more frequently with burned rock concentrations. Burned rock and faunal remains tended to be correlated as did artifacts and faunal remains. 
$41 Z V 83$

Mariposa Site

Level 1

FLINT FLAKES
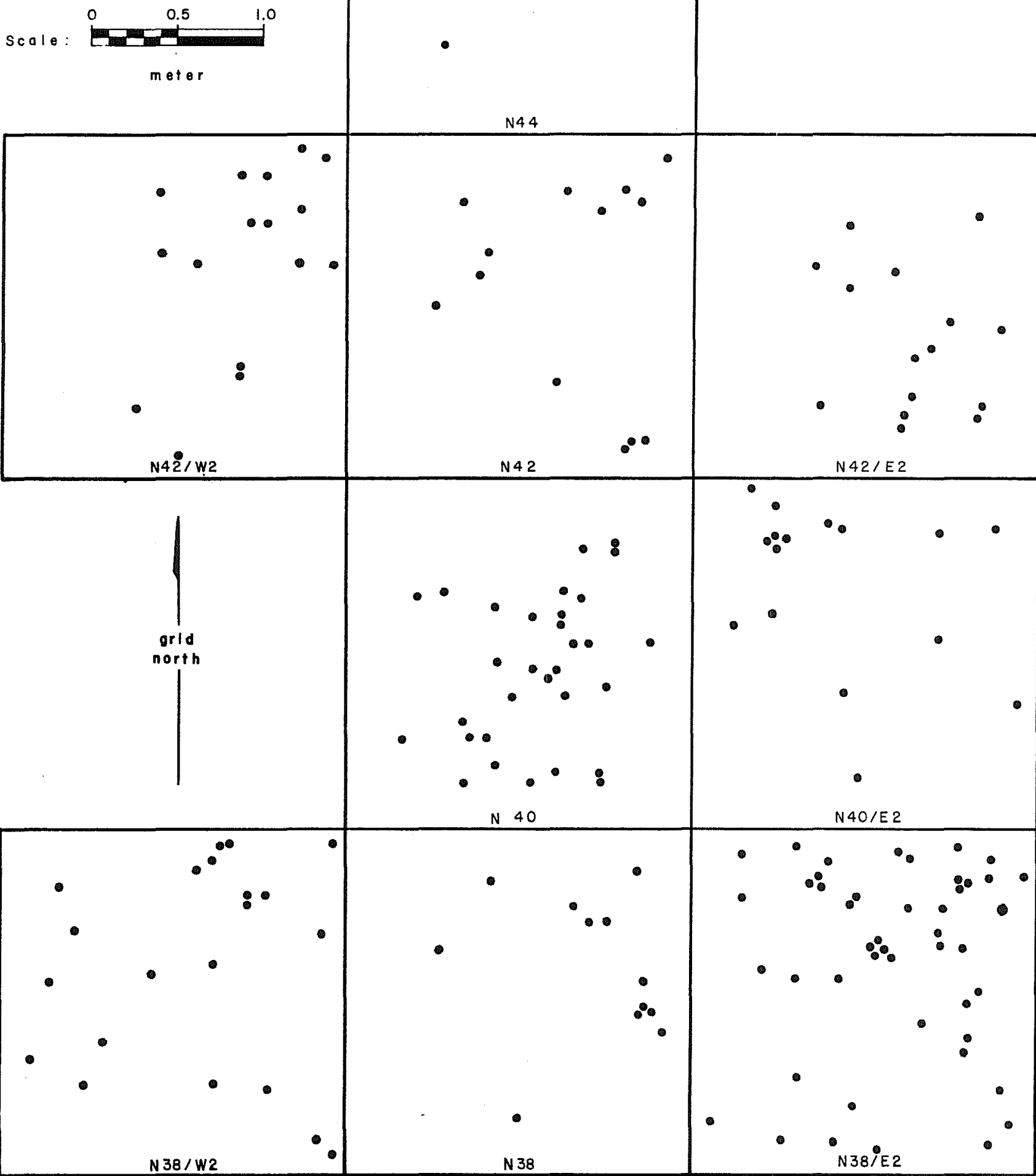

Map 6. Distribution Map of Flakes, Level One. 
$412 V 83$

Mariposa Site

Level I

BURNED ROCK
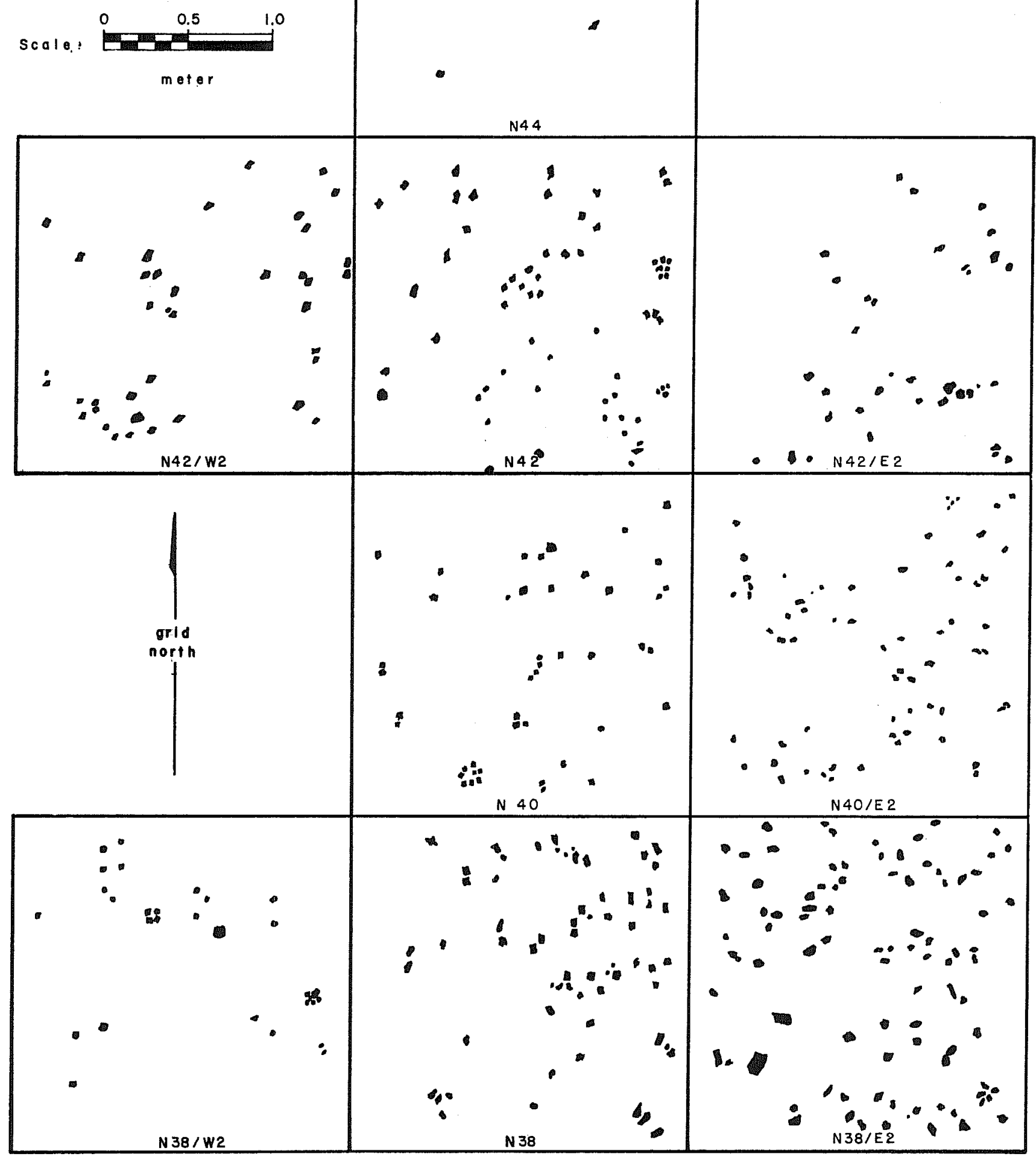

Map 7. Distribution of Burned Rock, Level One. 
116

$41 Z V 83$

Mariposa Site

Level I

FAUNAL REMAINS
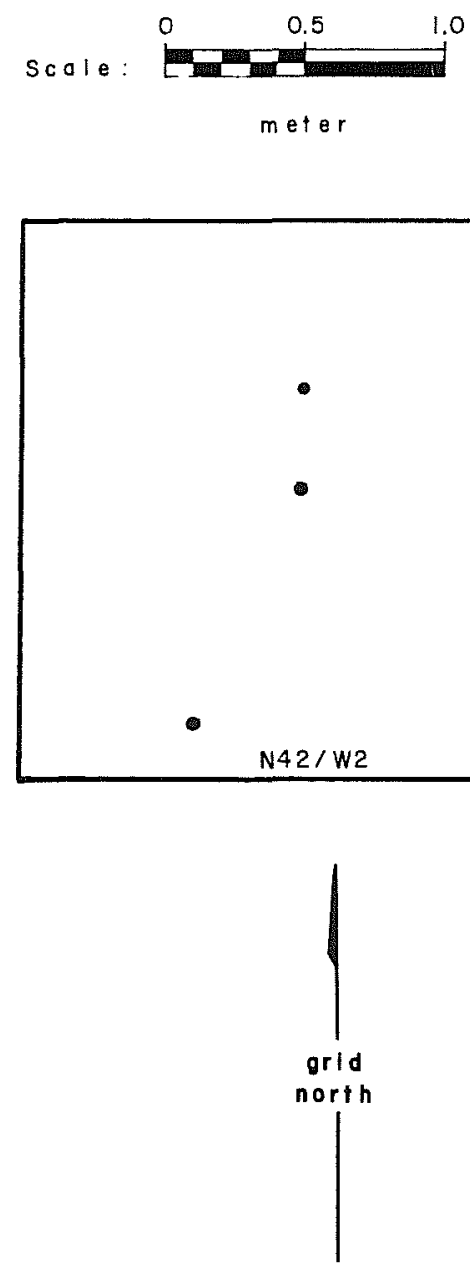

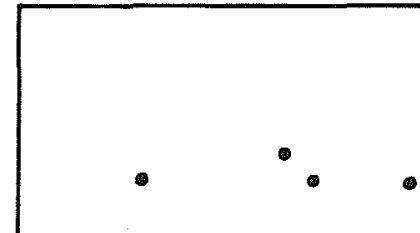

-

-

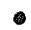

LEGEND

BONE

$\triangle$ MUSSEL SHELL

- snail shell
-

- N44

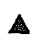

-

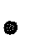

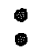

- N 42

N42/E2

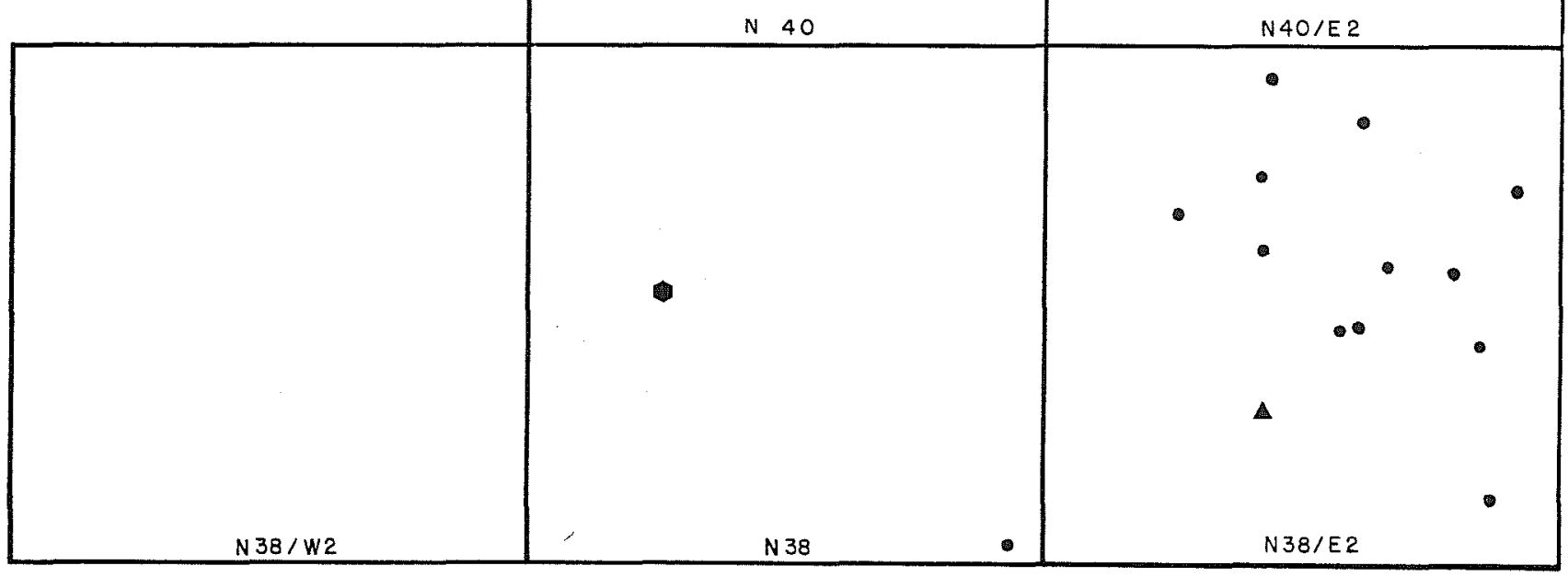

Map 8. Distribution Map of Faunal Remains, Level One. 


\author{
Level Two \\ (5-10 centimeters below the surface)
}

Artifacts (Map 9)

Significant concentrations of artifactual material are seen in the western half of the excavated area, especially in unit N42. A faint, semi-circular pattern may be located by combining excavation units N42/W2, N42, N40, and N38/W2. One artifact or less occurs in the remaining units.

\title{
Flakes (Map 10)
}

Towards the middle of the site and especially in excavation unit N40, flake concentrations occur. Smaller, more discrete clusters are preceived in N38, N38/E2, and N42/W2. N44 contained a very insignificant number of flakes.

\section{Burned Rock (Map 11)}

Depositional patterns for burned rock were very strong in this level. Major concentrations occur in units N42/E2, N42/W2, N40/E2, N38, and the western half of N38/E2. Possible clustering (hearth?) on a smaller scale is seen in N38/W2. Excavation unit $\mathrm{N40}$, which contained a significant flake concentration, revealed only a few, randomly scattered burned rocks. The idea that the major concentrations noted in N42/E2 and N38/E2 are possible hearths is reinforced by the presence of charcoal. Charcoal was associated with only the largest examples of burned rock. A minimum of two hearths is suggested by the evidence, but more hearths could have functioned in the other significant burned rock remains noted for this level.

\section{Faunal Remains (Map 12)}

Strong clustering is suggested by inspecting the recorded faunal remains for this level. Snail remains are tightly clustered in N40/E2, the southeast quadrant of N38, and in N40. Four distinct clusters are evident in N40, with the two largest clusters occurring in that unit's northwest quadrant. The 16 squaremeter area encompassed by excavation units N40, N40/E2, N38 and N38/E2 contains most of the snail shell concentrations recorded from level 2. A snail processing activity area can be seen for this general area (four contiguous excavation units or 16 square-meters), with discrete individual areas being pinpointed by the actual clusters themselves.

Mussel shell remains are associated with snail shells in N38/E2. A major depositional area for mussel shell is indicated for excavation units N42 and N42/E2. This area appears to be a river mussel processing area, the area where the inedible shells were deposited after excavation of the animals for food. In $\mathrm{N} 38$, a small cluster of bone fragments, snail shel1s, and mussel shells is indicated, probably indicating that all these subsistence items can be processed together, as well as individually. 
118

412 V 83

Mariposa Site

Level 2

ARTIFACTS

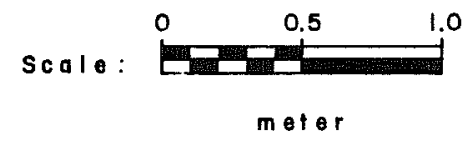

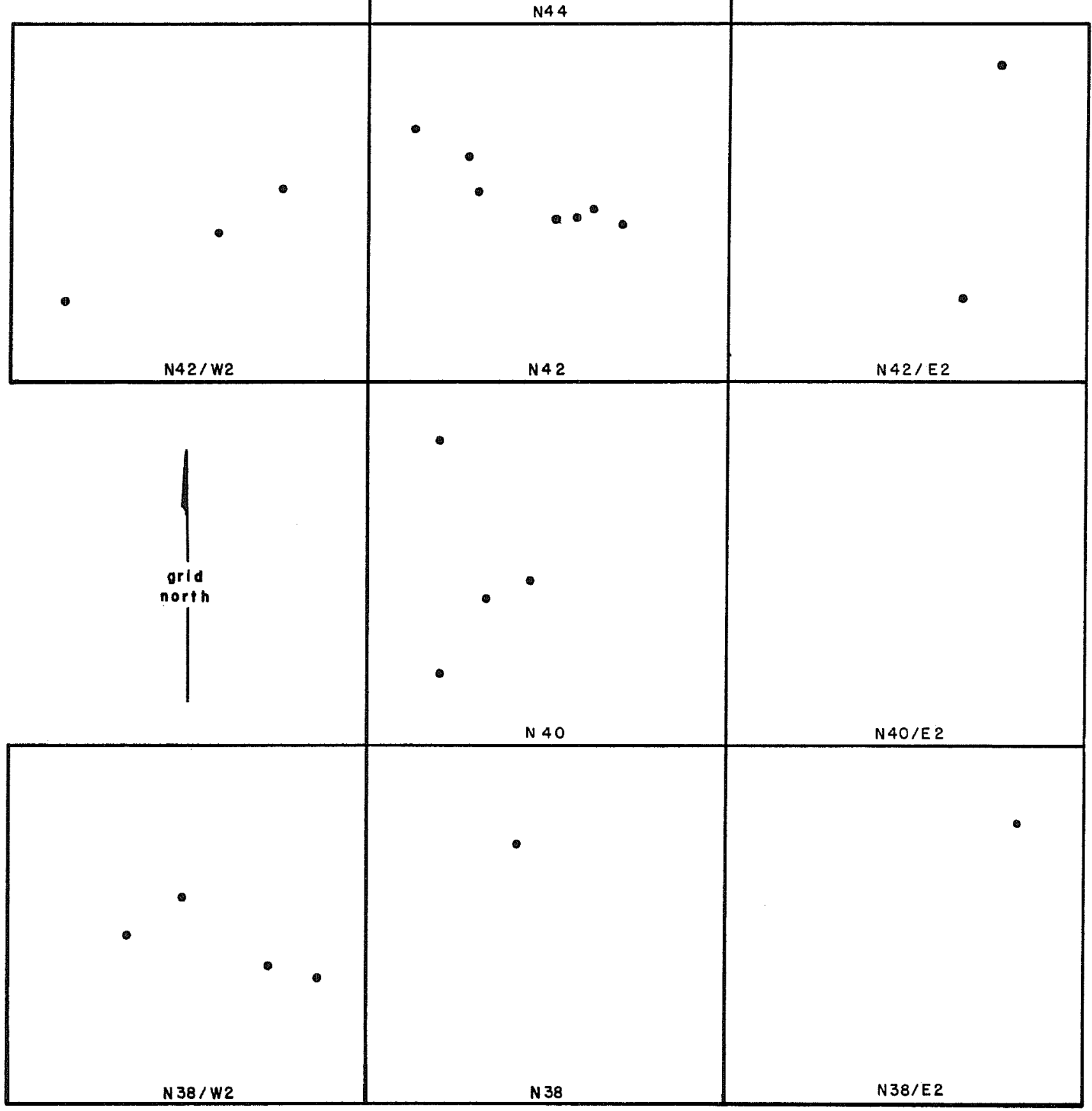

Map 9. Distribution Map of Artifacts, Level Two. 


\section{ZV 83}

Mariposa Site

Level 2

FLINT FLAKES

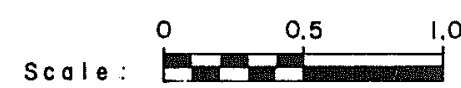

meter
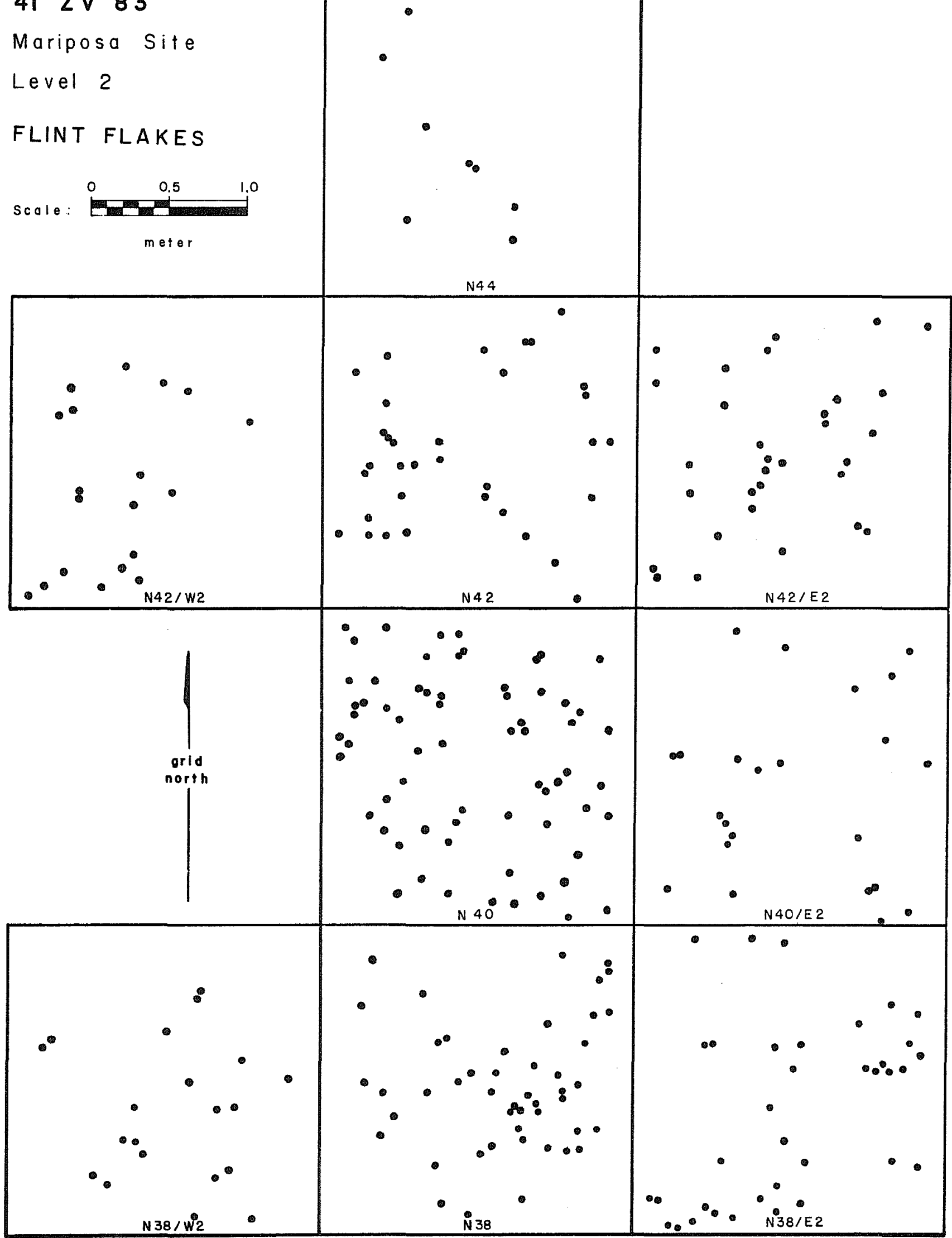

Map 10. Distribution Map of Flakes, Level Two. 


\section{$412 \vee 83$}

Mariposa Site

L.vel 2

BURNED ROCK

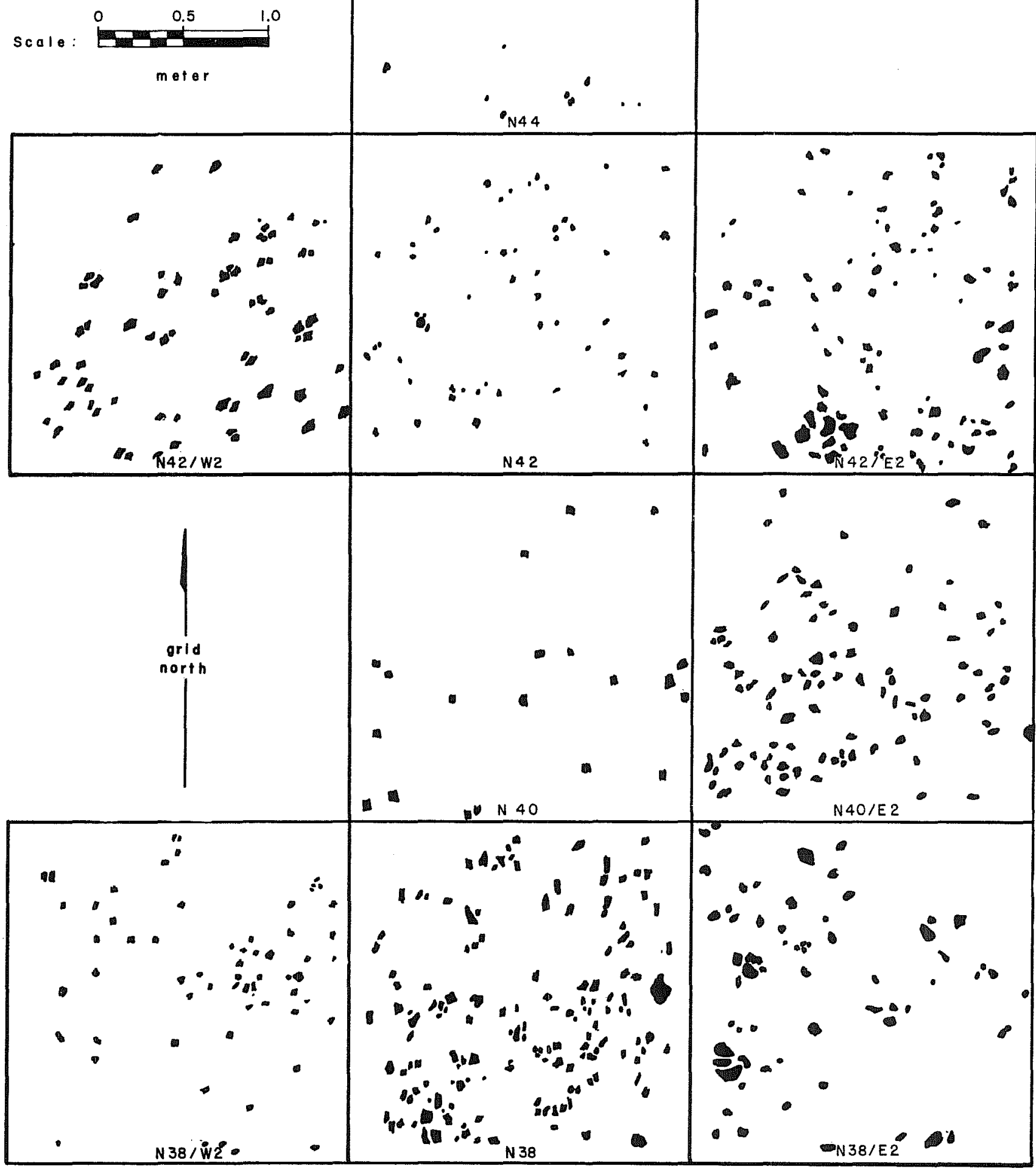

Map 11. Distribution Map of Burned Rock, Level Two. 
121

41 IV 83

Mariposa Site

Level 2

FAUNAL REMAINS
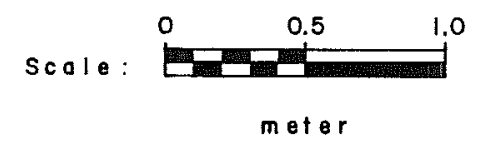

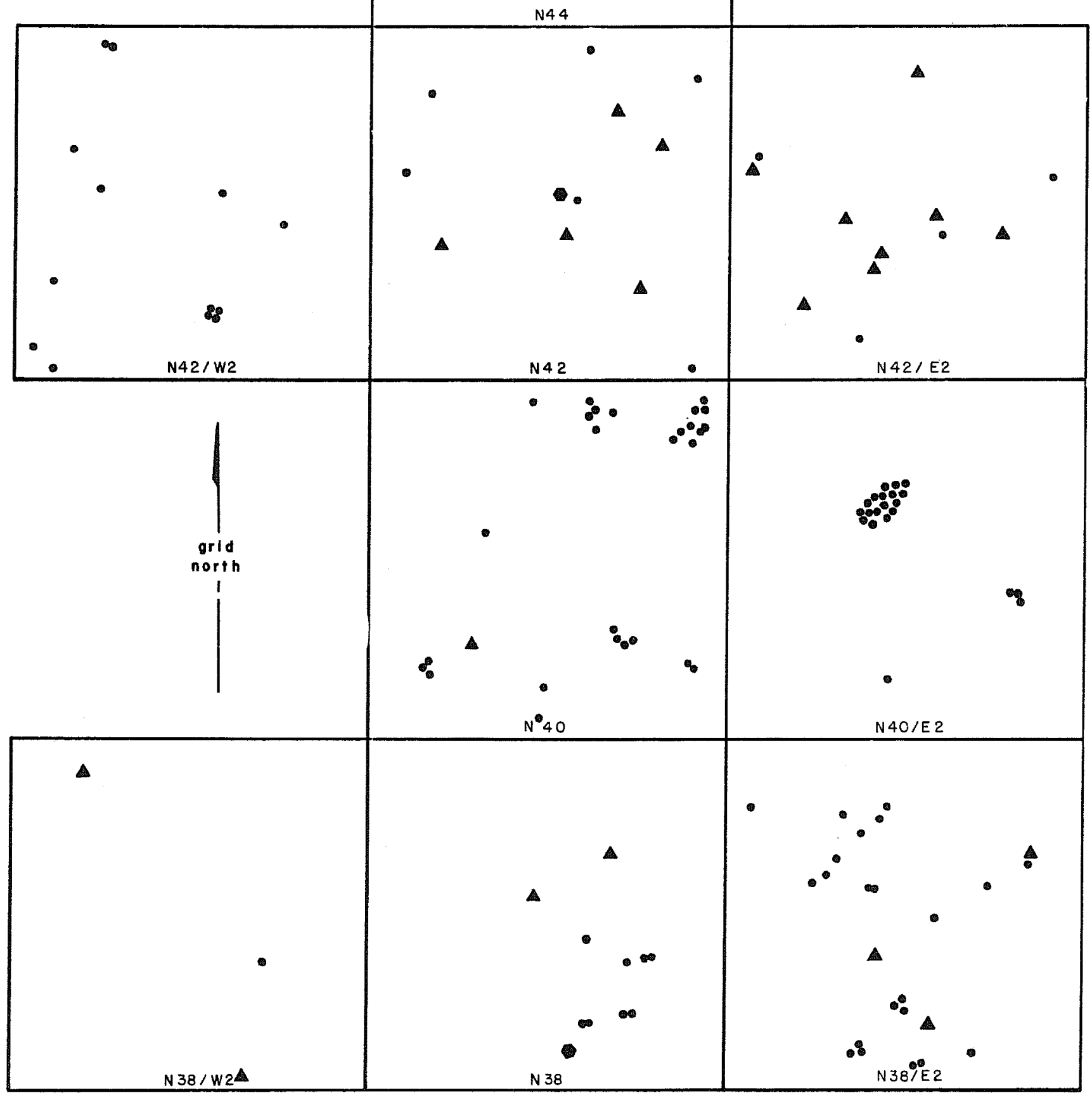

Map 12. Distribution Map of Faunal Remains, Level Two. 


\section{Summary}

Burned rock concentrations are entirely removed from artifact clusters. At the same time, burned rock and flake concentrations co-occur in N38/E2 and in N38. There is a major concentration of flakes in N40 but 1ittle burned rock. This pattern is also discerned in N42/W2. A possible hearth (1arge burned rock) in N42/W2 has a cluster of flakes to the east. Burned rock and faunal remains are closely associated with possible hearths in N42/W2, N38, and N32/ E2. Mussel remains are particularly associated with burned rock in N42/W2. However, many of the snail concentrations and occurrences of fauna are not directly tied to the clustering of burned rock. Examination of the maps for co-occurrence of flakes with faunal material shows both negative and positive results. Flakes occur with snails in N40, as we11 as in N40/W2 (western half). Bone, musse1s, and snails were deposited together with flakes in N38 and N38/ E2. Again, the significant snail cluster in N42/E2 was not correlated with any flake concentrations. The relationship between artifacts and faunal remains is quite strong in $\mathrm{N} 42$, which may indicate that this was a prime processing area for materials necessitating use of artifacts. No burned rock or hearth activity is seen here, however. Flakes and artifacts show no positive association in any area of the site.

Some general patterns are clearly being developed in the first two levels. Lithic debris (flakes) and finished lithic products (artifacts) do not occur together. It may wel1 be that the primary tool manufacturing areas at Mariposa were not excavated. Burned rock concentrations, which are probably hearth loci, show positive association with faunal materials and flakes but not artifacts. Flake and artifact depositional areas (especially artifact areas) tend to occur away from hearth areas. Separate subsistence activity areas (hearths) and lithic activity areas (flakes and artifacts) seem to be indicated.

\section{Level Three}

(10-15 centimeters below the surface)

\section{Artifacts (Map 13)}

No strong clustering patterns are observed. Artifacts were not recorded in N38/E2 and N40/E2. The most intensive areas of deposition seem to be in N40 and $\mathrm{N} 38 / \mathrm{W} 2$.

\section{Flakes (Map 14)}

Flake deposition is centered primarily in N40, essentially in the middle of the excavation area. The remainder of the flakes recorded from this level seem to be randomly scattered.

\section{Burned Rock (Map 15)}

Two clusters of burned rock appear in the southern half of unit N42/E2. Possible clustering in N40/E2 and in N42/W2 is also observed. Charcoal was recovered 


\section{$41 Z V 83$}

Mariposa Site

Level 3

\section{ARTIFACTS}

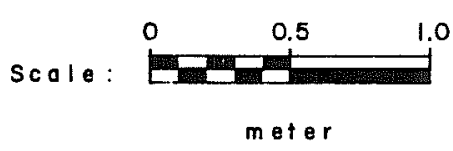

N4 4

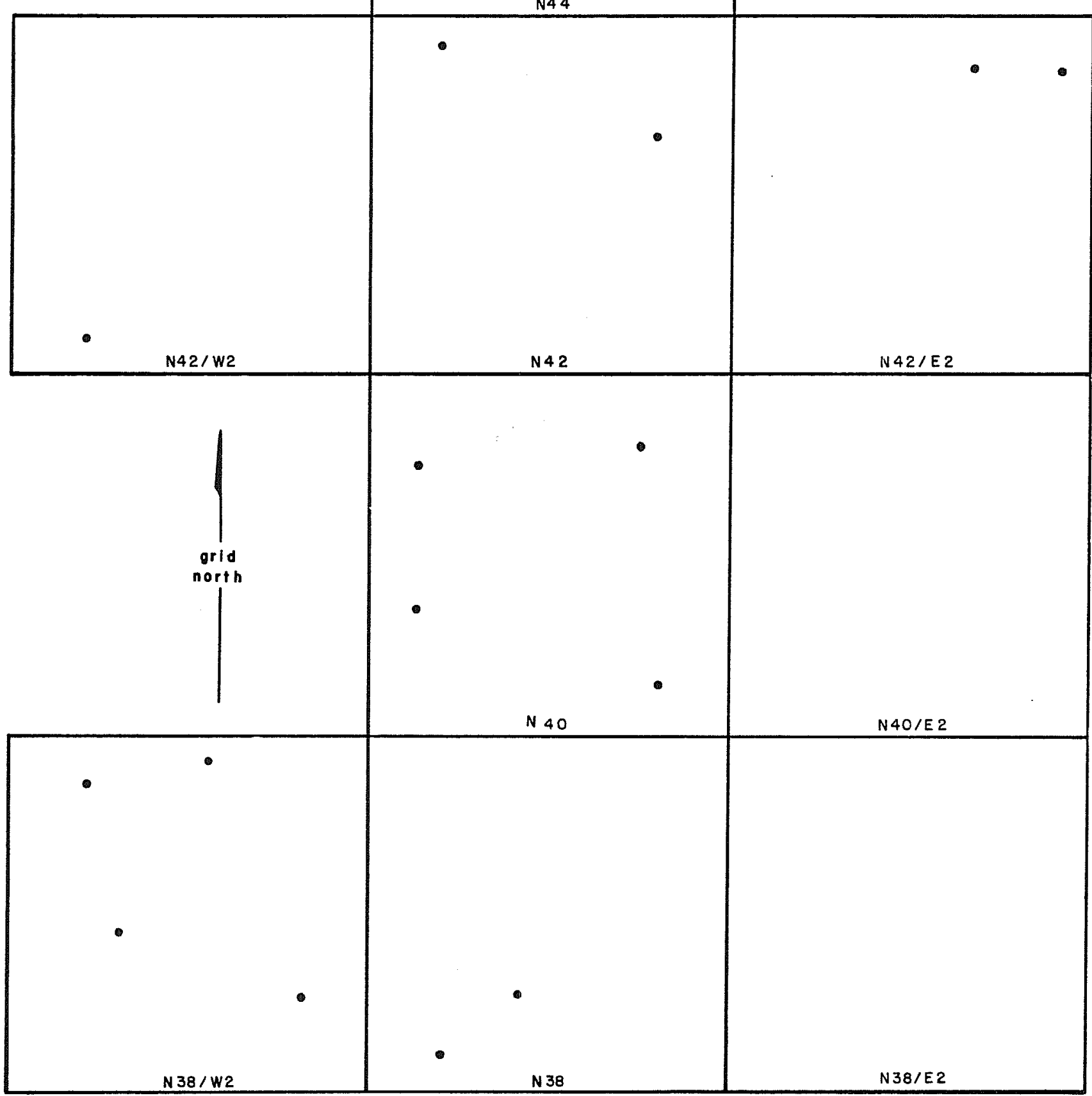

Map 13. Distribution Map of Artifacts, Leve1 Three. 
41 ZV 83

Mariposa Site

Level 3

FLINT FLAKES

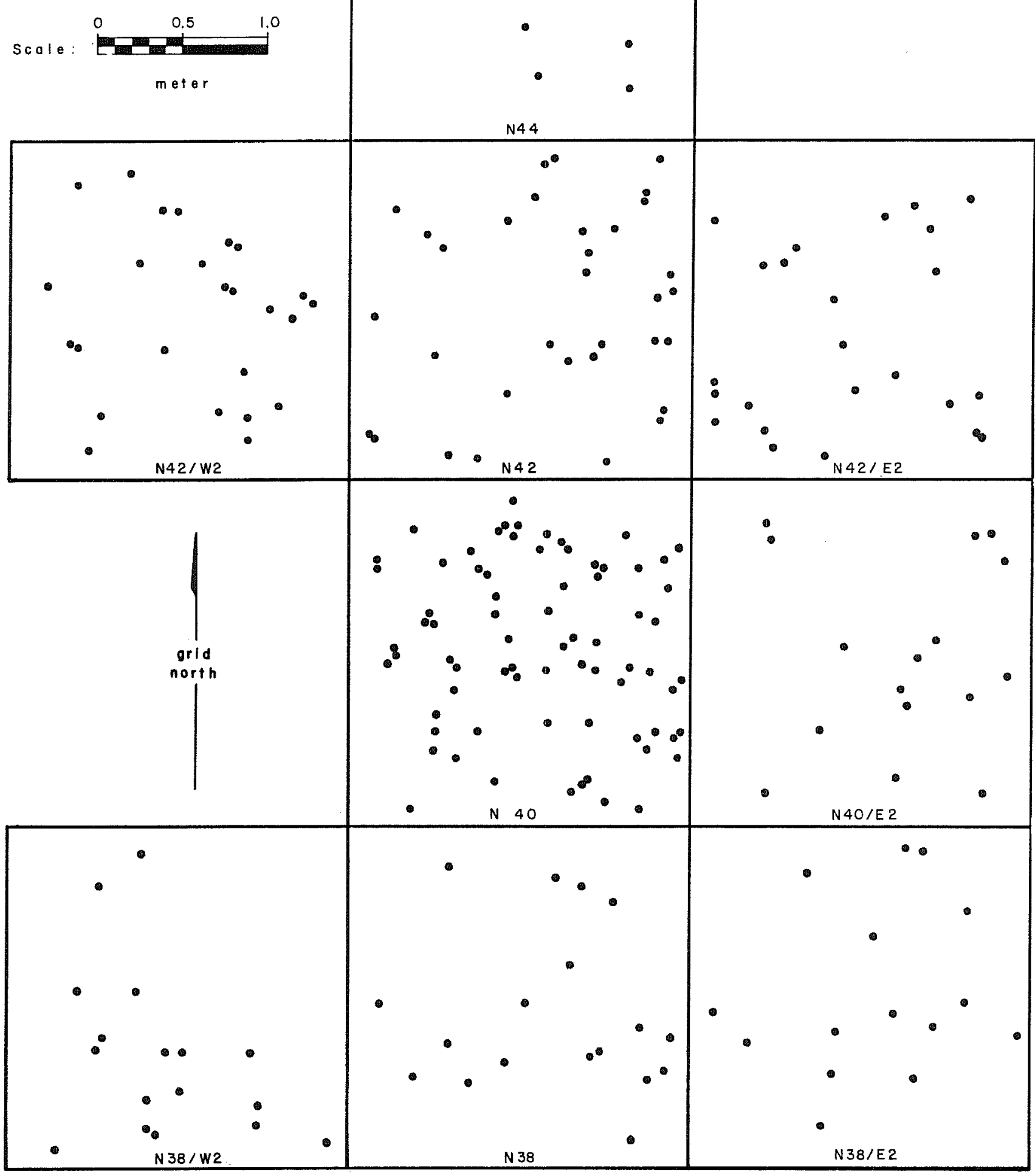

Map 14. Distribution Map of Flakes, Level Three. 
$41 Z V 83$

Mariposa Site

Level 3

BURNED ROCK

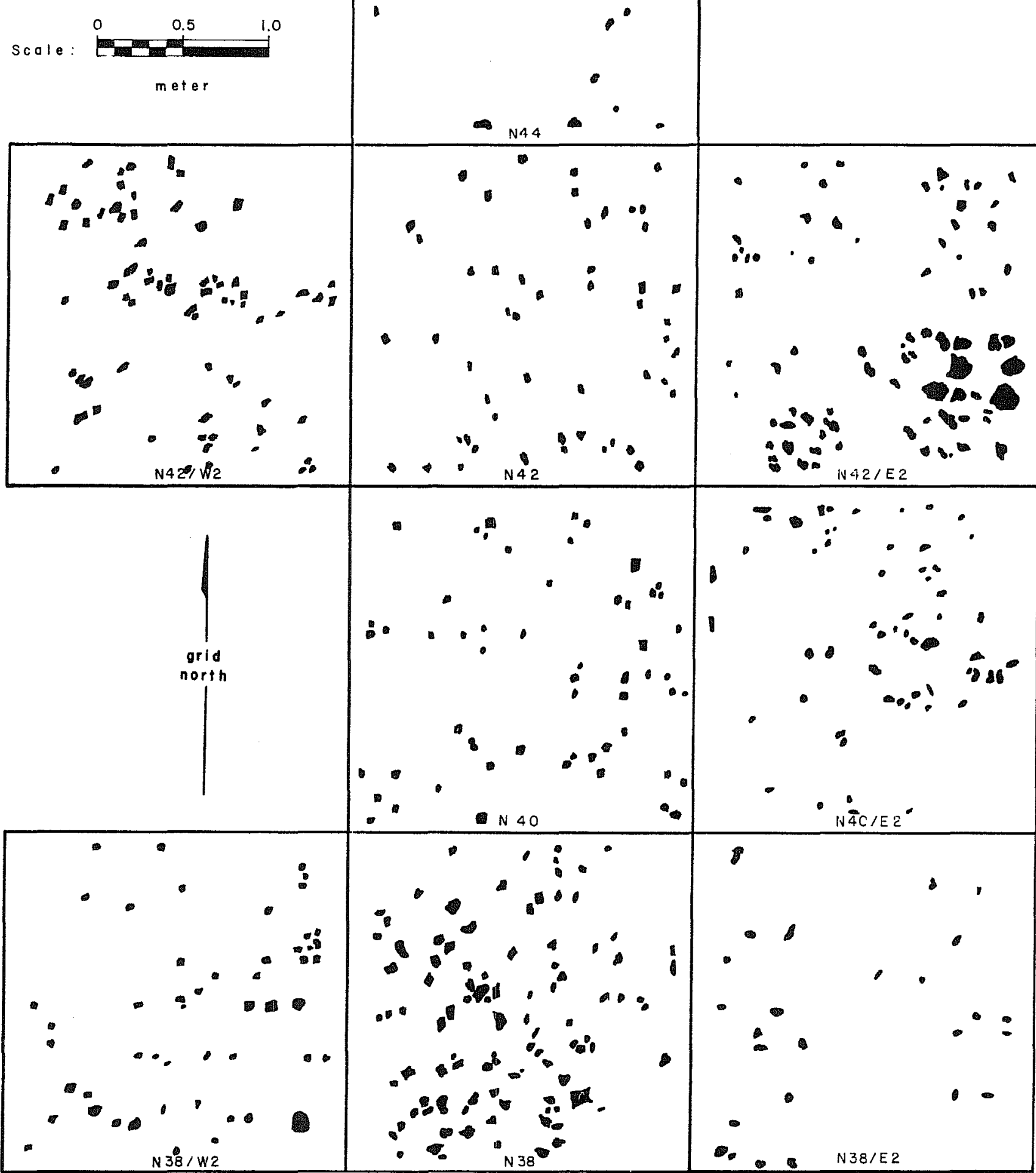

Map 15. Distribution Map of Burned Rock, Level Three. 
from the eastern half of N40/E2, in the western half of N38/E2, and in three areas within N38. Hearth activity is quite probable for the burned rock concentrations in N38, using charcoal as additional evidence, but the non-correlation of charcoal remains in N38/E2 and N40/E2 with burned rock concentrations hinders general conclusions.

\section{Faunal Remains (Map 16)}

Level three faunal remains were quite segregated. Snail clustering is observed in N44 and in N42/W2. Two discrete snail concentrations appear in N40, and several sma11 snail concentrations occur in N38. The southeast quadrant of N38/E2 contains a snail concentration. Mussel shell is concentrated in the northern half of $\mathrm{N} 40$ and is associated with shell in the northeast quadrant of that unit. Two isolated mussel shell fragments, associated with no other faunal material, occur here. Mussel shells, bone and snail shells are clustered together in the northern half of excavation unit N42. In the southern half of unit N38, a concentration of bone material as well as two discrete snail clusters is apparent.

It seems that the eastern margin of the site was not intensively utilized as depositional areas for faunal remains.

\section{Summary}

Except in excavation unit N38, a11 artifacts are outside and away from burned rock concentrations. The flake concentration in $\mathrm{N} 40$ is between the probable hearth areas. Burned rock concentrations and faunal remains co-occur in N38 but do not occur together to a significant degree in the remaining excavation units. Flake materials and faunal remains are associated in the northern half of N40, in N42, and in N44. Units N40/E2 and N42/E2 contain many flakes, randomly scattered, but very little faunal material. In terms of possible artifacts and faunal material correlations, N38 and the southern half of N42/W2 may be significant areas of such a relationship. Besides these two units, no relationship is apparent, however. Correlation of flake concentrations with artifact deposition is not readily apparent, except for some possible association in N38/W2, N38, and N44. 
$41 Z V 83$

Mariposa Site

Level 3

FAUNAL REMAINS
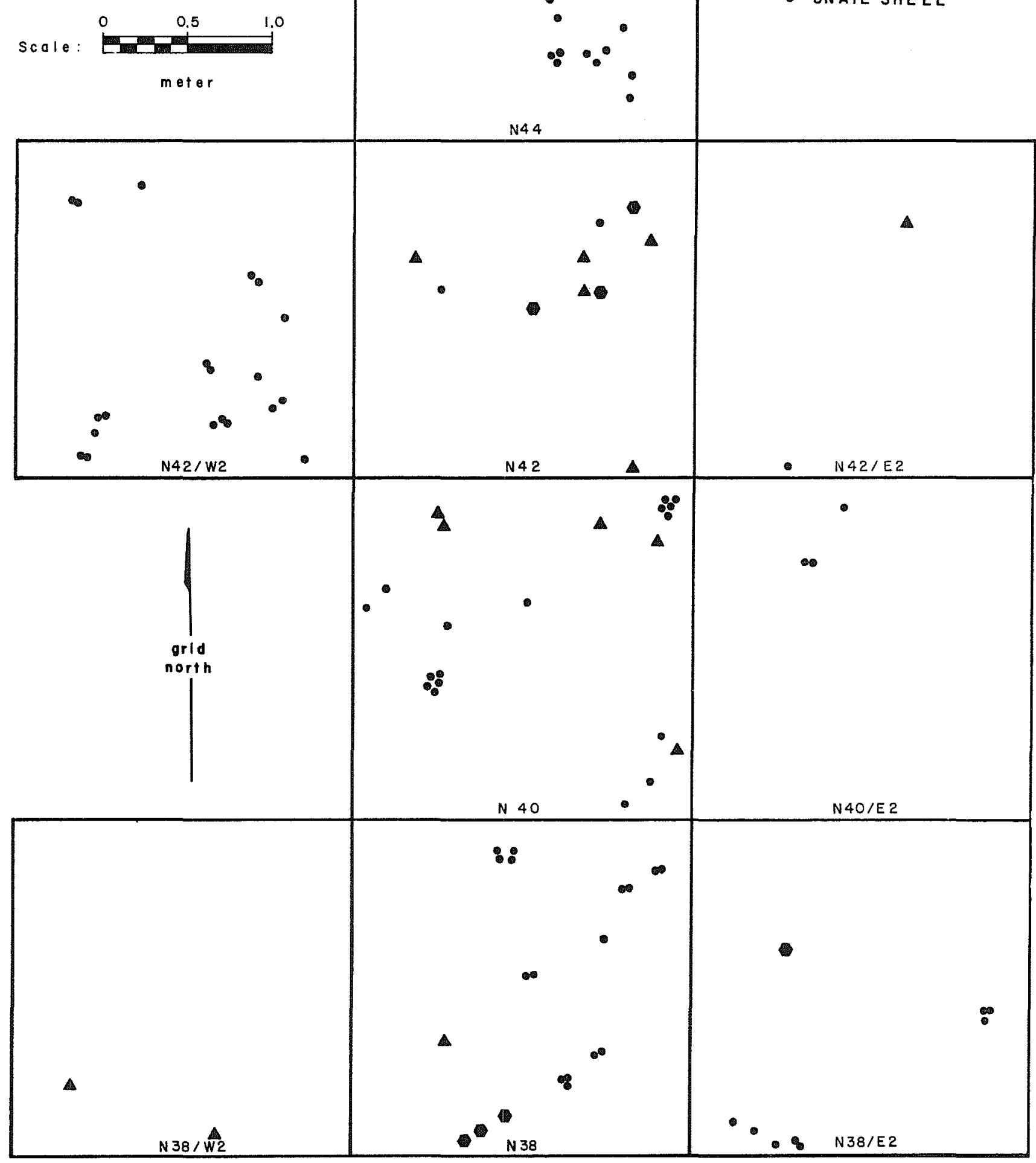

Map 16. Distribution Map of Faunal Remains, Level Three. 


\section{LITHIC TECHNOLOGY}

The accepted durability of lithic artifacts has generated a world-wide interest regarding the analys is of making prehistoric stone tools--1ithic technology. In a general sense, the subject of lithic technology encompasses the methods and processes involved in producing stone tools. When the manufacture or function of an artifact is not known, experimental replication may be employed to elucidate these problems (cf. Ascher 1961; Coles 1968; Hester, Heizer and Graham 1975:228-232; Wilmsen 1970, 1974). Other avenues of investigation are possible: a spectrum of investigations, ranging from the physical processes within the lithic material (cf. Speth 1974) to the recognition of individual chipping styles (Gunn 1975). Swanson (1975) has compiled recent views concerning the relationships between lithic technology and taxonomy, experimental lithic analyses, and the use of lithic technology in archaeological situations.

A brief review of the extensive literature concerning the topic of lithic technology indicates another avenue of interest, the lithic manufacturing process. Introduction of a diachronic view can illustrate the changes in tool types and manufacture, as shown by Bordes (1968). Classification of the products and byproducts introduced into the archaeological record by making lithic artifacts can be retraced as steps in the manufacturing process. This special area of investigation is, perhaps, the most directly useful for this thesis, since Hester (1975b) has already presented a testable model of lithic reduction for the study area.

Analysis of the stone tools and their manufacturing by-products is a way to infer cultural activities which produced them (Collins 1975). The manufacturing process has been described as an "etic" or generalized model composed of five steps:

(1) acquisition of raw materials, (2) core preparation and initial reduction, (3) optional primary trimming, (4) optional secondary trimming and shaping, and (5) optional maintenance modification (Collins .1975:17).

Hester (1975b) has incorporated portions of this etic model for describing the activity processes ("fabrication phases") involved in producing chipped stone industries on the Rio Grande Plain of Texas. Archaeological contexts here indicate that three "phases" of Collins' etic model can be recognized (Hester 1975b:214). Phase I, defined as the "procurement of raw (1ithic) materials," (Hester 1975b:214) is identical to Collins' Step 1 (above). Since suitable lithic resources for flintknapping are found only in terrace outcrops overlooking major stream channels of the Rio Grande Plain, terrace sites functioned as Phase I activity areas (Hester 1975b). These terrace sites are located away from the primary occupational sites of the area, which rest "on the floodplains, particularly on natural levees paralleling stream channels" (Hester 1975b:214). Terrace sites are uniquely situated with respect to chipped stone resources, so that only Phase I and the subsequent Phase II lithic activities occur here.

Phase II activities are concentrated to produce the "initial working and shaping of the raw material (using hammerstone percussion techniques)" (Hester 1975b: 214), or core preparation and initial reduction (Collins' Step 2, above). Two 
distinct avenues of activity can be followed during this stage. Terrace cobbles could have been prepared (reduced) as cores for future flake removal. Flakes produced by this activity are thought to be "used as blanks for tool manufacture" (Hester 1975b:214). This flake-tool sequence is contrasted by a coretool sequence in which cores are reduced into "preforms" (roughly-shaped bifaces) to be further reduced and made into tools (Hester 1975b:214). Analyses of materials encountered at the two types of sites (terrace workshop and floodplain occupation) have indicated that flakes removed by the flake-tool sequence were made at the terrace locations while core preforms produced by the core-tool sequence were carried to floodplain occupation sites for further modification. Several varieties of cores have been identified from archaeological sites on the Rio Grande Plain (cf. Hester 1975b and core model presented earlier), and these cores are considered to be an integral part of Phase II activities. While a core-blade industry has been postulated for this area and nearby regions of Texas (Hester 1975b:417-418; Hester and Shafer 1975), no evidence of this 1ithic industry was recovered from the Mariposa site.

Shaping, trimming and completion of lithic tools are considered to be Phase III activities (Hester 1975b:218). Phase III, as presented above, incorporated Collins' Steps 3, 4 and 5. These activities occur at floodplain occupation sites, "using flake blanks obtained from cores or preforms brought down from the terrace workshops" (Hester 1975b:218). Specific activities linked to this phase include bifacial thinning and final trimming (of both flake blanks and preforms) into completed tools (such as projectile points, knives, perforators, etc.). Flake blanks do not necessarily have to be Bifacially thinned; unifacial chipping and trimming could produce scrapers, notches and gravers (Hester 1975b).

Lithic debris resulting from each phase is quite distinctive and reflects the different activities associated with Phases I, II and III. Hester (1975b:218) has commented on this fact:

The workshops (used in Phase I and II) are dominated by decortication flakes. Interior flakes, those removed from a shaped core, and thinning flakes are rare. At occupation sites (where Phase III took place), decortication flakes are almost entirely absent. Instead, there are much higher percentages of interior flakes, some of which are large and represent blanks for tool manufacture; others are quite sma 11, probably representing core trimming activities. There are also numerous thinning flakes . . Most are apparently the result of bifacial reduction.

Bifacial "overshot flakes" and unifacial retouch flakes also result from Phase III activities at occupation sites (Hester 1975b:218-219).

Analys is of lithic artifacts and debitage (cf. Chapter V) was oriented towards a technological description, allowing for a test of the Collins-Hester model. If the model as presented above is accurate, then the artifact assemblage at Mariposa should contain some distinctive items. Mariposa's physical location, on a floodplain and near a stream channel, indicates that it most likely functioned as an occupation site rather than a workshop site. This being so, according to the model, only Phase III activity by-products (and products) are 
likely to be present (Hester 1975b:218). These should include biface thinning flakes, pressure flakes, finished and broken tools, and rejected preforms.

Primary cortex flakes, large cores, and tested cores (with one or two flakes removed) should be absent. This distinction is made between occupation sites and workshop sites (on terraces), as these separate areas reflect "different kinds of flintworking" (Hester 1975b:218).

Compilation of the relative frequencies of the items mentioned above will constitute a brief test of the model. Similar data from the Holdsworth site (41 ZV 14), the Honeymoon site (4I ZV 34), and the Stewart site (41 ZV 121) will also be presented and evaluated in light of the Collins-Hester model. These sites were chosen because they are located in the general vicinity of Mariposa and because two of them (Holdsworth and Stewart) are believed to be occupation sites.

Examination of the flakes recovered from Mariposa should show a predominance of bifacial thinning flakes, pressure flakes, and interior flakes when compared to primary and secondary cortex flakes. Table 15, which lists the frequency of flake types recorded from Mariposa, indicates that this is a basically accurate assessment (after excluding flake fragments). Only $4.4 \%$ of the flakes are primary cortex flakes, while $27.6 \%$ are biface thinning flakes. No pressure flakes were recovered, probably since the 1/4-inch screen used at the site would allow these small specimens to escape detection. Frequencies recorded for both secondary cortex flakes and interior flakes $(35.7 \%$ and $32.3 \%$ respectively) are greater than biface thinning flakes.

TABLE 15

FLAKE TYPES RECOVERED FROM MARIPOSA: NUMBER AND RELATIVE PERCENTAGE

\begin{tabular}{|c|c|c|}
\hline & Number & $\begin{array}{r}\text { Relative } \\
\text { Percentage } \\
\end{array}$ \\
\hline Primary Cortex Flakes & 40 & 4.4 \\
\hline Secondary Cortex Flakes & 321 & 35.7 \\
\hline Interior Flakes & 291 & 32.3 \\
\hline Biface Thinning Flakes & 248 & 27.6 \\
\hline TOTAL & 900 & 100.0 \\
\hline
\end{tabular}

Turning to three archaeological sites situated in similar environmental conditions (and in northwestern Zavala County), tabulated flake frequencies reveal further general support to the Hester-Coliins model (see Table 16). Primary cortex flakes (not to be expected) contribute a meager $1.9 \%$ and $2.1 \%$ to the recovered flakes at the Holdsworth and Stewart sites respectively (Hester and 
Hil1 1972). At Holdsworth, biface thinning flakes account for $24.2 \%$ of the flake sample, and interior flakes dominate the sample with $45.7 \%$ of the flakes. Biface thinning flakes dominate the flake sample at the Stewart site $(56.9 \%)$, followed by interior flakes, which contribute $25.3 \%$ of the sample.

Data from the Honeymoon site are somewhat different (Hill and Hester 1971). Here a recorded low percentage of biface thinning flakes (10.5\%) is also associated with a relatively high percentage of primary cortex flakes $(10.5 \%)$.

TABLE 16

FLAKE TYPE FREQUENCY (PERCENTAGE) RECORDED

FROM FOUR RIO GRANDE PLAIN (SOUTH TEXAS) SITES

Mariposa Honeymoon Holdsworth Stewart

Primary Cortex

4.4

10.5

1.9

2.1

Secondary Cortex

35.7

46.0

28.2

15.7

Interior

32.3

33.0

45.7

25.3

Biface Thinning

27.6

10.5

24.2

56.9

Mariposa Site, 41 ZV 83

Honeymoon Site, Area A, 41 ZV 34

Holdsworth Site, 41 ZV 14

Stewart Site, 41 ZV 121

This occurrence has been interpreted to be the result of the possible production of cores or usable flakes. Hill and Hester (1971:58) also feel that this site is not an occupation site. This would account for the distinctly different recovered flake type frequencies from this site.

Clearly, the prediction that primary cortex flakes will be scarce at floodplain occupation sites in this area is substantiated, since no occupation site listed contained more than $5 \%$ of these flakes within their respective flake samples. Bifacial thinning flake frequencies were, however, high at only one site (Stewart); these flakes constituted approximately one-fourth of the flake samples recorded for the other sites. Interior flakes, thought to be removed from core interiors (Hester and Hil1 1972:46), were recorded in highest frequency at the Holdsworth site. These flakes generally accounted for at least one-quarter of the flake samples from the remaining sites considered here. Mariposa exhib$i$ ted the highest frequency of secondary cortex flakes, followed by the Holdsworth 
site. These flakes, which occur subsequent to the primary cortex flakes in a core reduction sequence (Hester and Hil1 1972:46), represent a reduction activity from Phase II (Hester 1975b). The high $(35.7 \%)$ frequency of this flake type at Mariposa does not easily correspond to the Collins-Hester model.

Finished and broken tools, as well as rejected preforms, are also Phase III activity by-products and should be represented at floodplain occupation sites such as Mariposa (and Holdsworth and Stewart). At the same time, large cores and "tested" cores should contribute only a small part, if any, to the tool assemblage. If one computes the ratio of finished tools, broken tools, and preforms recovered at a site (i.e., all tool categories except cores) to large cores and tested cores, one can predict a large value if the model is accurate. Conversely, small ratio values would tend to make the model incorrect or at least insufficient in this area.

According to the stated model, only preforms and flake blanks destined to become either finished tools or broken (during manufacture or use) tools should be present at occupation sites. It is assumed that very few, if any, cores should be present at these sites; cores should instead be located at terrace sites close to the lithic resources of the region. For the purposes of this limited study, cores are thought not to occur at occupation sites for two reasons: (1) Quantification of "large" cores is not readily apparent--when is a core smal1? (2) Other references used in this study do not distinguish between large and smali cores, and therefore their results can be more easily compared to the results of this study. However, the author does wish to point out that core nuclei, or cores that are physically non-usable because al1 possible flakes from them have been removed, are likely to occur in limited numbers at occupation sites.

Table 17 summarizes the necessary information considered here. Data were drawn from the analys is of the lithic materials recovered at the Mariposa site, the Holdsworth and Stewart sites (Hester and Hill 1972), and the Oulline site (41 LS 3) (Hester, White and White 1969).

Two of the sites analyzed (Mariposa and Stewart) had relatively low ratio figures while the remaining two sites (Holdsworth and Oulline) had comparatively greater ratio values. This conflict casts some doubt on the validity of the collins-Hester mode1. The fact that the ratio of tool frequency to core frequency is low at two sites indicates that core reduction activities (Phase II) are occurring at occupation sites. This is reinforced by the fact that secondary cortex flake frequency is also relatively high at Mariposa (see Table 15). Since three of the four sites examined here were either surface collected or tested (by test pits), the recovered data may be affected by sampling bias. It may well be that future excavation at these sites would record more cores and secondary cortex flakes in relation to the total lithic assemblage. In any case, it is clear that the excavated material from the Mariposa site indicates that Phase II activities can occur at occupation sites. Tested cores considered suitable for further reduction into tools or flakes may have been transported from terrace areas into the floodplain. At Mariposa Phase II by-products were recovered in sufficient quantity to suggest that this transportation of cores may have occurred. 
TABLE 17

CORE FREQUENCY, OTHER TOOL FREQUENCY, AND

RATIO OF TOOLS/CORES FREQUENCY AT

FOUR RIO GRANDE PLAIN SITES

\begin{tabular}{lccc} 
& $\begin{array}{c}\text { Frequency } \\
\text { of cores }\end{array}$ & $\begin{array}{c}\text { Frequency } \\
\text { of Other } \\
\text { Tools }\end{array}$ & $\begin{array}{c}\text { Ratio of } \\
\text { Core/Tool } \\
\text { Frequencies }\end{array}$ \\
\hline Mariposa Site & .164 & .836 & $5: 1$ \\
Holdsworth Site & .078 & .922 & $11: 8$ \\
Stewart Site & .316 & .684 & $2: 7$ \\
Oulline Site & .065 & .935 & $14: 4$
\end{tabular}

Another aspect of the lithic technology expressed by the artifacts recovered from Mariposa is related to the general tool industry type. As stated earlier in this section, a core-tool industry and a flake-tool industry have been postulated as occurring in south Texas archaeological contexts. From Mariposa, flakes were prepared as tools in the following categories: utilized flakes, trimmed flakes, scrapers, 9 of 24 bifaces, and 6 of 42 projectile points. It must be emphasized that the only criteria used here to describe flake-tools is the presence of flake attributes (bulb of force, striking platform, rings of compression on the ventral surface of a flake). If these atributes could not be recognized, then no basis for distinguishing flake-tools from core-tools was considered conclusive. There were several bifaces which retained cortex on at least one of their faces, which may be evidence of the core-tool industry.

One last item should be addressed before closing this section. Flakes from Mariposa were examined for striking platform type. This was initiated to gain insight concerning the modes of core platform preparation practiced by the Late Prehistoric inhabitants of Mariposa. Referring back to the flake analysis undertaken in Chapter $V$, the following platform types and their respective frequencies were recognized:

$\begin{array}{lr}\text { Single Facet Platform } & 46.2 \% \\ \text { Multi-Facet Platform } & 31.7 \% \\ \text { Crushed or Shattered Platform } & 8.0 \% \\ \text { Cortex Platform } & 11.1 \% \\ \text { Convergent Platform } & 3.0 \%\end{array}$

As expressed by Hester and Hil1 (1972), several core preparation techniques are indicated. Cortex platforms indicate that cores were reduced with no formal 
preparation. Cores undergoing preparation by removing one flake and using the new fracture surface for a striking platform produce flakes with single facet platforms. These flakes were the most frequently occurring type and may suggest a preferred core reduction procedure. More extensive faceting (flake removal) for preparing more core striking platforms wi11 result in flakes with multi-faceted platforms. A unique platform type caused by striking flakes on previous flake scar ridges (convergent planes; cf. Hester 1971) are convergent flake platforms. This flake platform type occurred least frequently in the Mariposa sample. Finally, crushed or shattered platforms, where only platform remnants are evident, also were observed. U1timately, these flake platform types will be integrated into the core reduction sequence previously presented (see Chapter V). Time did not allow for such a detailed study to be presented here. 


\section{INTERSITE COMPARISONS}

Once materials from archaeological sites have been analyzed and interpretations prepared, comparisons with (temporally and culturally) related regional sites can qualify (and perhaps quantify) apparent similarities and differences. Evaluation of such results will often lead to a crystallization of ideas concerning such topics as settlement patterns, subs is tence techniques, 1ithic assemblages, specialized environmental adaptations and lithic resource utilization. Only initial steps can be pursued in this direction for Late Prehistoric sites near Mariposa. This situation arises since so little published results are available from this region, and the majority of these have appeared only in the last six years or so.

Tested sites to be considered here include the Holdsworth (41 ZV 14) and Stewart (41 ZV 121) sites (Hester and Hi11 1972), 41 ZV 152 (Hester et aZ. 1975), Tortuga Flat (Hill and Hester 1973), the Oulline site, 41 LS 3 (Hester, White and White 1969), and some of the sites surveyed and described by Hester and $\mathrm{Hi11}(1975 \mathrm{~b}: 3-6)$. The unpublished results of major excavations at $41 \mathrm{ZV} 10$ (also on the Chaparrosa Ranch) will soon provide comparative information. Upper levels of this site contained evidence of Late Prehistoric occupation ( $T$. R. Hester, personal communication).

At least 16 "major" Late Prehistoric sites have been recorded from a limited study area of southern Texas (Hester and Hil1 1975b:3-6). The Holdsworth, Tortuga Flat and Mariposa sites are included in this figure. Only the sites mentioned in the previous paragraph will be compared to Mariposa, since they contain the most detailed published information.

Some comparative statements concerning general site function and location have been already prepared. Hester and Hil1 (1975b:7) have ascertained that "all of the presently documented Late Prehistoric sites are occupation loci, generally with concentrated midden deposits 10 to $30 \mathrm{~cm}$ thick." These middens characteristically contain lithic debris, land gastropods (especially Rabdotus sp.), river mussel shells (Unio sp.), other faunal materials, scattered burned rock (sandstone and chert), baked clay and charcoal (Hester and Hi11 1975b; Hester 1975c). It is most often the case that these sites are situated adjacent to creek banks in riparian microenvironments (Hester and Hi11 1975b:7; Hester 1975c).

When compared to other Late Prehistoric sites of the region, Mariposa exhibits some unique characteristics. The extensive faunal remains from test pits and feature excavations at most tested Late Prehistoric sites, particularly the "Bone Pile" at Tortuga Flat (41 ZV 155; Hill and Hester 1973), the 11 faunal species recognized at $41 \mathrm{ZV} 152$ (Hester et al. 1975), and the recovered bone from Holdsworth (Hester and $\mathrm{Hi} 11$ 1972) are conspicuously lacking at Mariposa. It appears likely that, at least for the areas excavated, land snails played a more important role as a subsistence item at Mariposa. Utilization of fauna (bone, snail shells and mussel shells) was concentrated into distinct patterns or foci, where snail extraction may have been an important activity.

The recorded features at Mariposa are consistent with those from similar sites. Hearth areas, with associated charcoal, ash, clay lumps and some lithic debris 
are found at Mariposa as well as most other regional Late Prehistoric sites (Hester and Hill 1975b). Specialized lithic activity areas, such as a bifacial reduction area at Tortuga Flat (Hester and Hill 1975b:7), are contained within Mariposa (i.e., a uniface retouch area in level 2 of 42). Surface clusters of ceramics, reported to occur at Tortuga Flat (Hill and Hester 1973), are nonexistent at Mariposa. In fact, while many Late Prehistoric sites do contain some pottery, none was found at Mariposa. Flake and artifact distribution maps are presented from Mariposa, but there are none currently available from nearby sites. These maps also indicated preferred lithic activity areas. Diachronicaliy, the distribution maps from Mariposa indicate that at Mariposa, as well as at many other Late Prehistoirc sites, the occupation levels can best be recognized as zones "with numerous, of ten overlapping, discrete occupational episodes" (Hester and Hill 1975b:20).

Specialized (unique) cultural features have been reported from areal Late Prehistoric contexts. A buried (female) with associated burial goods in situ was recovered from $41 \mathrm{ZV} 152$ (Hester et az. 1975). Fifteen bone beads (tubular and barrel-shaped) were interred with the burial. A Tortugas dart point and a suite of faunal remains were also documented at this site (Hester et al. 1975). Another cultural feature recorded at Holdsworth may possibly represent a "partially-burned brush hut structure" (Hester and Hil1 1975b:8).

Lithic assemblages characteristic of Late Prehistoric archaeological context are consistent for most sites, including Mariposa. Characteristic Scazzorn and Perdiz projectile points, along with triangular varieties, compose the arrow point component. These have also been recovered from Tortuga Flat, Oulline and the Holdsworth sites. Zavala points, which retain both arrow point and dart point attributes, were recovered from Mariposa in associated contexts with Perdiz and Scalzom points. Zavala points, though not associated with sites compared here, have been hypothesized to be "coeval with arrow point forms and were part of the late prehistoric cultural inventory" (Hester and Hill 1975b:8, see also Hill and Hester 1971). This has been substantiated by excavations at Mariposa, although it should be noted also that Zavala points are well represented (compared to Perdiz and Scallorn specimens) in the lower (earlier) contexts of the site.

Other bifacial tools occurring in Late Prehistoric sites include ovate and triangular forms, drills and perforators. Drills and perforators were not present at Mariposa. Unifacial tools such as end scrapers and side scrapers are well represented at Mariposa, as well as the other Late Prehistoric sites considered here. Hammerstones, considered to be common items in the Late Prehistoric material inventory (Hester and Hill 1975b:9), are sadly lacking at Mariposa. Manos and grinding slabs, seen to occur infrequently in most Late Prehistoric sites (Hester and Hill 1975b:9), are quite frequent at Mariposa. Scratched and grooved sandstone is another common artifact type at Mariposa. Lithic debitage analyses have been published from a few Late Prehistoric sites (Hi11 and Hester 1971; Hester and Hi11 1972; Hester 1975b) and comparison of Mariposa's debitage analys is with these studies was done earlier. Results of this comparison will not be repeated in detail here; suffice it to say that the lithic debitage from Mariposa is quite distinct in some aspects from many sites and similar (in other aspects) to many sites. Causes for this situation must await a more thorough examination, but the limited study in Chapter VIII indicates that Phase II reduction sequences are occurring at the Mariposa site. 
Integrating radiocarbon dates into the above framework should establish the temporal parameters we are dealing with. For the sites being compared, Mariposa, Holdsworth and Tortuga Flat have all produced radiocarbon dates. Occupations of Holdsworth and Tortuga Flat begin about A.D. 1440 and end close to.A.D. 1760. Dates from the Mariposa site are listed in Table 1; the Late Prehistoric occupations here span a period of time from A.D. 1430 to A.D. 1650. A11 three sites were occupied into the early Historic period, yet none of them contain evidence for European contact. Returning to projectile points, it is apparent that for three Late Prehistoric sites on the Rio Grande Plain, Scalzorn and Perdiz points were still being used into protohistoric times. This statement, initially forwarded by $\mathrm{Hill}$ and Hester (1973), is further reinforced by pertinent data from the Mariposa site (see also Hester 1975c). 


\section{$X$. SUMMARY AND CONCLUSIONS}

The testing and excavation of the Mariposa site, 41 ZV 83 in Zavala County, Texas, has produced a significant amount of archaeological information concerning the Late Prehistoric period on the Rio Grande Plain. Examination of the present environment indicates that ample and varied flora and fauna are available to man within a very favorable climatic setting. This particular setting has not been constant through time, however, since grassland-savannas existing at the end of the Pleistocene have now been replaced by a thorny brush environment.

Earliest evidence for man in the region also occurs near the end of the Pleistocene. The archaeological record documents man's existence from this initial entry (ca. 11,000 years ago) unti1 historic (European) contact. Unfortunately, the archaeological evidence is in many ways meager. Much more work is necessary before adequately detailed information can be synthesized into a realistic "processual" picture of the regional archaeology. Perhaps the best evidence has been produced for the Late Prehistoric period, since problems specifically concerned with technology, subsistence and settlement patterns, microenvironmental zone utilization, and site functionality have been addressed, at least in a preliminary fashion. The report produced here will contribute to and consequently expand on those ideas which have previously been put forth by Hester (1971, 1974b, 1974c, 1975a, 1975c) and Hester and Hi11 (1975b).

Extending approximately 6000 square meters horizontally, Mariposa contains abundant cultural debris from the surface to a depth of nearly $90 \mathrm{~cm}$. Cultural material was concentrated in the uppermost $20 \mathrm{~cm}$. Radiocarbon dates from this upper level of the site average around A.D. 1500, while a date of A.D. 620 exists for a deeper level. This lower level may be associated with probable occupation(s) of Mariposa during the Archaic period.

Material remains excavated from Mariposa yielded an assemblage generally resembling those from similar Late Prehistoric sites in the region. Faunal materials such as land gastropods (Rabdotus sp.), river mussels (Unio sp.), and mammal bone fragments were recovered in an area marked by scattered burned rock and hearth activity loci. Hearths were represented by the deposition of large specimens of burned rock, charcoal and infrequent pieces of baked clay. Lithic flakes and artifacts were encountered throughout the site. Primary cortex flakes, secondary cortex flakes, interior flakes and biface thinning flakes occurred in a ration of 1:9:8:7. Artifacts recovered from Mariposa include several types of cores, various bifaces and unifaces such as end scrapers, side scrapers, and end and side scrapers. Flakes were utilized as tools directly after manufacture and without modification ("utilized flakes") and they were also "retouched" to function as tools. Distinctive projectile point "types" include the Scazlorn and Perdiz varieties. These appear to be coeval throughout the Late Prehistoric occupation(s) at Mariposa. Zavala points appear in quantity in earlier (deeper) contexts and continue to be used along with the Scalzorn and Perdiz points.

Within the site itself, horizontal patterning was manifested by the separation of specific cultural activities into discrete "activity areas." This is best illustrated by the patterning of faunal remains, where discrete snail shell loci were observed. Bone fragments, mussel shell remains and snail shells were often clustered together, indicating areas associated with subsistence activities. 
Hearths, another area of distinct activity, were evidenced by the concentration or clustering of large specimens of burned rock, usually associated with charcoal. Many times hearths were also accompanied by clusters of artifacts, flakes, and faunal remains. It was often the case that lithic activity, as well as the deposition of faunal remains, was established away from (or between) hearth loci. Flake debris and artifacts were only rarely associated in the same areas; at the same time, clustered faunal remains were readily encountered with concentrations of flakes and/or artifacts.

Analysis of lithic materials occurring at Mariposa was oriented toward evaluating a preliminary model of the lithic industries observed from sites on the Rio Grande Plain. Detailed study of the lithic material from Mariposa indicated that tools were manufactured by either core-reduction or flake production and modification, since both processes can be shown to occur through examination of the cores recovered from the site. In light of the Collins-Hester model (Hester 1975b), it is apparent that Phase II activities can occur at occupation sites such as Mariposa, given the fact that relatively large amounts of cores and secondary cortex flakes occurred at Mariposa.

The majority of information recovered at the Mariposa site is quite comparable to other Late Prehistoric sites nearby. However, the high frequency of ground sandstone slabs at Mariposa may indicate an unusually intensive reliance upon processing vegetal materials. At the same time, the low frequency of hammerstones at Mariposa is unique among Late Prehistoric sites so far investigated. The variety of faunal remains, especially vertebrate, which is characteristic of most Late Prehistoric sites, was not encountered at the site. The differences, which are few in comparison to the many similarities, must be viewed with some caution. Mariposa, which was tested twice and excavated for one season, remains the only Late Prehistoric site extensively excavated. Comparative information from other Late Prehistoric contexts rests primarily on surface collections and/or test pits. It is quite apparent that this disparity of sampling could be responsible for the observed differences. It is also quite apparent that archaeological research in this region of Texas is far from complete and much work needs to be done. 


\section{REFERENCES CITED}

Alexander, H. L., Jr.

1963 The Levi Site: A Paleo-Indian Campsite in Central Texas. American Antiquity 28(4):510-528.

Alexander, R. K.

1970 Archeological Excavations at Parida Cave, Val Verde County, Texas. Papers of the Texas Archeological Salvage Project 19.

Al1en, D. C. and E. P. Cheatum

1961 Ecological Implications of Fresh-water and Land Gastropods in Texas Archeological Studies. Bulletin of the Texas Archeological Society $31: 291-316$.

Arguedas, R. de la Borbolla and L. Aveleyra Arroya de Anda

1953 A Plainview Point from Northern Tamaulipas. American Antiquity $18(4): 392-393$.

Arriaga, D.

1974 Soil Description of Archeological Site (4I ZV 83). Report from Soil Conservation Service, Uvalde, Texas.

Ascher, R.

1961 Analogy in Archaeological Interpretation. Southwestern Journal of Anthropology 17:317-325.

Bass, W. B.

1971 Human Osteology: A Laboratory and Field Manual. Columbia, Missouri.

Birmingham, W. W. and T. R. Hester

1976 Late Pheistocene Archaeological Remains from the Johnston-Heller Site, Texas Coastal Plain. In: Papers on Paleo-Indian Archaeology in Texas, I. Center for Archaeological Research, The University of Texas at San Antonio, Special Report 3:15-33.

Blair, W. F.

1950 The Biotic Provinces of Texas. Texas Joumal of Science 2(1):93-115.

1952 Mammals of the Tamaulipan Biotic Province in Texas. Texas Jourmal of Science 4(2):230-250. 
Bogusch, E. R.

1952 Brush Invasion in the Rio Grande Plain of Texas. Texas Joumal of Science 4(1):85-91.

Bordes, F.

1968 The Old Stone Age. McGraw-Hill Book Company, New York.

Bryant, M., Jr.

1970 Genera1 Comment. Radiocarbon 12(2):625.

Bryant, M., Jr. and D. A. Larson

1968 Pollen Analysis of the Devil's Mouth Site. In: The Devil's Mouth Site, the third session, 1967, by William M. Sorrow. Papers of the Texas Archeological Salvage Project 14:57-70.

Bryson, R. A.

1974 A Perspective on Climatic Change. Science 184(4138):753-760.

Butzer, K.W.

1971 Environment and Archeology: An Ecological Approach to Prehistory. Aldine-Atherton, Inc., Chicago.

Campbe11, T. N.

1960 Archeology of the Central and Southern Sections of the Texas

Coast. Bulzetin of the Texas Archeological Society 29:145-176.

1975 The Payaya Indians of Southern Texas. Southern Texas ArchaeoZogical Association, Special Publication 1.

Carter, W. T.

1931 The Soils of Texas. Texas Agricultural Experiment Station Bulletin 9.

Chambers, W. T.

1946 The Geography of Texas. The Steck Vaughn Company, Austin.

Clark, J.W., Jr.

1973 The Problem of the Land Snail Genus Rabdotus in Texas Archaeological Sites. The Nautilus $87(1): 24$. 
Coles, J. M.

1968 Experimental Archaeology. Proceedings of the Society of Antiquaries of Scotzand 99:1-21.

Collins, M. B.

1975 Lithic Technology as a Means of Processual Inference. In: Lithic Technology: Making and Using Stone Tools (E. H.

Swanson, ed.):15-34. Aldine, Chicago.

Corbin, J. E.

1974 A Model for Cultural Succession for the Coastal Bend Area of

Texas. Bulletin of the Texas Archeological Society 45:29-54.

Corliss, D. W.

1972 Neckwidth of Projectile Points: An Index of Cultural Continuity and Change. Occasional Papers of the Idaho State University Museum 29.

Crabtree, D. E.

1972 An Introduction to Flintworking. Occasional Papers of the Idaho State University Museum 28.

Dacey, M. F.

1973 Statistical Tests of Spatial Association in the Locations of Tool Types. American Antiquity 38(3):320-328.

Dibble, D. S. and D. Lorrain

1968 Bonfire Shelter: A Stratified Bison Kill Site, Val Verde County, Texas. Miscellaneous Papers of the Texas Memorial Museum 1.

Enlow, D. H. and T. N. Campbell

1955 Some Paleo-Indian Projectile Points from the Southeastern Periphery of the Great Plains. Panhandle-Plains Historical Review 28:29-37.

Epstein, J. F.

1962 Centipede and Damp Caves, Excavations in Val Verde County, Texas. Bulletin of the Texas Archeological Society 33:1-129.

1969 The San Isidro Site, An Early Man Campsite in Nuevo Leon, Mexico. Department of Anthropology, The University of Texas at Austin, Anthropology Series 7. 
1972 Some Implications of Recent Excavations and Surveys in Nuevo Leon and Coahuila. The Texas Joumal of Science 24(1):45-56.

Feder, $N$.

1976 The Use of Trend Surface Analysis in Examining Activity Patterns at Anangula, Aleutians. Paper presented at the 75th annual meeting of the American Anthropological Association, Washington, D.C.

Fenenga, $F$.

1953 The Weights of Chipped Stone Points: A Clue to Their Functions. Southwestern Journal of Anthropology 9:309-323.

Fenneman, N. M.

1938 Physiography of the Eastem United States. McGraw-Hi11, New York. Gilbert, B. M.

1973 Manmazian Osteo-Archaeology: North America. University of Missouri, Columbia.

Gunn, J.

1975 Idiosyncratic Behavior in Chipping Style: Some Hypotheses and Preliminary Analysis. In: Lithic Technology, edited by

E. Swanson, 35-61. Mouton, The Hague.

Harris, D. R.

1966 Recent Plant Invasions in the Arid and Semiarid Southwest of the United States. Annals of the Association of American Geographers 56:408-422.

Hartle, D. D. and R. L. Stephenson

1951 Archaeological Investigations at the Falcon Reservoir, Starr County, Texas. Department of Anthropology, The University of Texas at Austin, River Bas in Survey, mimeographed manuscript.

Haynes, C. V.

1966 Elephant Hunting in North America. Scientific American 214(6): 104-112.

Hester, T. R.

1966 A Clovis Point from Southwest Texas. Newsbulletin of the Southern Plains Archeological Society 12:2-3. 
1967 Notes on the Distribution of the Plainview Type in Southwest Texas. Newsbulletin of the Southern Plains Archeological Society 14:3-8.

1968a Folsom Points from Southwest Texas. Plains Anthropologist $13(40): 117$.

1968b Notes on Pottery Bearing Sites in Southern Texas. Bullroarer $3(2): 9-11$.

1968c Paleo-Indian Artifacts from Sites Along San Miguel Creek: Atascosa, Frio and McMullen Counties, Texas. Bulletin of the Texas Archeological Society 39:147-161.

1970a An Interim Statement on Archaeological Research at Chaparrosa Ranch, Texas. Report submitted to the State Archeologist's Office, Austin.

1970b Metal Projectile Points from Southern Texas. The Record 29:9-11.

1971 Hunters and Gatherers of the Rio Grande Plain and the Lower Coast of Texas. Paper presented at the annual meeting of the Texas Academy of Science, Nacogdoches.

1974a On Fluted Points and South Texas Archeology. Texas Archeology 18(2): 11-14.

1974b Prehistoric Subsistence and Settlement Systems on the Rio Grande Plain, Southern Texas. Yearbook of the American Philosophical Society 1973:594-596.

1974c Some Observations on Archaeology at Chaparrosa Ranch, 1974. La Tierra 1(3):19-22.

1974d A Bibliographic Guide to the Archaeology of Southern Texas. La Tierra 1(4):18-36.

1975a A Chronological Overview of Prehistoric Southern and SouthCentral Texas. Paper presented at the 1975 Conference, "The Prehistory of Northeastern Mexico and Texas," Monterrey, Mexico.

1975b Chipped Stone Industries on the Rio Grande Plain, Texas: Some Preliminary Observations. Texas Journal of Science 26(1-2): 213-222.

1975c Late Prehistoric Cultural Patterns Along the Lower Rio Grande of Texas. Bulletin of the Texas Archeological Society 46:107-125.

1975d The Natural Introduction of Mollusca in Archaeological Sites: An Example from Southern Texas. Journal of Field Archaeology $2: 273-275$.

1976a Late Pleistocene Aboriginal Adaptations in Texas. In: Papers on Paleo-Indian Archaeology in Texas. Center for Archaeological Research, The University of Texas at San Antonio, Special Report $3: 1-14$. 
1976b The Archaic of Southern Texas. In: The Texas Archaic: A Symposium, edited by T. R. Hester. Center for Archaeological Research, The University of Texas at San Antonio, Special Report 2:83-90.

1978 Early Human Occupations in South Central and Southwestern Texas: Preliminary Papers on the Baker Cave and St. Mary's Hall Sites. Center for Archaeological Research, The University of Texas at San Antonio.

n:d. Unpublished field notes from excavations at the Mariposa Site, 41 ZV 83. On file, Center for Archaeological Research, The University of Texas at San Antonio.

Hester, T. R. and F. A. Bass, Jr.

1974 An Archaeological Survey of Portions of the Chiltipin-San Fernando Creek Watershed, Jim Wells County, Texas. Center for Archaeological Research, The University of Texas at San Antonio, Archaeological survey Report 4.

Hester, T. R., F. A. Bass, Jr., A. A. Fox, E. S. Harris and T. Kelly

1977 Archaeological Research at the Hinojosa Site (41 JW 8), Jim Wells County, Southern Texas. Center for Archaeological Research, The University of Texas at San Antonio, Archaeological Sumey Report 42.

Hester, T. R. and M. B. Collins

1974 Evidence for Heat Treating of Southern Texas Projectile Points. Bulletin of the Texas Archeological Society 45:219-224.

Hester, T. R., D. Gilbow and A. D. Albee

1973 A Functional Analys is of Clear Fork Artifacts from the Rio Grande Plain of Texas. American Antiquity 38(1):90-96.

Hester, T. R., R. F. Heizer and J. A. Graham

1975 Field Methods in Archaeology. Mayfield, Palo Alto.

Hester, T. R. and T. C. Hill, Jr.

1971a An Initial Study of a Prehistoric Ceramic Tradition in Southern Texas. Plains Anthropologist 16:195-203.

1971b Notes on Scottsbluff Points from the Texas Coastal Plain. Southwestern Lore 37(1):27-33.

1972 Prehistoric Occupation at the Holdsworth and Stewart Sites on the Rio Grande Plain of Texas. Bulletin of the Texas Archaeological Society 42:33-74. 
1975a Eating Land Snails in Prehistoric Southern Texas: Ethnohistoric and Experimental Data. The Nautilus 89(2):37-38.

1975b Some Aspects of Late Prehistoric and Protohistoric Archaeology in Southern Texas. Center for Archaeological Research, The University of Texas at Son Antonio, Special Report 1.

Hester, T. R., T. C. Hill, Jr., D. Gifford and S. Holbrook

1975 Archaeological Salvage of Site 41 ZV 152, Rio Grande Plain of Texas. Texas Journal of Science 26(1-2):223-228.

Hester, T. R. and R. C. Parker

1970 The Berclair Site: A Late Prehistoric Component of Goliad County, Southern Texas. Buzletin of the Texas Archeological Society 41:1-23.

Hester, T. R. and H. J. Shafer

1975 An Initial Study of Blade Technology on the Central and Southern Texas Coast. Plains Anthropologist 20(69):175-185.

Hester, T. R., L. D. White and J. White

1969 Archaeological Materials from the Oulline Site and Other Sites in LaSalle County, Texas. Texas Journal of Science 21:130-165.

Hi11, T. C., Jr. and T. R. Hester

1971 Isolated Late Prehistoric and Archaic Components at the Honeymoon Site ( 41 ZV 34), Southern Texas. Plains Anthropologist 15(54):52-57.

1973 A Preliminary Report on the Tortuga Flat Site: A Protohistoric Campsite in Southern Texas. Texas Archeology 17(2):10-14.

Hi11, T. C., Jr., J. B. Holdsworth and T. R. Hester

1972 Yucca Exploitation: A Contemporary Account from the Rio Grande Plain. In: Archaeological Papers Presented to J. Wo House (assembled by $T$. R. Hester):10-11.

Holdsworth, J.

1972 A Study of Modern Flora and Fauna in the Vicinity of the Holdsworth Site (41 ZV 14). Bulletin of the Texas Archeological Society 43:65-73.

House, $K$.

1974 A Paleo-Indian Fluted Point from Live Oak County, Texas. Texas Archeology 18(1):17-19. 
Hunt, C. B.

1972 Physiography of the United States. McGraw-Hill, New York. Inglis, J. M.

1964 A History of Vegetation on the Rio Grande Plain. I'exas Parks and Wildlife Department Bulletin 45.

Jelinek, N. A.

1967 A Prehistoric Sequence in the Middle Pecos Valley, New Mexico. University of Michigan Muserm of Anthropology, Anthropological Papers 31.

Johnson, E. H.

1931 The Natural Regions of Texas. The University of Texas Bulletin 3113. Bureau of Business Research Monograph 8.

Johnson, L., Jr.

1964 The Devil's Mouth Site: A Stratified Campsite at Amistad Reservoir, Val Verde County, Texas. Department of Anthropology, The University of Texas at Austin, Archaeology Series 6.

Johnston, M. C.

1963 Past and Present Grasslands of Southern Texas and Northeastern Mexico. Ecology 44(3):456-466.

Kelley, J.C.

1959 The Desert Cultures and the Balcones Phase: Archaic Manifestations in the Southwest and Texas. American Antiquity 24(3):276-388.

Krieger, A.

1954 A Radiocarbon Date on the Falcon Focus. Bulzetin of the Texas Archeological Society 25:565.

Lundelius, E. L., Jr.

1967 Late-Pleistocene and Holocene Faunal History of Central Texas. In: Pleistocene Extinctions: The Search for a Cause, P. S. Martin and H. E. Wright, Jr., eds: 287-320. Yale University Press, New Haven.

MacNeish, R. S.

1947 A Preliminary Report on Coastal Tamaulipas, Mexico. American Antiquity 13(1):1-15.

1958 Preliminary Archaeological Investigations in the Sierra Tamaulipas, Mexico. Transactions of the American Philosophical Society 48(6). 
Mallouf, R. J., D. E. Fox and A. K. Briggs

1973 An Assessment of the Cultural Resources of Palmetto Bend Reservoir, Jackson County, Texas. Texas Historical Comission and Texas Water Deveopment Board Archeological Survey Report 11.

Mason, R. J.

1962 The Paleo-Indian Tradition in Eastern North America. Current Anthropology 3(3):227-246.

Mitche11, J. L.

1974a Additional Metal Points from Southern Texas. La Tierra 1:47-51.

1974b An Unfluted Folsom-1ike Projectile Point from Webb County, Texas. La Tierra 1(2):9-11.

1974c 41 AT 18: An Archaeological Site in Atascosa County, Texas. La Tierra $1(1): 32-36$.

Mitche11, J. L. and J. Winsch

1973 A Paleo-Indian Point from South Texas. Ohio Archaeologist 23(2):9. Montgomery, J. L., C. Moffat and I. Richie

19751975 Test Excavations, Chaparrosa 28. Center for Archaeological Research, The University of Texas at San Antonio, manuscript photocopied.

Newcomb, W. W., Jr.

1956 A Reappraisal of the "Cultural Sink" of Texas. Southwestern Journal of Anthropology 12(2):145-153.

1958 Indian Tribes of Texas. Bulletin of the Texas Archeological Society 29:1-34.

1961 The Indians of Texas. University of Texas Press, Austin. Newton, M. B., Jr.

1968 The Distribution and Character of Sites, Arroyo Los 01mos, Starr County, Texas. Bulletin of the Texas Archeological Society 38:18-34.

Nunley, J. P.

1971 Archaeological Interpretation and the Particularistic Model: The Coahuiltecan Case. Plains Anthropologist 16(54):302-310. 
Nunley, J. P. and T. R. Hester

1966 Preliminary Archeological Investigations in Dimmit County, Texas. Texas Journal of Science 18(3):233-253.

1975 An Assessment of Archaeological Resources in Portions of Starr County, Texas. Center for Archaeological Research, The University of Texas at San Antonio, Archaeological Survey Report 7.

Orchard, C. D. and T. N. Campbel1

1954 Evidence of Early Man from the Vicinity of San Antonio, Texas. Texas Journal of Science 6(4):454-465.

Prewitt, E. R.

1974 Preliminary Archeological Investigations in the Rio Grande Delta of Texas. Bulletin of the Texas Archeological Society 45:55-66.

Price, W. A. and G. Gunter

1943 Certain Recent Geological and Biological Changes in South Texas, With Consideration of Probable Causes. Proceedings and Transactions of the Texas Academy of Science, 1942:138-156.

Ruecking, F., Jr.

1953 The Economic System of the Coahuiltecan Indians of Southern Texas and Northeastern Mexico. Texas Journal of Science 5(4):480-497.

1954 Ceremonies of the Coahuiltecan Indians of Southern Texas and Northeastern Mexico. Texas Journal of Science 6(3):330-339.

1955a The Coahuiltecan Indians of Southern Texas and Northeastern Mexico. Unpublished M.A. thesis, Department of Anthropology, University of Texas, Austin.

1955b The Social Organization of the Coahuiltecan Indians of Southern Texas and Northeastern Texas. Texas Journal of Science $7(4): 357-388$.

Sayles, E. B.

1935 An Archeological Survey of Texas. Medazzion Papers XVII. Gila Pueblo, Arizona.

Schuetz, M. K.

1966 The Granberg Site: An Archaic Indian Habitation in Bexar County, Texas. Witte Museum Studies, 1.

1969 The History and Archeology of Mission San Juan Capistrano, San Antonio, Texas II: Description of the Artifacts and Ethnohistory of the Coahuiltecan Indians. State Buizding Commission Archeological Program, Report 11. 
Sellards, E. H.

1940 Pleistocene Artifacts and Associated Fossils from Bee County, Texas. Bulletin of the Geological Society of America 51(11): 1627-1657.

1952 Early Man in America: A Study in Prehistory. University of Texas Press, Austin.

Semken, H. A.

1967 Mammal Remains from Rattlesnake Cave, Kinney County, Texas. The Pearce-Sellards Series 7.

Shafer, H. J.

1969 Archeological Investigations in Robert Lee Reservoir Basin, West Central Texas. Papers of the Texas Archeological Salvage Project 17.

1970 Notes on Uniface Retouch Technology. American Antiquity 35(4): 480-487.

Shafer, H. J. and E. P. Baxter

1975 An Archeological Survey of the Lignite Project, Atascosa and McMullen Counties, Texas. Texas A\&M University, Anthropological Laboratory Report 20.

Shimer, J. A.

1972 Field Guide to Landforms in the United States. The Macmillan Company, New York.

Shiner, J. L.

1969 Component Analysis for Archaic Sites. Bulzetin of the Texas Archeological Society 40:215-229.

1970 Activity Analysis of a Prehistoric Site. Bulletin of the Texas Archeological Society 41:25-35.

Skeels, L. L. M.

1972 An Ethnohistorical Survey of Texas Indians. Texas Historical Survey Committee Report 22.

Skinner, S. A.

1971 Prehistoric Settlement of the De Cordova Bend Reservoir, Central Texas. Bulletin of the Texas Archeological Society 42:149-269. 
Smith, H. M., M. H. Layton, J. T. Miller, T. W. Glassey and R. M. Marshall

1940 Soil Survey of Zavala County, Texas. United States Department of Agriculture, Bureau of Plant Industry Series 1934, 21.

Sollberger, J. B. and T. R. Hester

1972 The Strohacker Site: A Review of Pre-Archaic Manifestations in Texas. Plains Anthropologist 17(58):326-344.

Sorrow, W. M.

1968 The Devil's Mouth Site: The Third Season - 1967. Papers of the Texas Archeological Salvage Project 14.

Sorrow, W. M., H. J. Shafer and R. Ross

1967 Excavations at Stillhouse Hollow Reservoir. Papers of the Texas Archeological Salvage Project 11.

Speth, J. D.

1974 Experimental Investigations of Hard Hammer Percussion Flaking. Tebiwa 17(1):7-36.

Suhm, D. A.

1957 Excavations at the Smith Rockshelter, Travis County, Texas.

Texas Journat of Science 69(1):63-107.

Suhm, D. A. and E. B. Jelks

1962 Handbook of Texas Archeology: Type Descriptions. Texas Archeological Society Special Publication 1 and Texas Memorial Museum Bulletin 4.

Suhm, D. A., A. D. Krieger and E. B. Jelks

1954 An Introductory Handbook of Texas Archeology. Buzletin of the Texas Archeological Society 25.

Swanson, E. (ed.)

1975 Lithic Technology. Mouton, The Hague.

Thornbury, W. D.

1965 Regional Geomorphology of the United States. John Wiley and Sons, Inc., New York.

Thornwaite, C. W.

1948 An Approach Toward a Rational Classification of Climate. Geographical Review 38:55-94. 
Troike, R. C.

1962 Notes on Coahuiltecan Ethnography. Bulletin of the Texas Archeological Society 32 (for 1961):57-63.

Valastro, S., Jr., E. M. Davis and C. T. Rightmire

1970 University of Texas at Austin Radiocarbon Dates VI. Radiocarbon $10(2): 384-401$.

Varner, D. M.

1968 The Nature of Non-buried Archaeological Data: Problems in Northeastern Mexico. Bulletin of the Texas Archeological Society $38: 51-65$.

Wakefield, W.

1968 Archeological Surveys of Palmetto Bend and Choke Canyon Reservoirs, Texas. Texas Archeological Salvage Project Survey Report 5.

Weir, F. A.

1956 Surface Artifacts from La Perdida, Starr County, Texas. Bulletin of the Texas Archeological Society 26:59-78.

Wells, P.V.

1970 Historical Factors Controlling Vegetation Patterns and Floristic Distributions in the Central Plains Region of North America. In: Pleistocene and Recent Environments of the Central Great Plains. University of Kansas Special Publication 3:211-221.

Whallon, R., Jr.

1973 Spatial Analysis of 0ccupation Floors I: Application of Dimensional Analysis of Variance. American Antiquity 38(3):266-278.

1974 Spatial Analysis of 0ccupation Floors II: The Application of Nearest Neighbor Analysis. American Antiquity 39(1):16-34.

Wilmsen, E. N.

1970 Lithic Analysis and Cultural Inference: A Paleo-Indian Case. Anthropological Papers of the University of Arizona 16.

1974 Lindenmeier: A Pleistocene Hunting Society. Harper and Row, New York.

Work, J. H. and C. L. Douglas

1970 Excavations at Baker Cave, Val Verde County, Texas. Bulletin of the Texas Memorial Museum 16. 